\title{
Tungsten-Catalyzed Allylic Substitution with Heteroatom Nu- cleophile: Reaction Development and Synthetic Applications
}

\author{
Yaoyao Xu, Muhammad Salman, Shahid Khan, Junjie Zhang and Ajmal Khan* \\ Department of Applied Chemistry, School of Science, and Xi'an Key Laboratory of Sustainable Energy \\ Materials Chemistry, Xi'an Jiaotong University, Xi'an 710049, P. R. China \\ E-mail: ajmalkhan@xjtu.edu.cn
}

Table of Contents

NMR charts .S2-S36

HPLC charts S37 


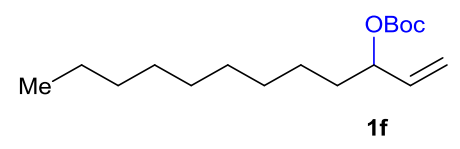

${ }^{1} \mathrm{H}$ NMR spectrum $\left(400 \mathrm{MHz}, \mathrm{CDCl}_{3}\right)$ of $1 \mathrm{f}$

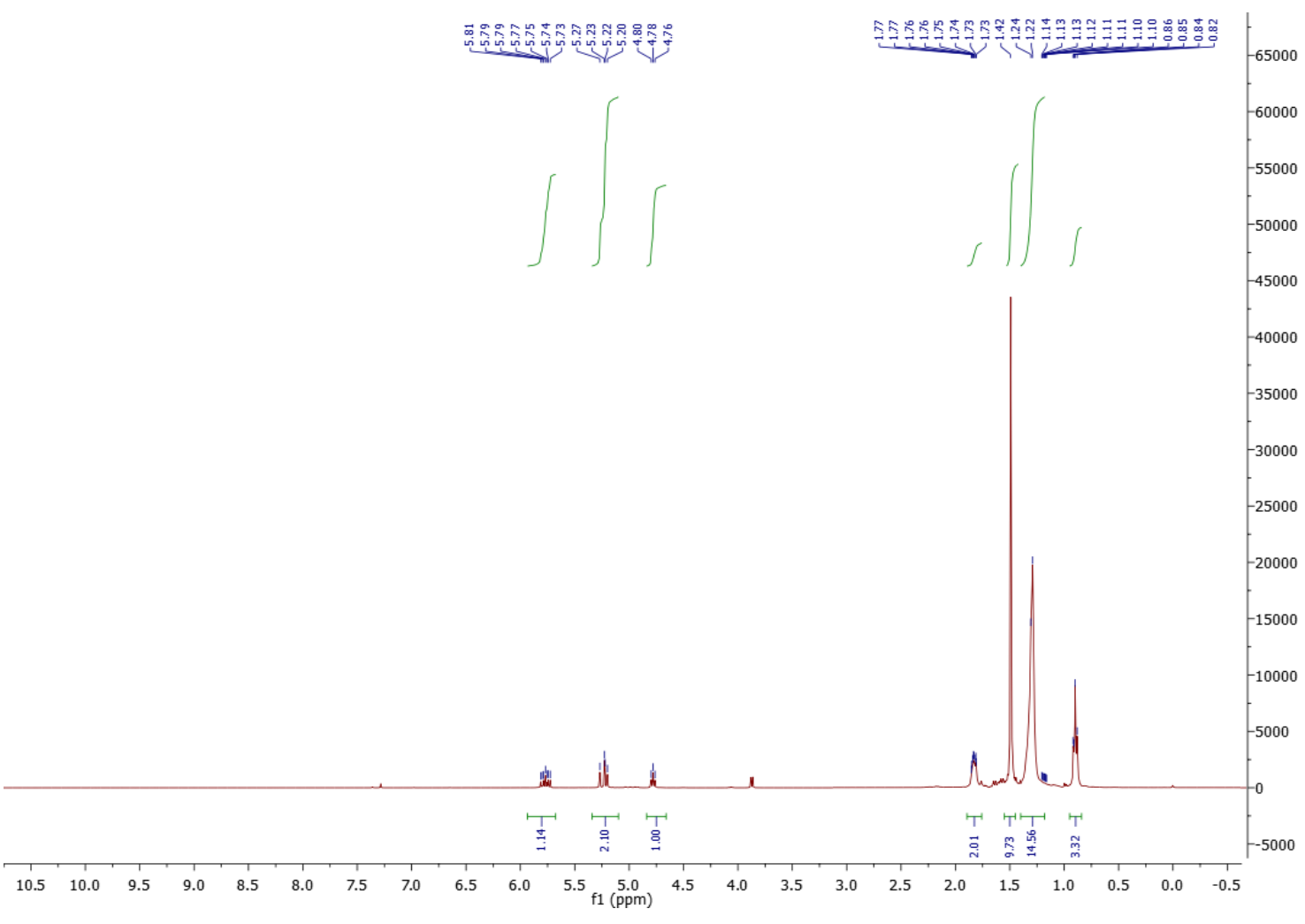

${ }^{13} \mathrm{C}$ NMR spectrum $\left(100 \mathrm{MHz}, \mathrm{CDCl}_{3}\right)$ of $1 \mathrm{f}$

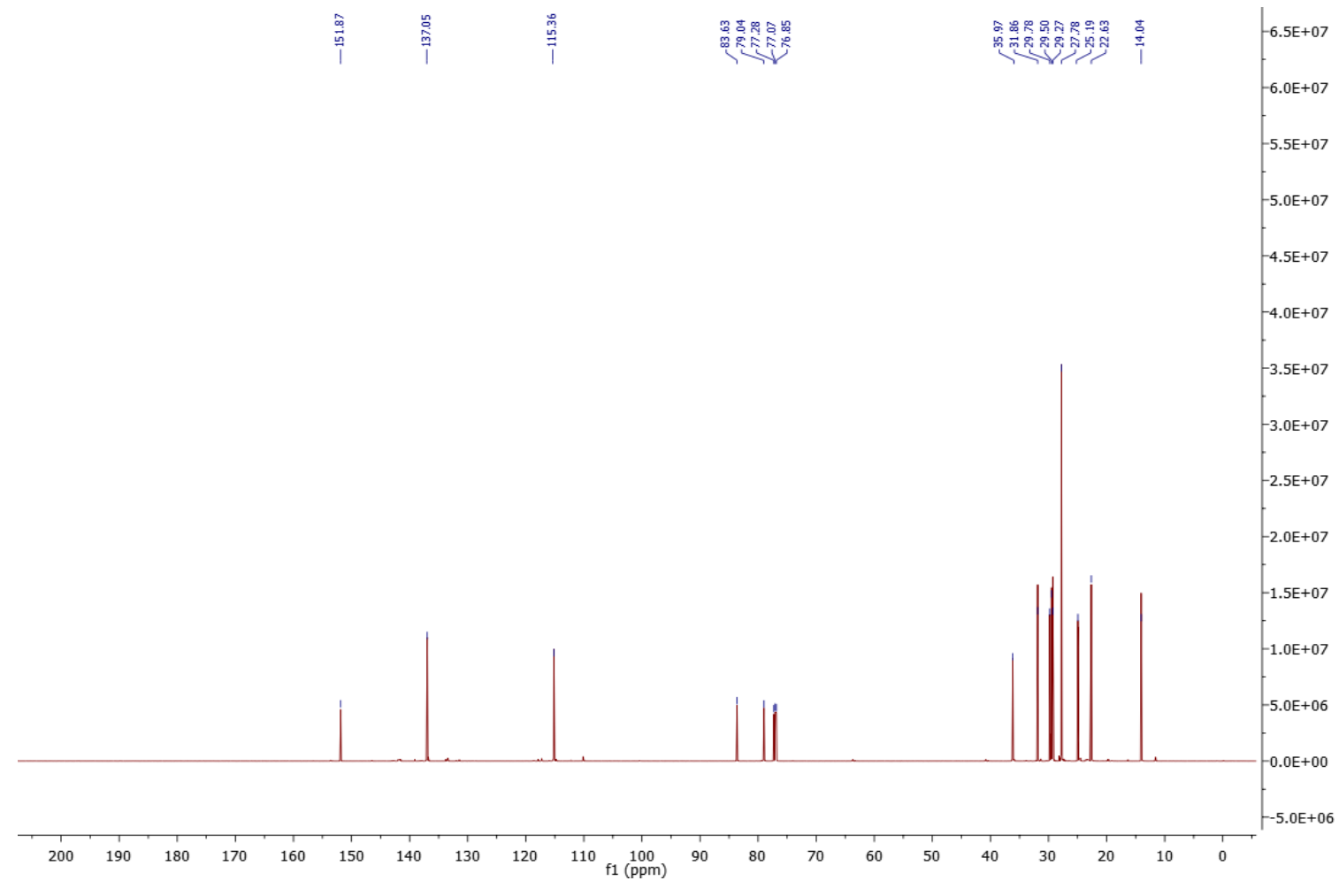




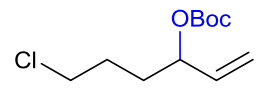

$1 \mathrm{~h}$

${ }^{1} \mathrm{H}$ NMR spectrum $\left(400 \mathrm{MHz}, \mathrm{CDCl}_{3}\right)$ of $1 \mathrm{~h}$
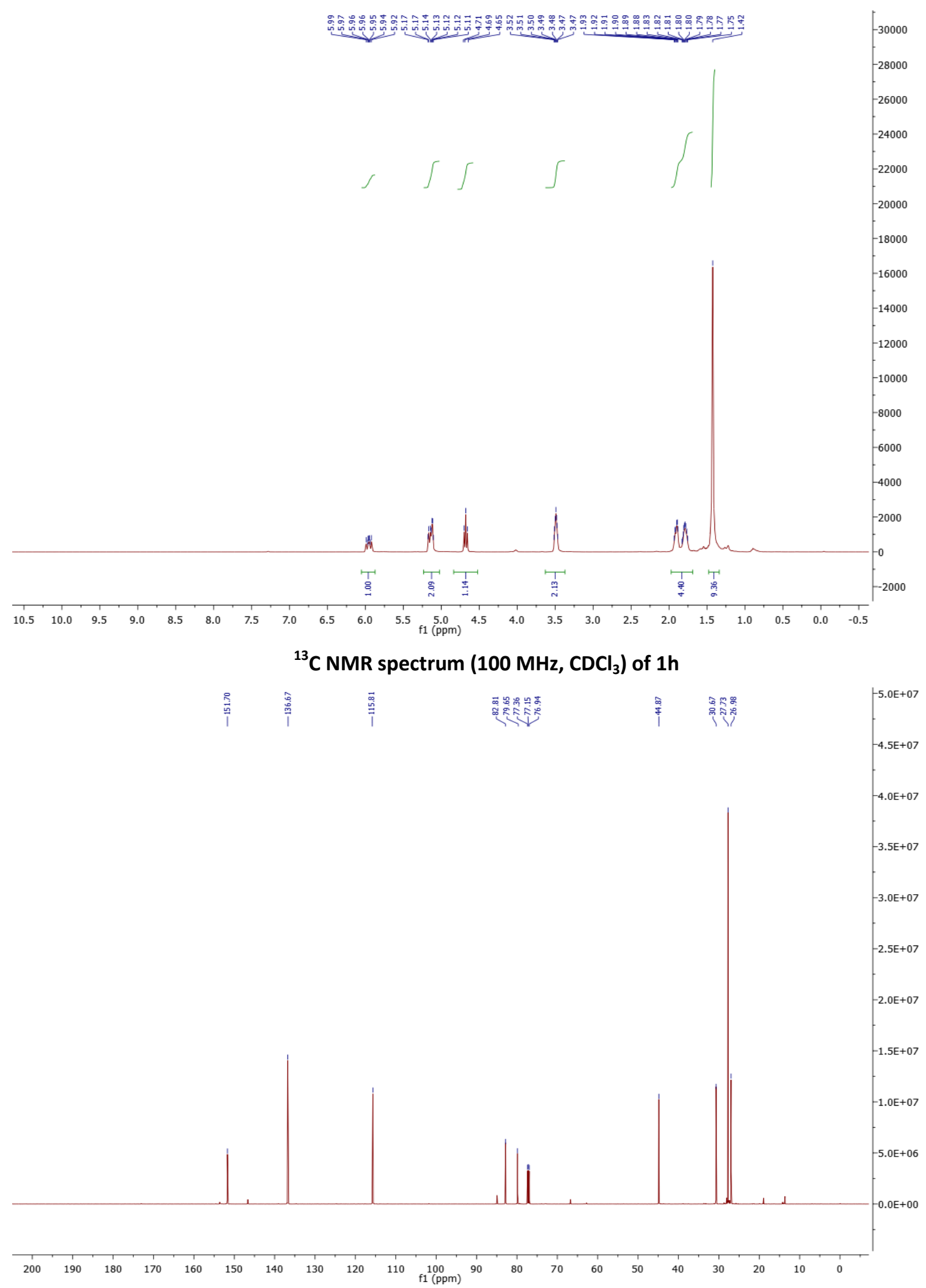


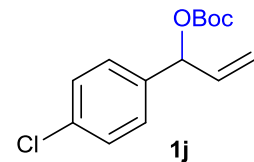

${ }^{1} \mathrm{H}$ NMR spectrum $\left(400 \mathrm{MHz}, \mathrm{CDCl}_{3}\right)$ of $1 \mathrm{j}$

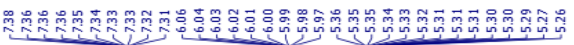

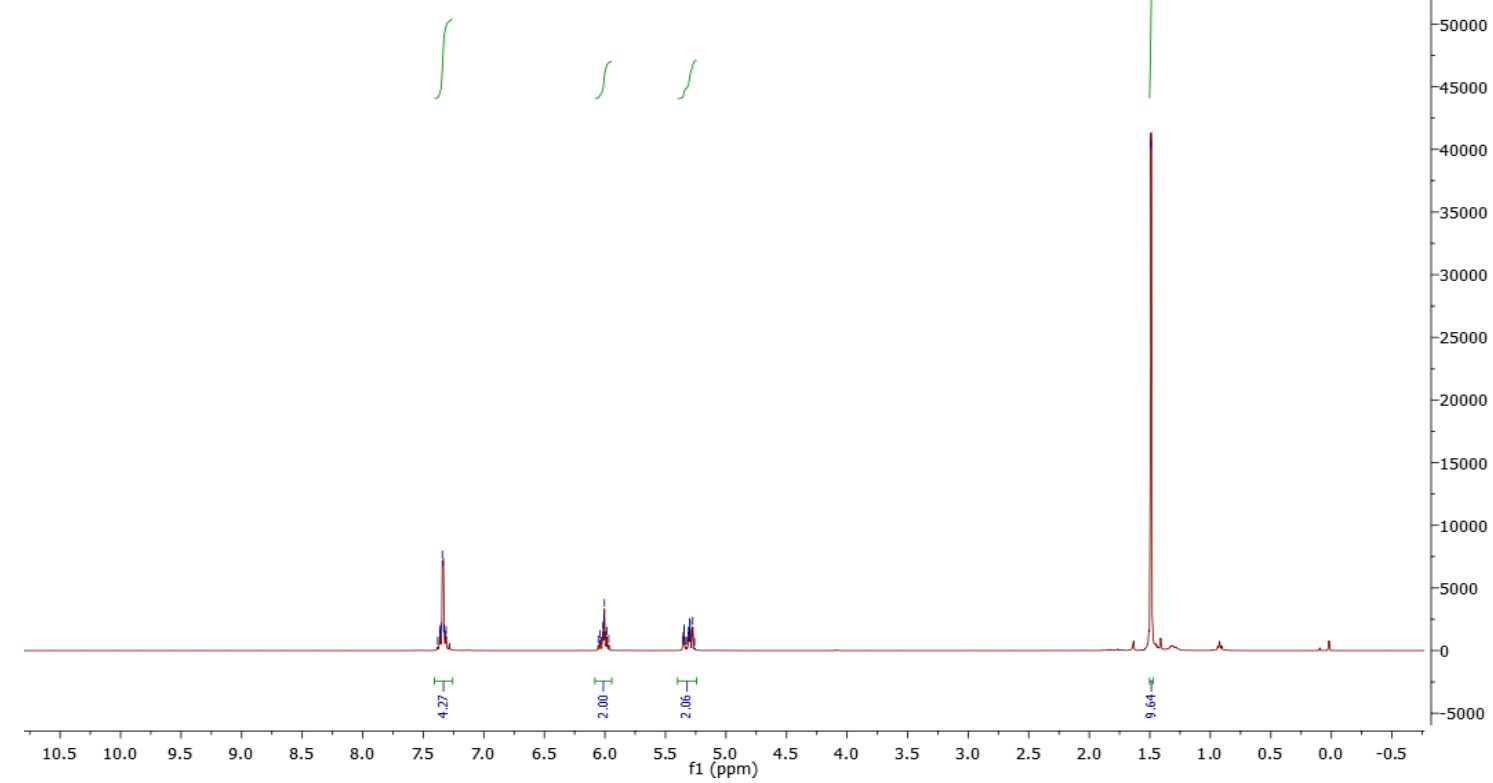

${ }^{13} \mathrm{C} \mathrm{NMR}$ spectrum $\left(100 \mathrm{MHz}, \mathrm{CDCl}_{3}\right)$ of $1 \mathrm{j}$

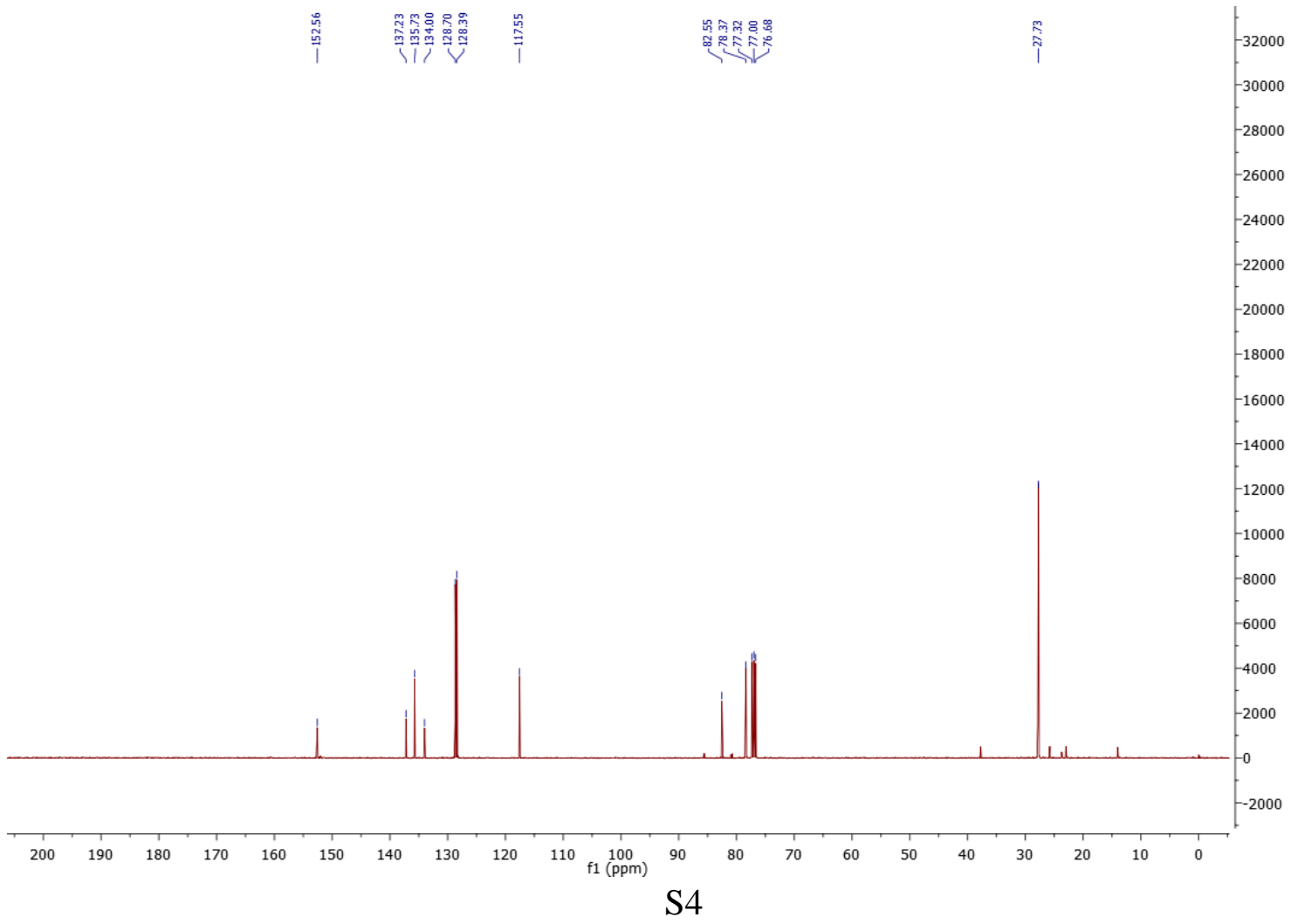




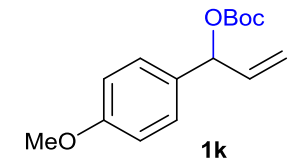

${ }^{1} \mathrm{H}$ NMR spectrum $\left(400 \mathrm{MHz}, \mathrm{CDCl}_{3}\right)$ of $1 \mathrm{k}$

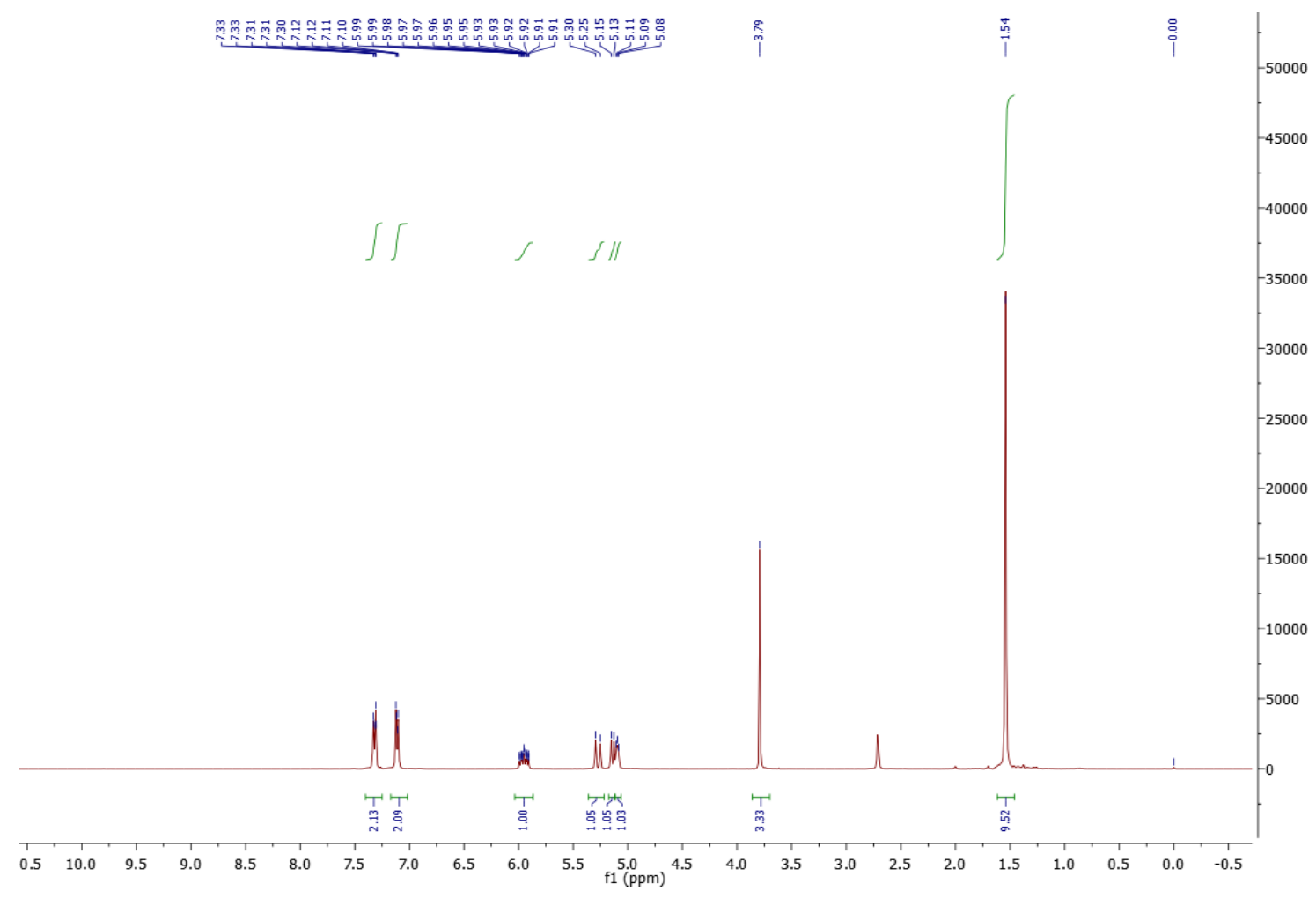

${ }^{13} \mathrm{C}$ NMR spectrum $\left(100 \mathrm{MHz}, \mathrm{CDCl}_{3}\right)$ of $1 \mathrm{k}$

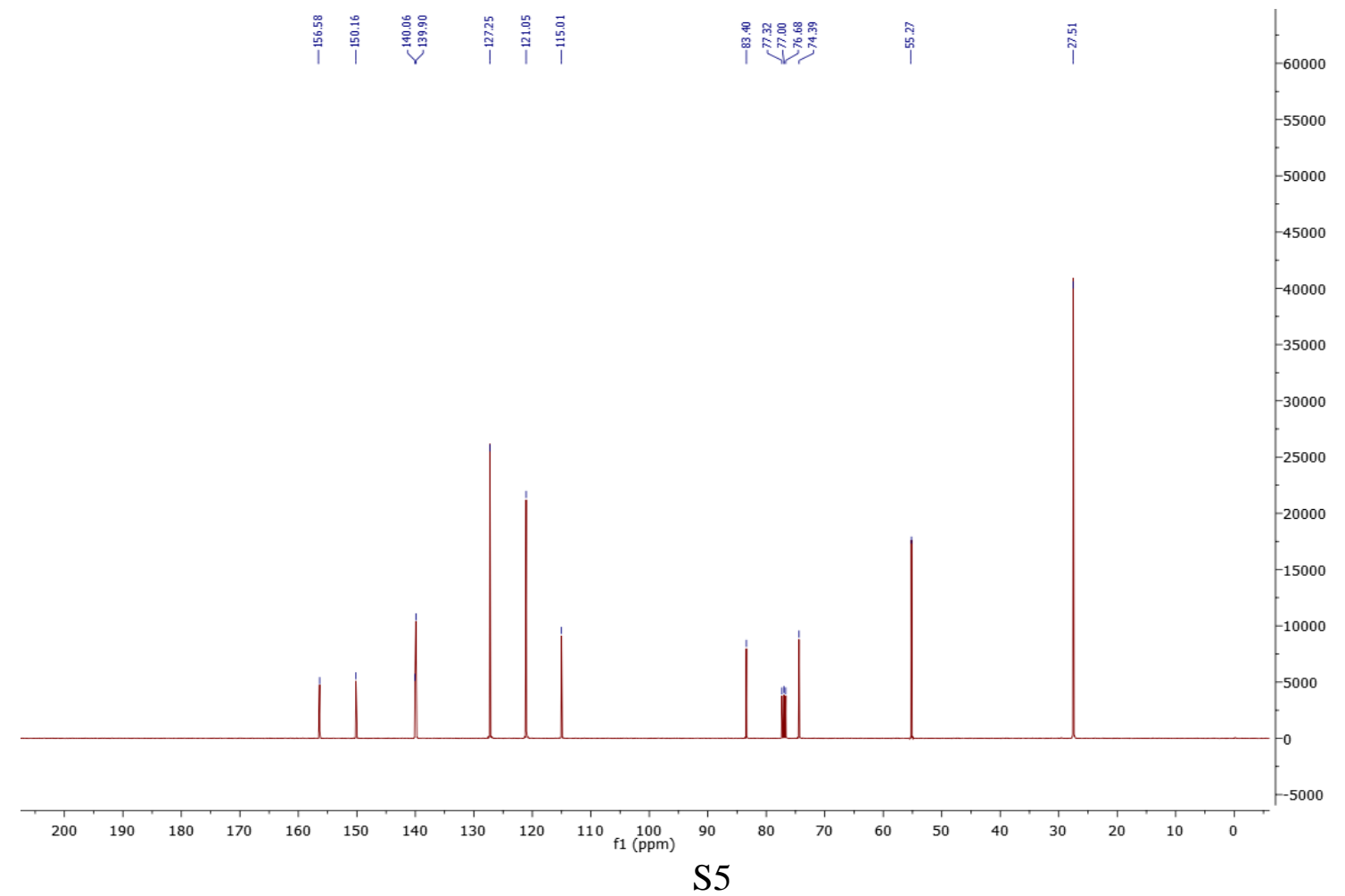


<smiles>C=CC(CCc1ccccc1)S(=O)(=O)c1ccccc1</smiles>

${ }^{1} \mathrm{H}$ NMR spectrum $\left(400 \mathrm{MHz}, \mathrm{CDCl}_{3}\right)$ of $3 \mathrm{ca}$

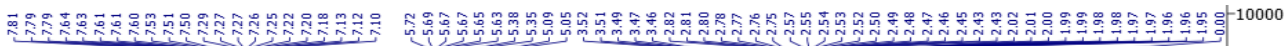

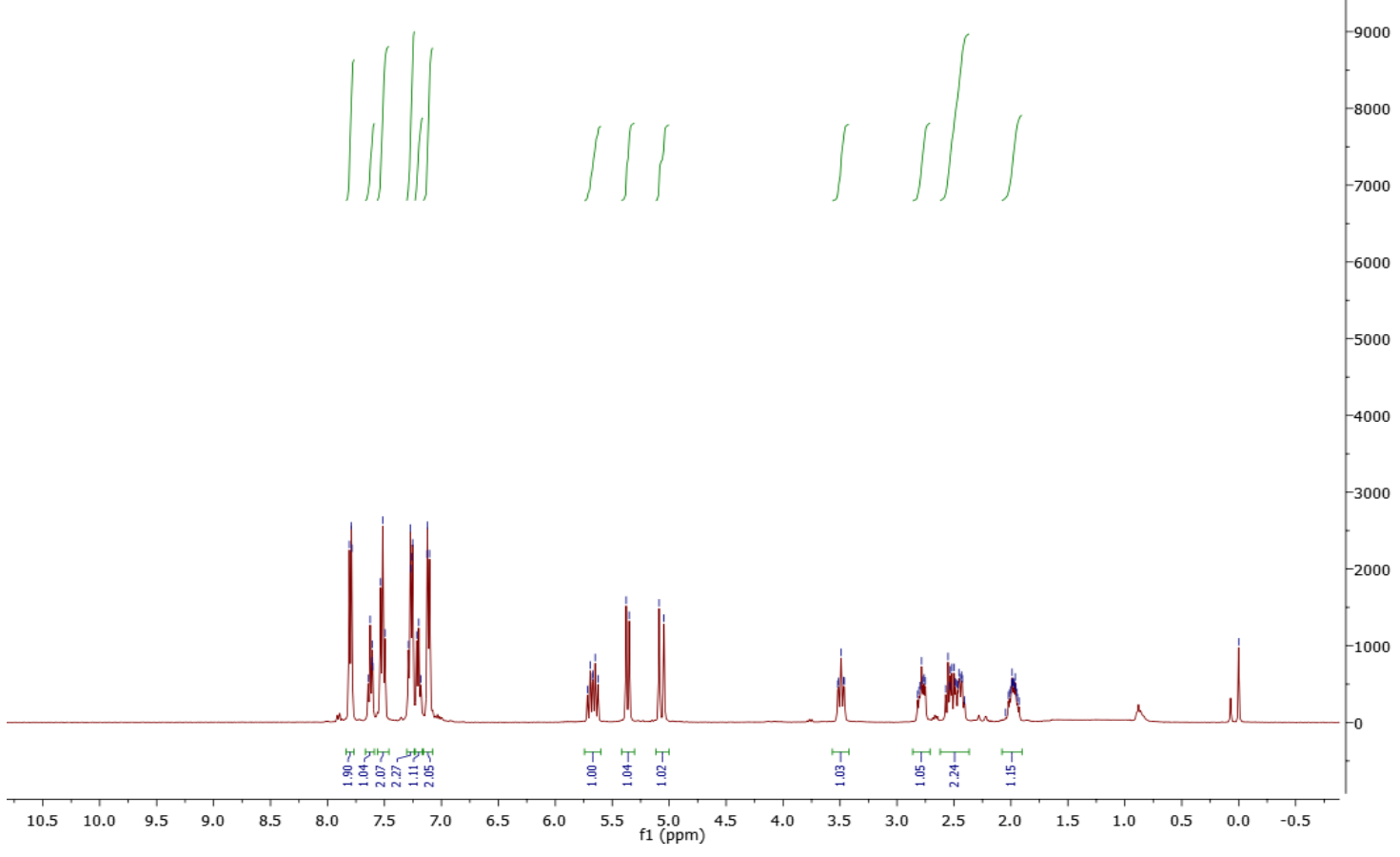

${ }^{13} \mathrm{C} \mathrm{NMR}$ spectrum $\left(100 \mathrm{MHz}, \mathrm{CDCl}_{3}\right)$ of $3 \mathrm{ca}$

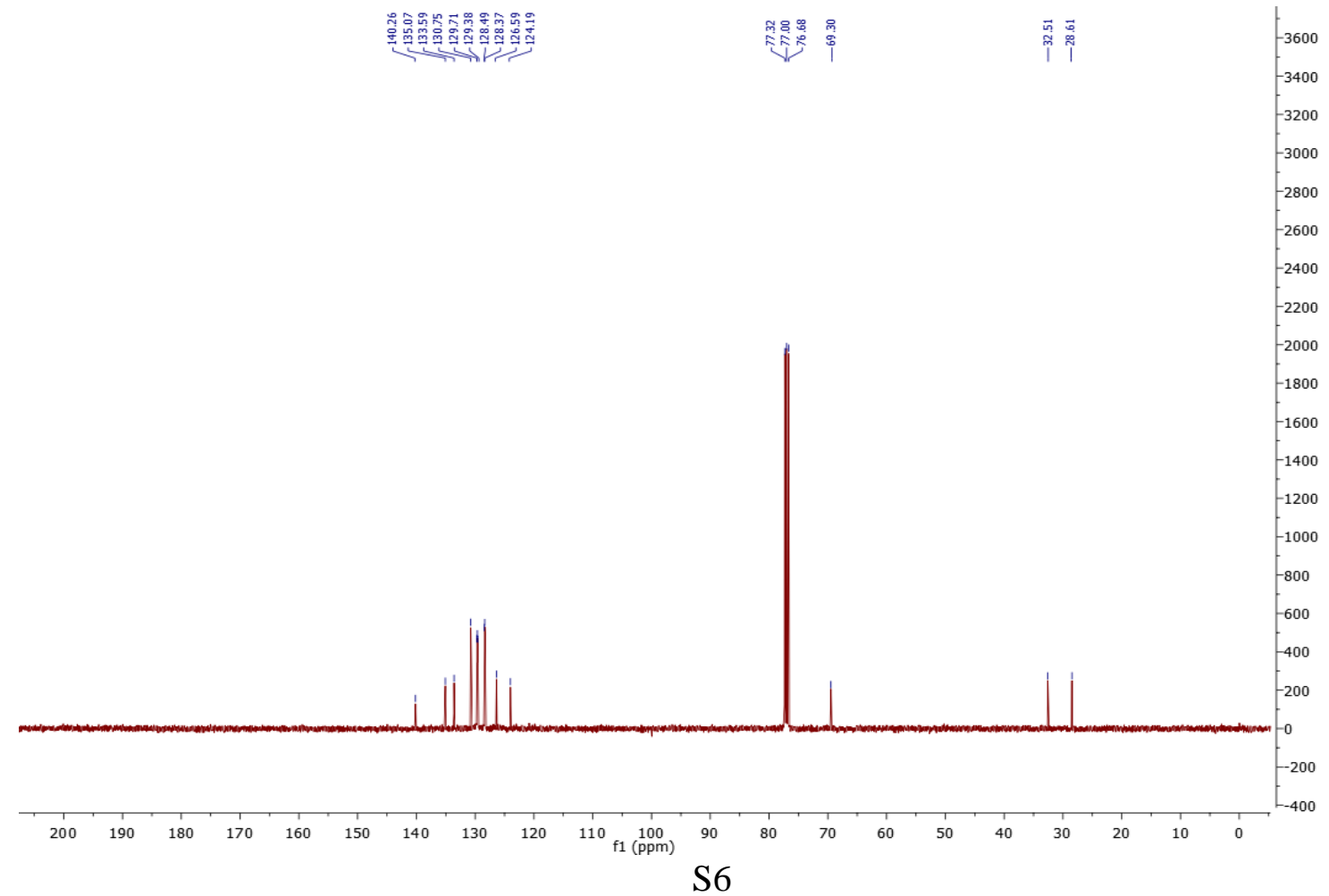


<smiles>C=CC(CC[NH3+])S(=O)(=O)c1ccccc1</smiles>

${ }^{1} \mathrm{H}$ NMR spectrum $\left(400 \mathrm{MHz}, \mathrm{CDCl}_{3}\right)$ of $3 \mathrm{da}$

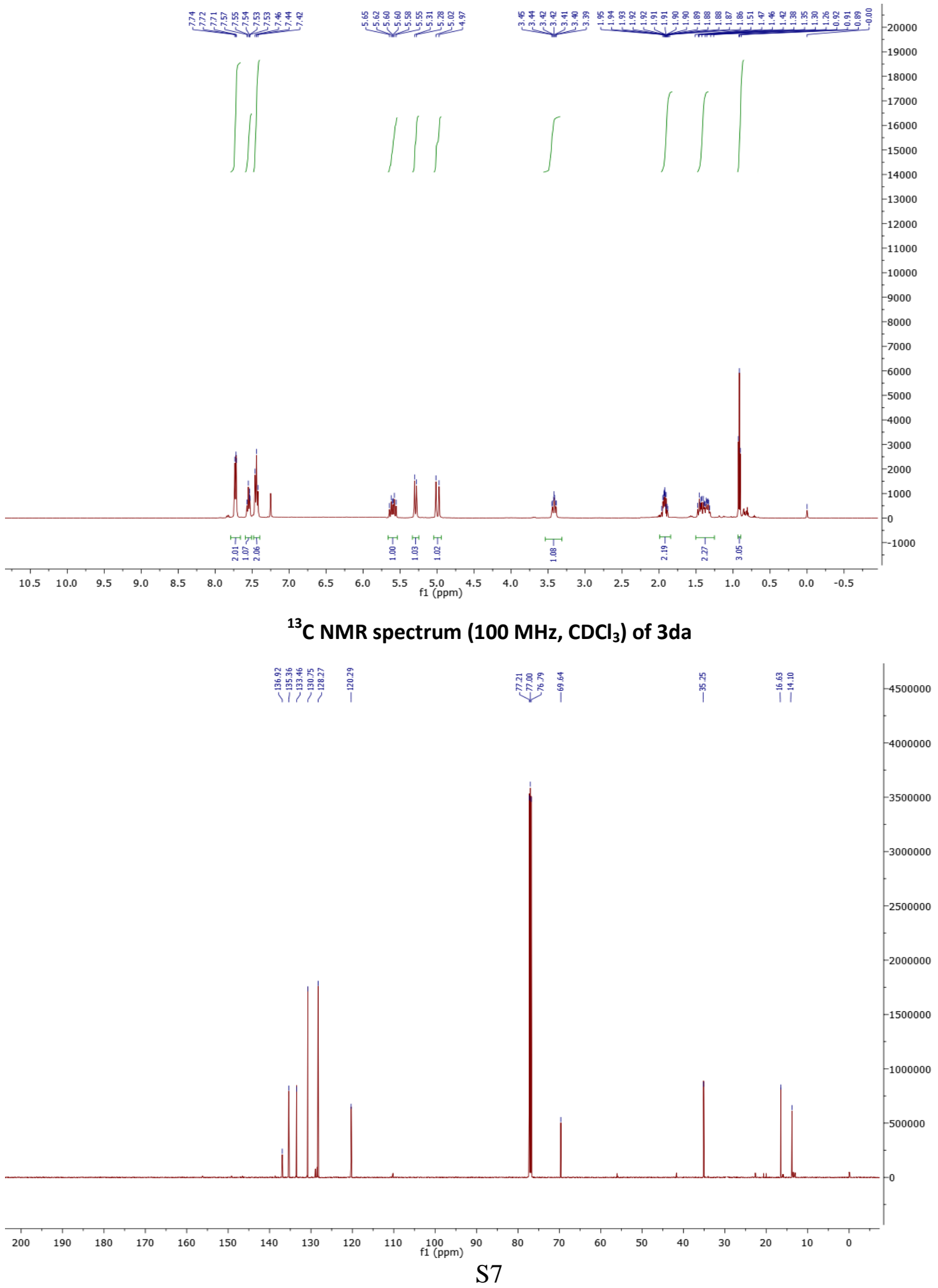




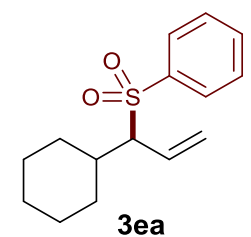

${ }^{1} \mathrm{H}$ NMR spectrum $\left(400 \mathrm{MHz}, \mathrm{CDCl}_{3}\right)$ of $3 e a$

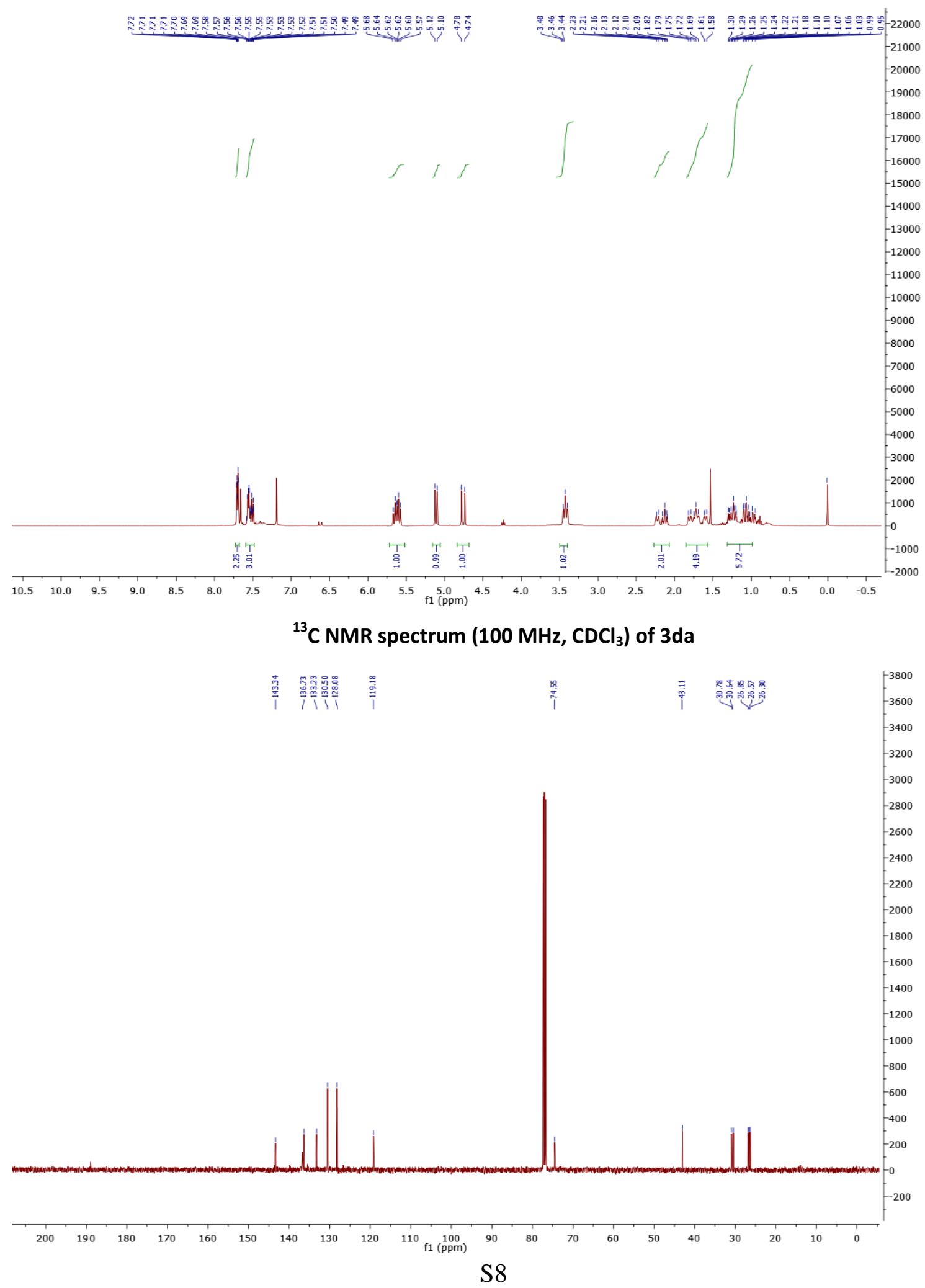




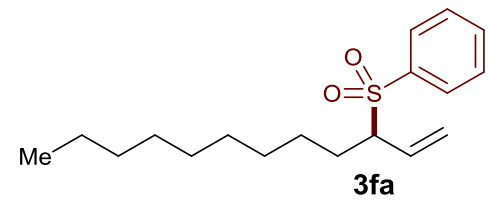

${ }^{1} \mathrm{H}$ NMR spectrum $\left(400 \mathrm{MHz}, \mathrm{CDCl}_{3}\right.$ ) of $3 \mathrm{fa}$

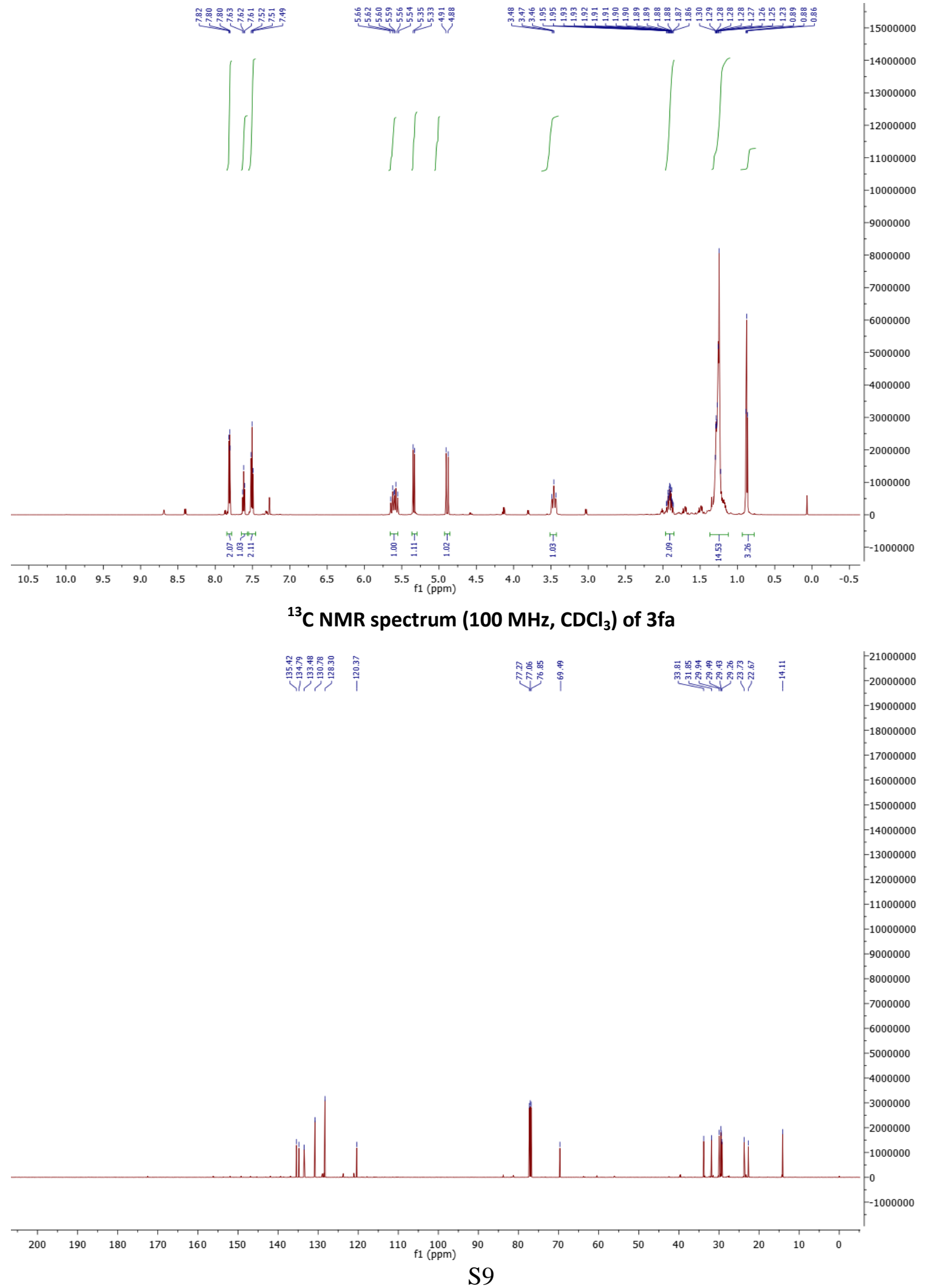




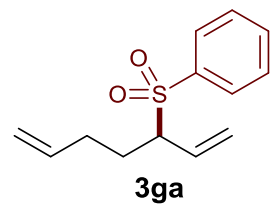

${ }^{1} \mathrm{H}$ NMR spectrum $\left(400 \mathrm{MHz}, \mathrm{CDCl}_{3}\right.$ ) of 3ga

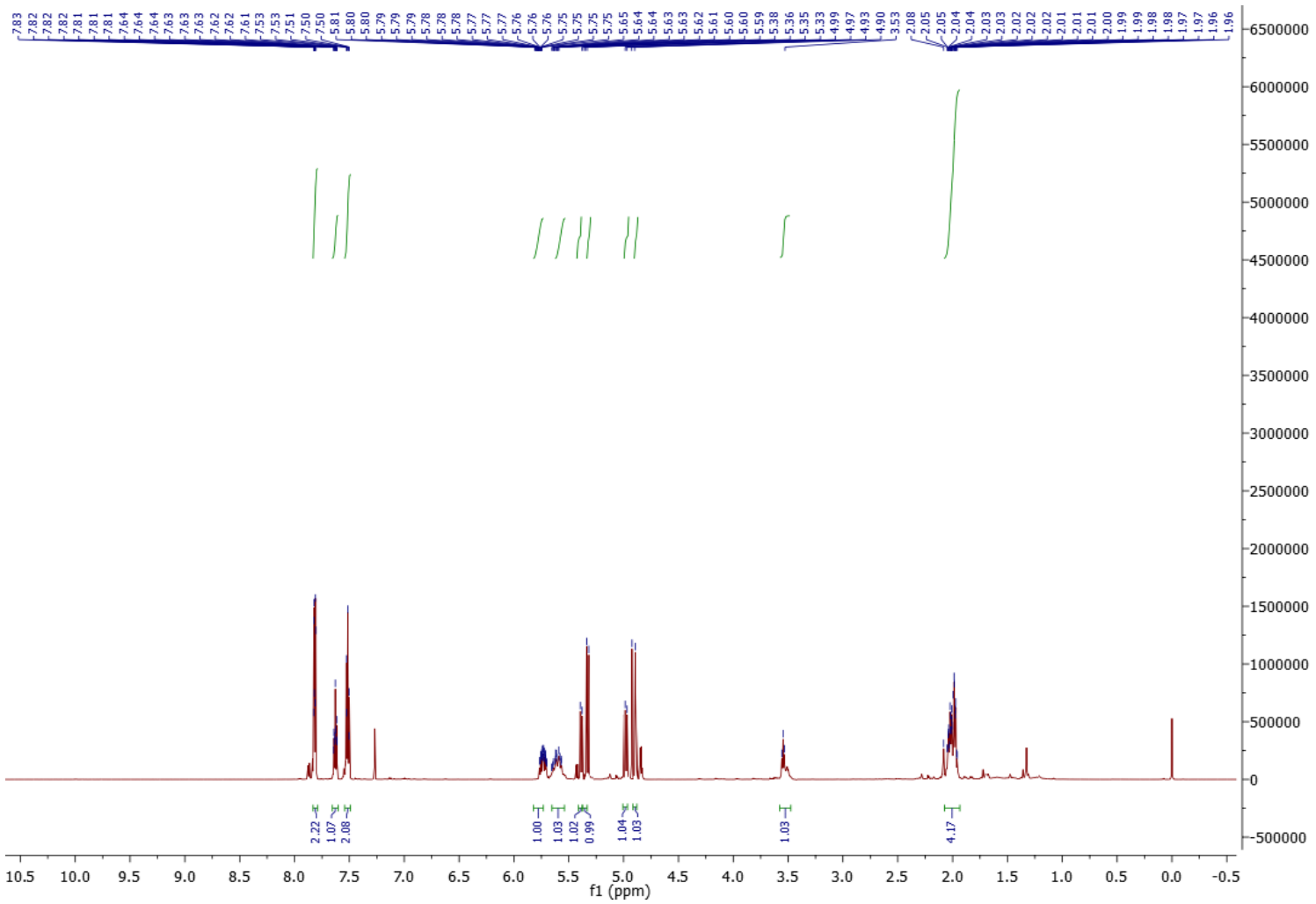

${ }^{13} \mathrm{C}$ NMR spectrum $\left(100 \mathrm{MHz}, \mathrm{CDCl}_{3}\right)$ of 3ga

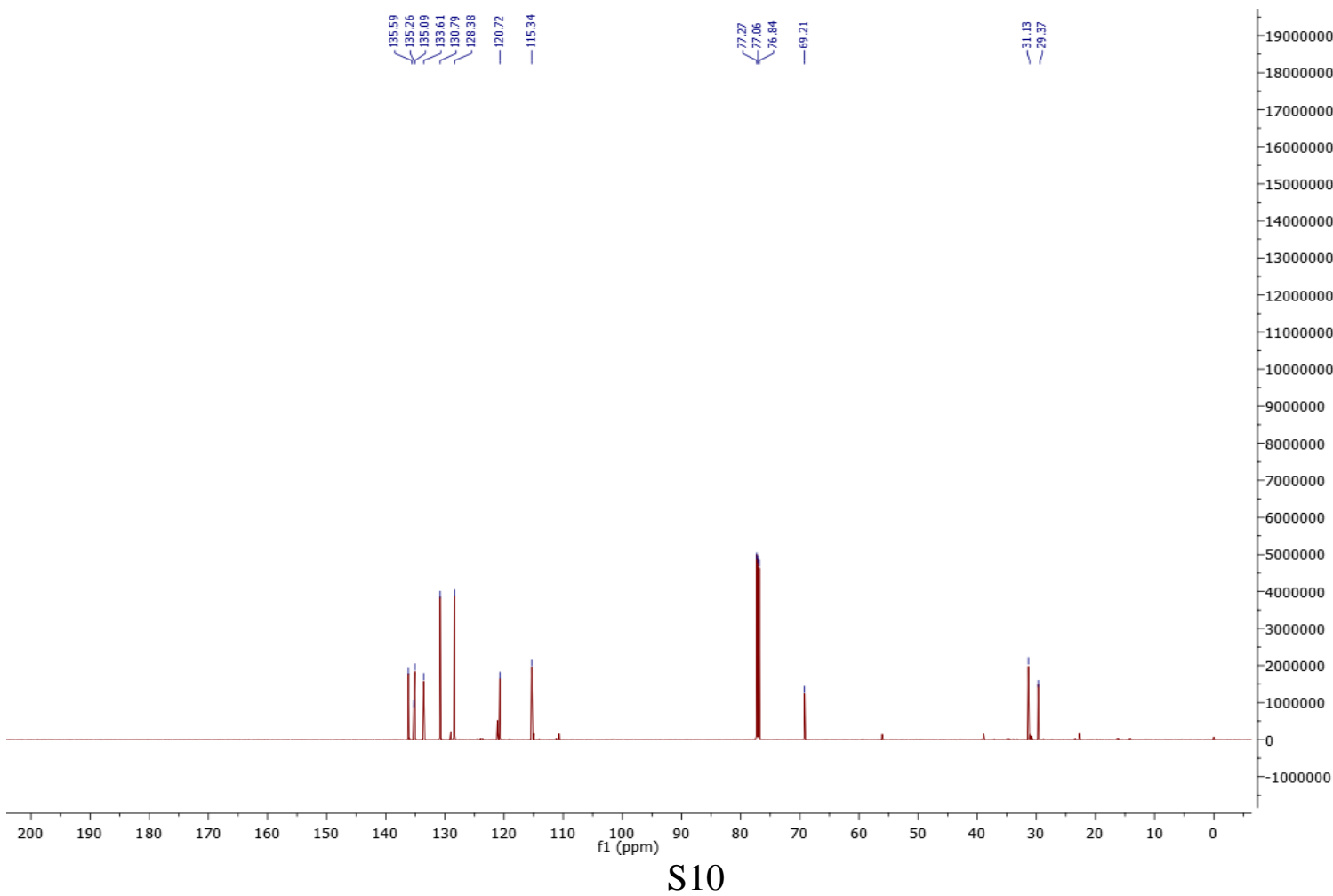




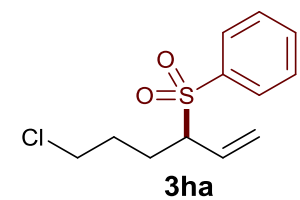

${ }^{1} \mathrm{H}$ NMR spectrum (400 MHz, $\mathrm{CDCl}_{3}$ ) of 3ha

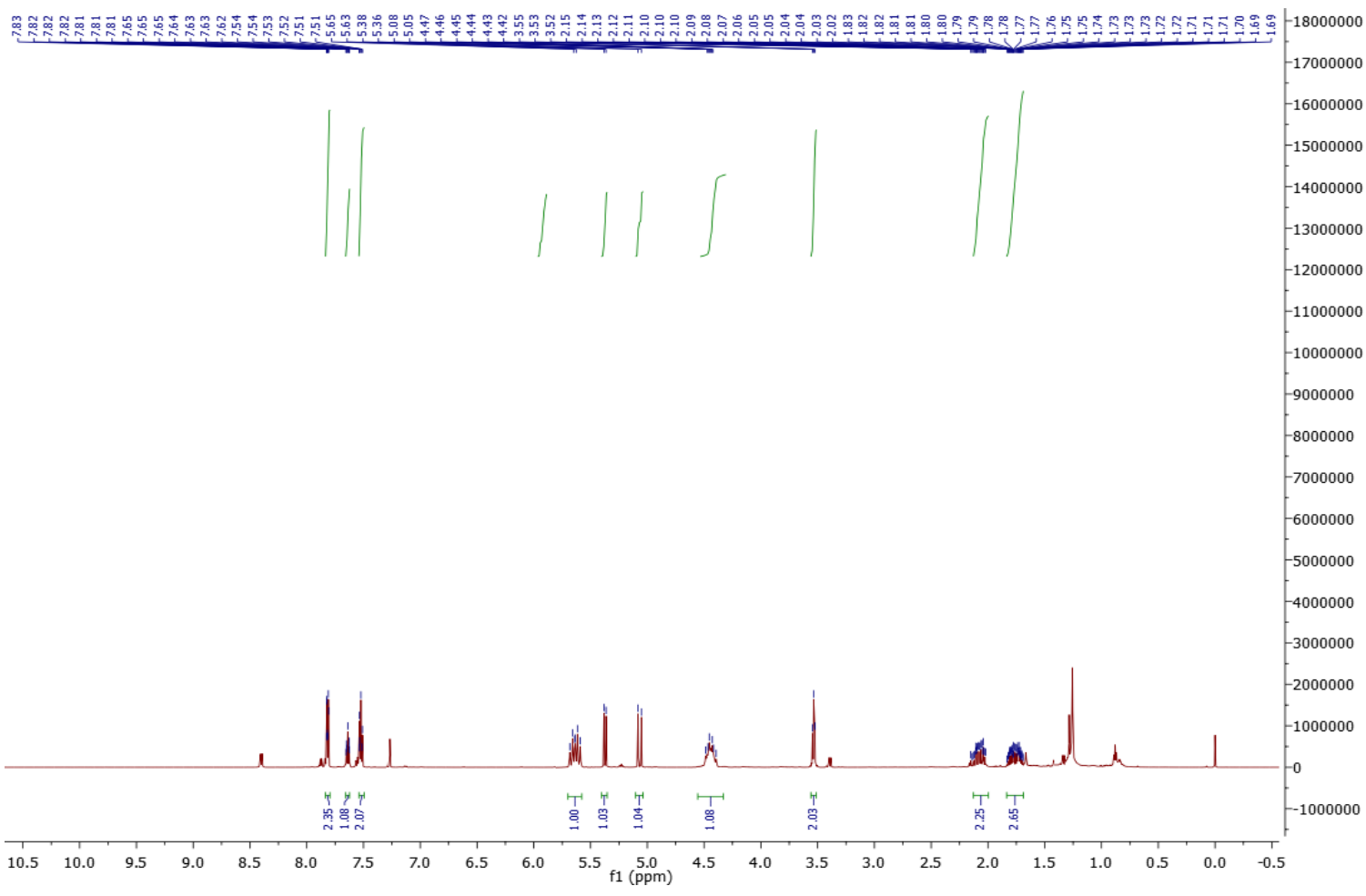

${ }^{13} \mathrm{C}$ NMR spectrum $\left(100 \mathrm{MHz}, \mathrm{CDCl}_{3}\right)$ of 3 ha

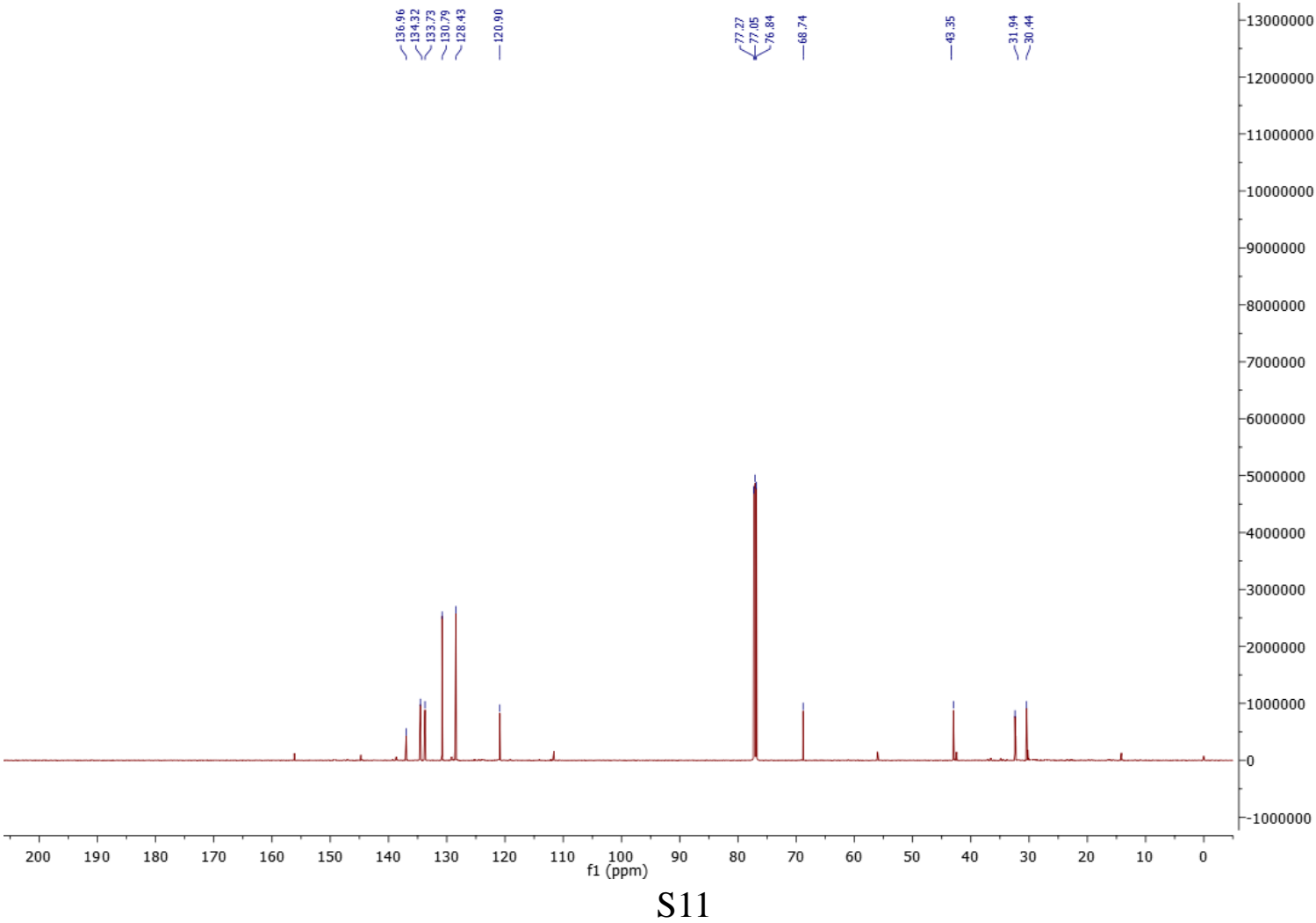




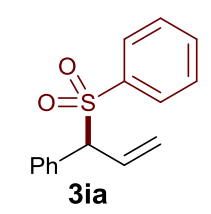

${ }^{1} \mathrm{H}$ NMR spectrum $\left(400 \mathrm{MHz}, \mathrm{CDCl}_{3}\right)$ of $31 \mathrm{a}$

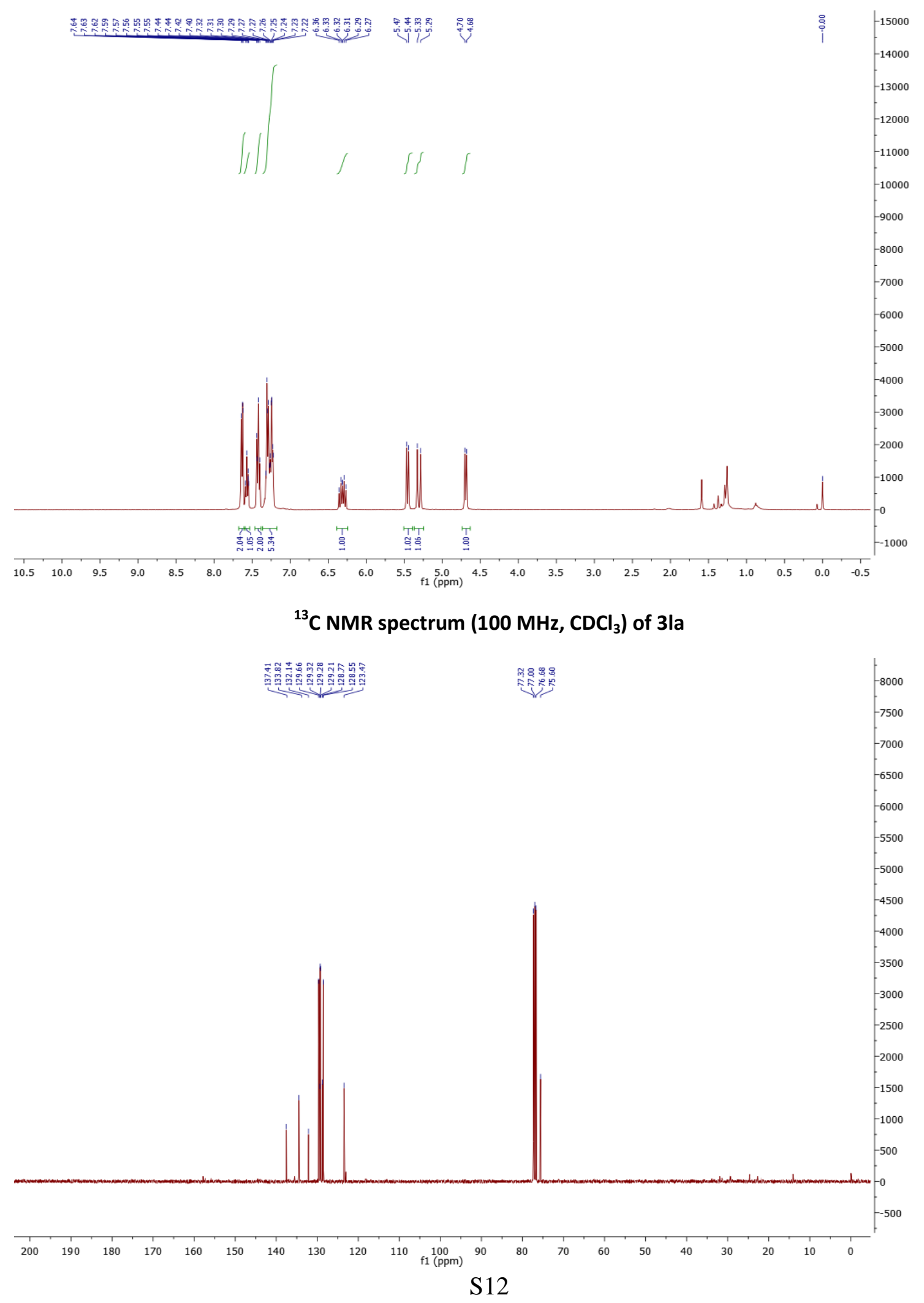




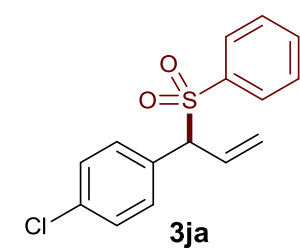

${ }^{1} \mathrm{H}$ NMR spectrum $\left(400 \mathrm{MHz}, \mathrm{CDCl}_{3}\right)$ of $3 \mathrm{ja}$

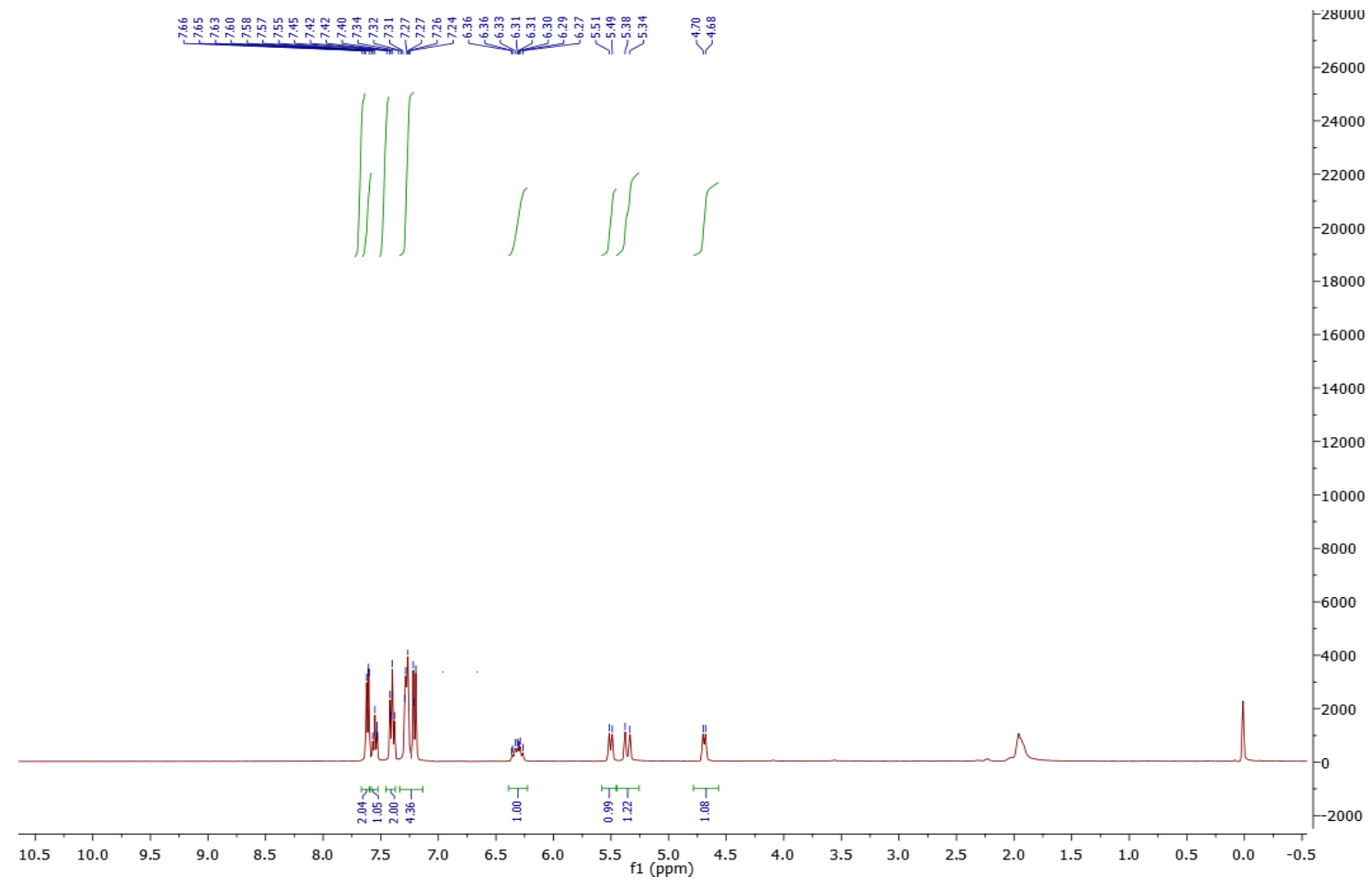

${ }^{13} \mathrm{C} \mathrm{NMR}$ spectrum $\left(100 \mathrm{MHz}, \mathrm{CDCl}_{3}\right)$ of 3ja

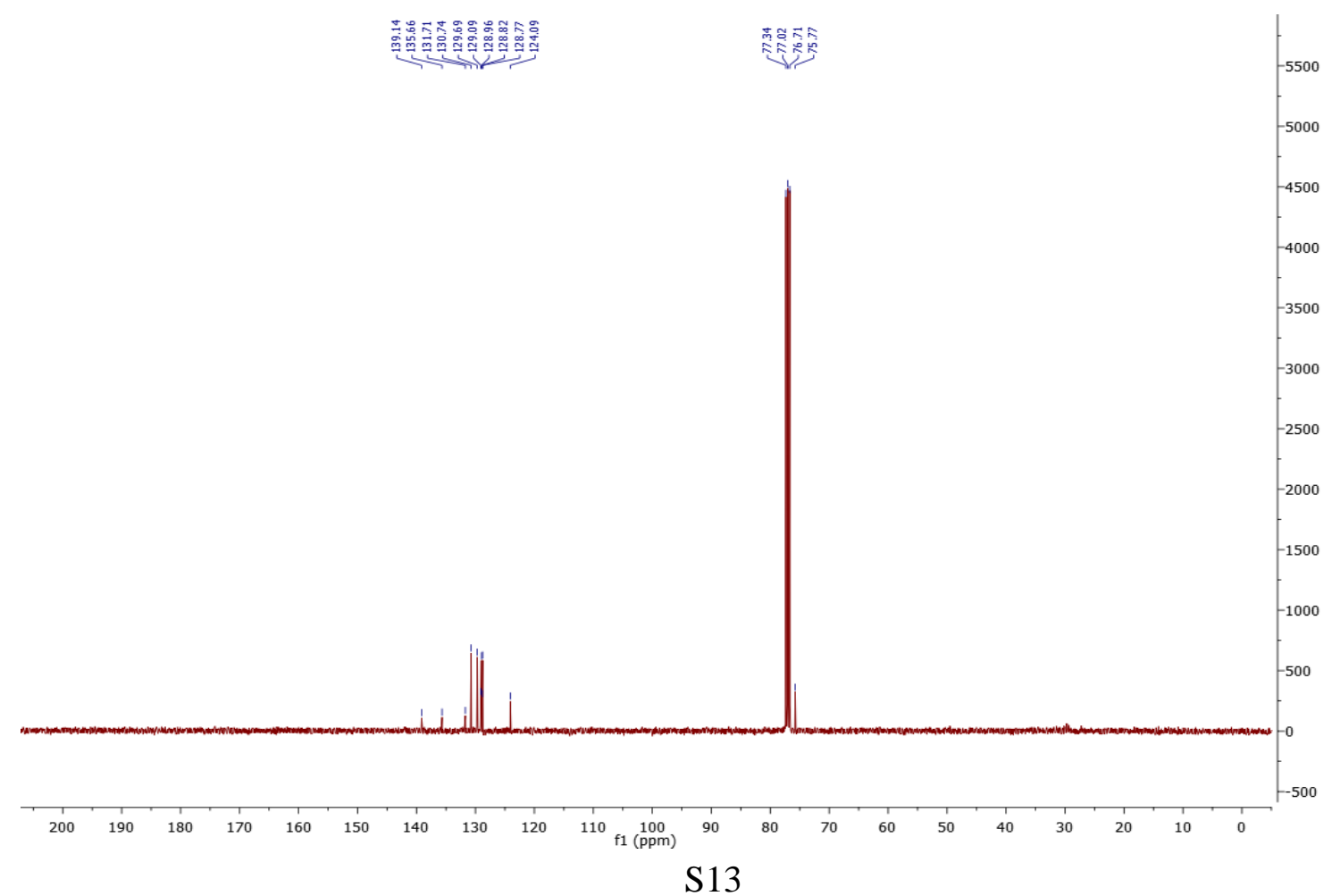




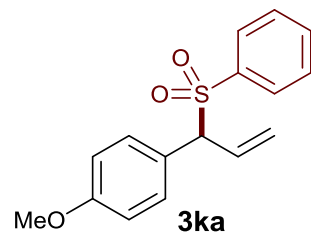

${ }^{1} \mathrm{H}$ NMR spectrum (400 $\mathrm{MHz}, \mathrm{CDCl}_{3}$ ) of $3 \mathrm{ka}$

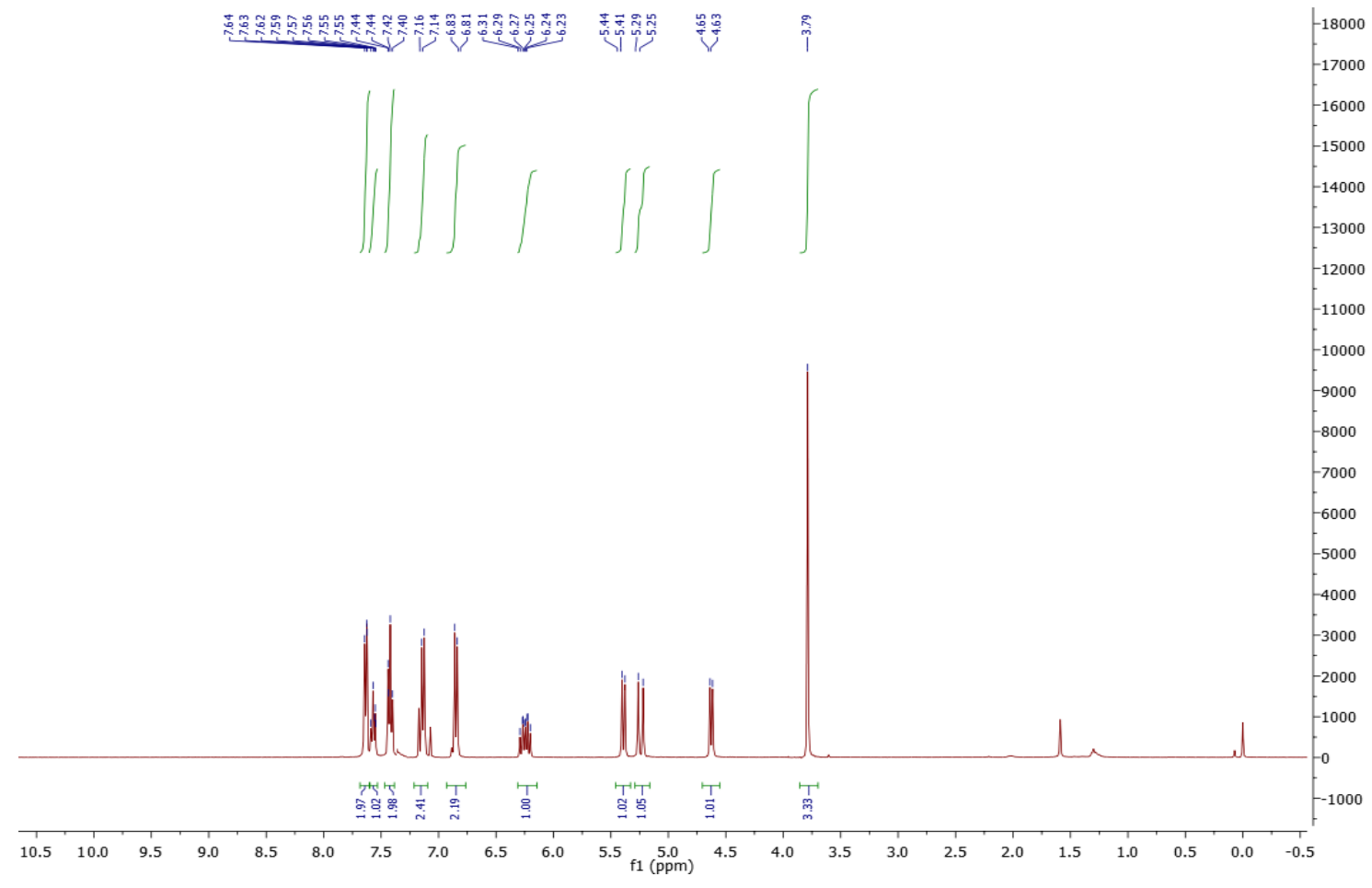

${ }^{13} \mathrm{C}$ NMR spectrum $\left(100 \mathrm{MHz}, \mathrm{CDCl}_{3}\right)$ of $3 \mathrm{ka}$

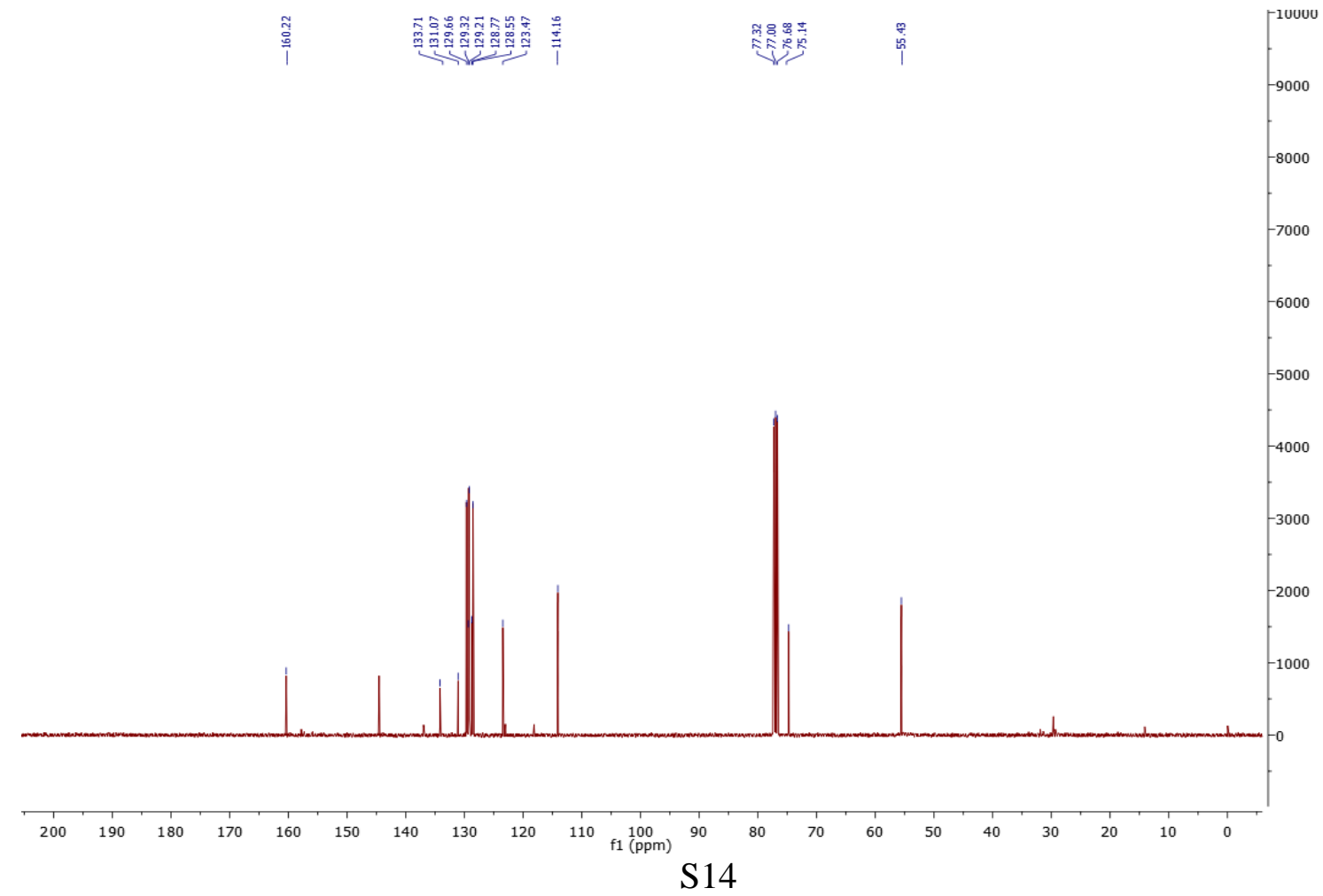




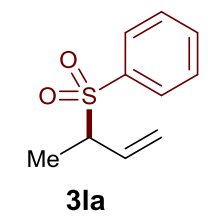

${ }^{1} \mathrm{H}$ NMR spectrum $\left(400 \mathrm{MHz} \mathrm{CDCl}_{3}\right)$ of 3la
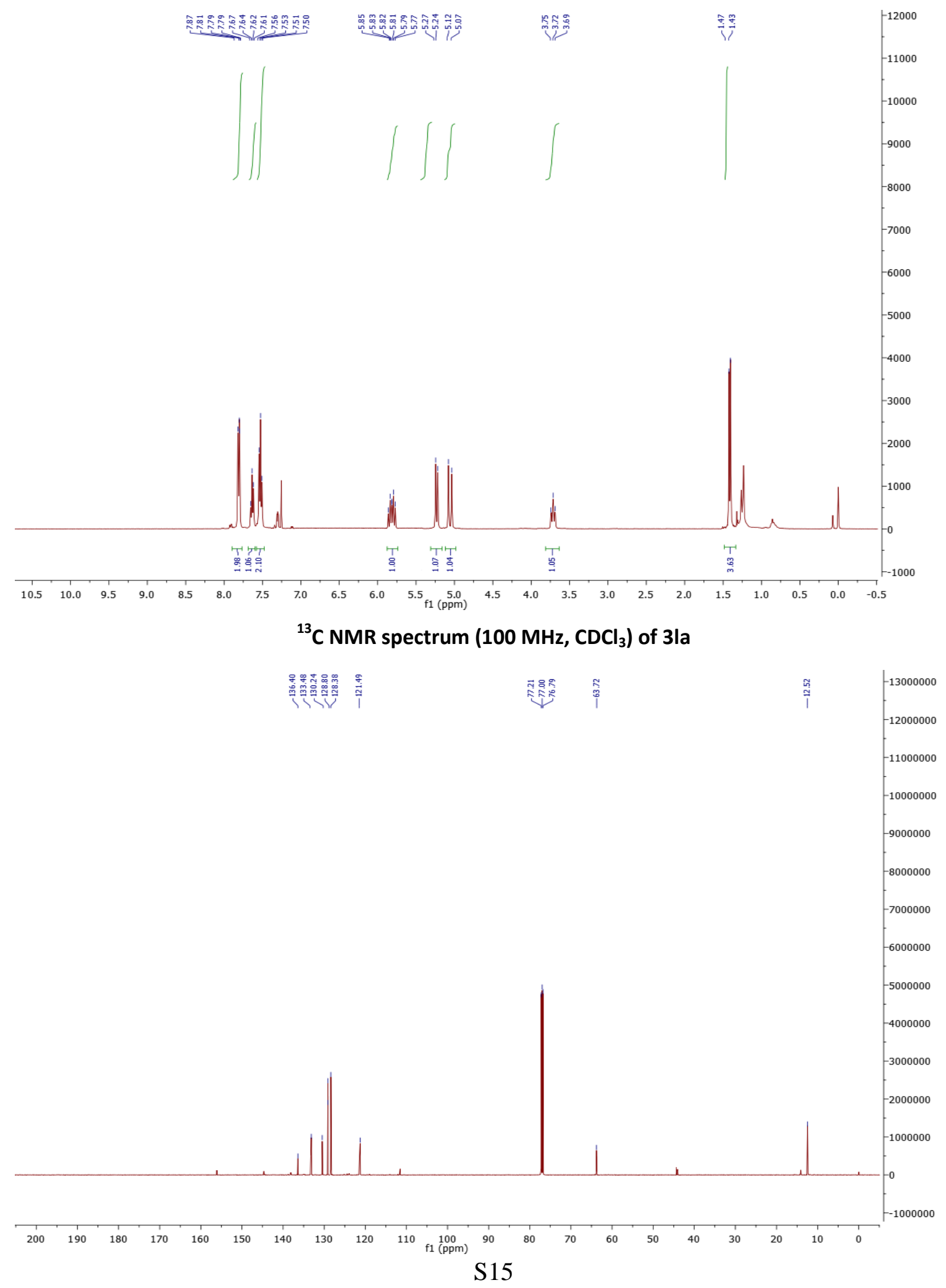
<smiles>C=CC(CCc1ccccc1)S(=O)(=O)c1ccc(C)cc1</smiles>

${ }^{1} \mathrm{H}$ NMR spectrum (400 MHz, $\mathrm{CDCl}_{3}$ ) of 3ob

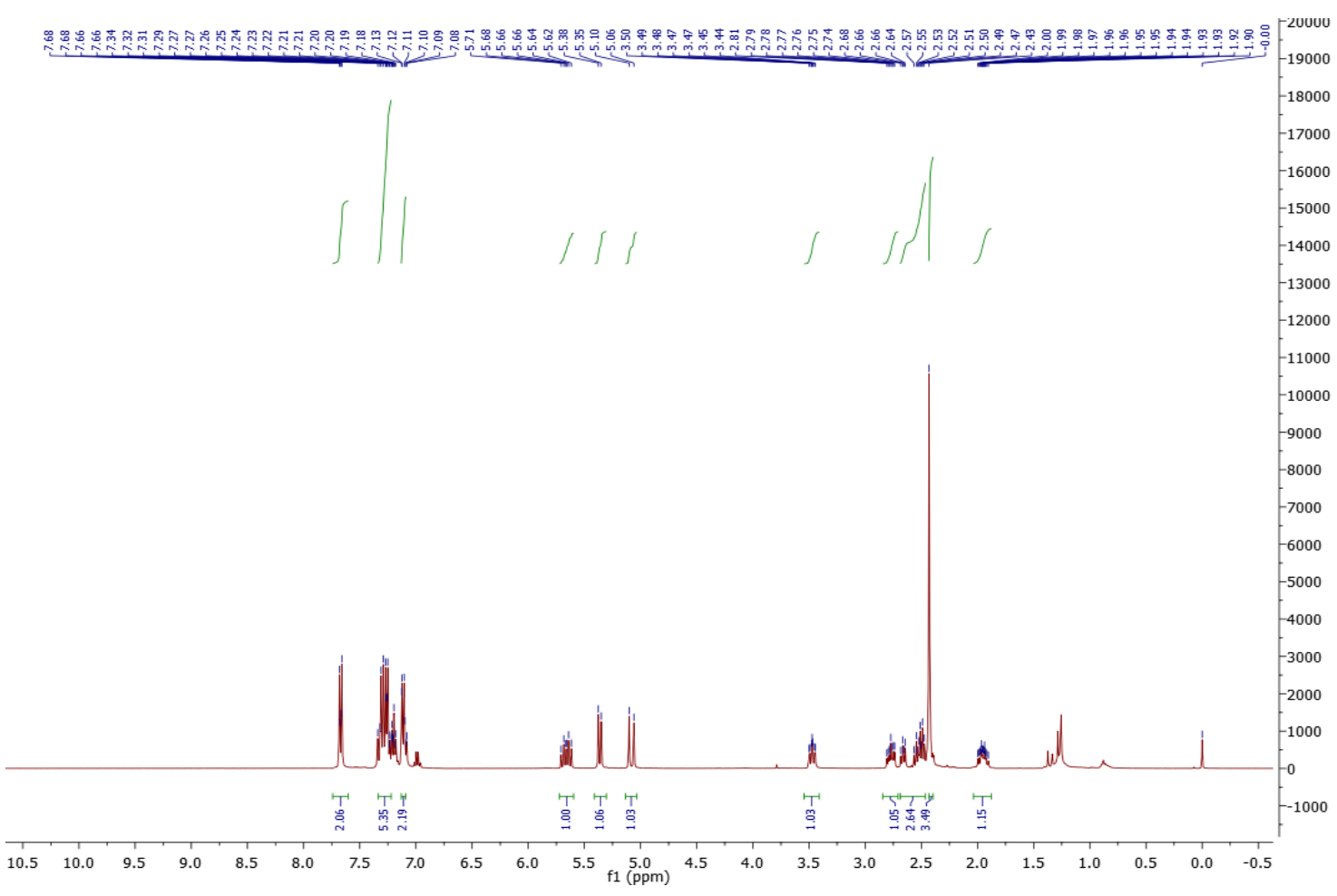

${ }^{13} \mathrm{C}$ NMR spectrum $\left(100 \mathrm{MHz}, \mathrm{CDCl}_{3}\right)$ of $30 \mathrm{~b}$

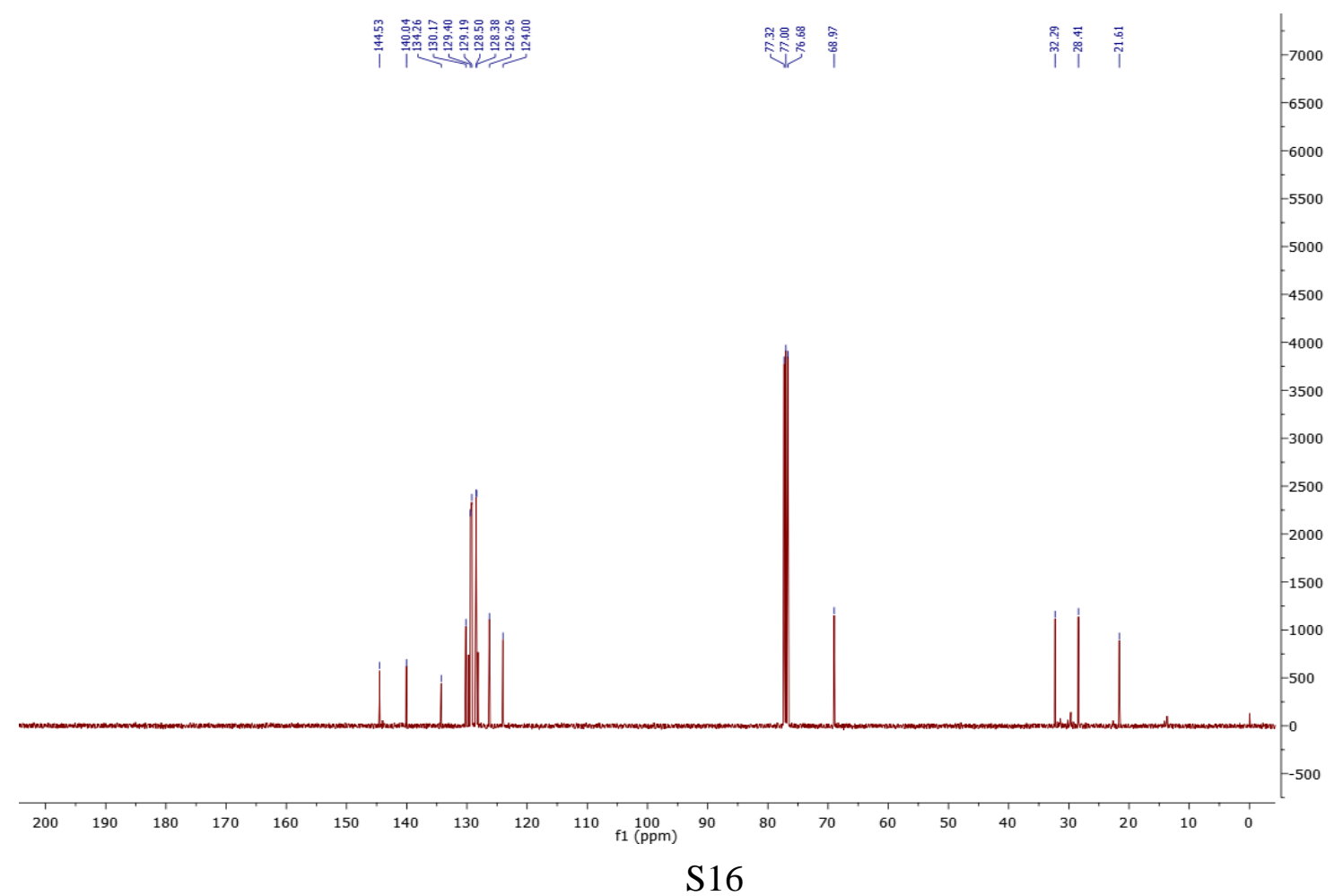




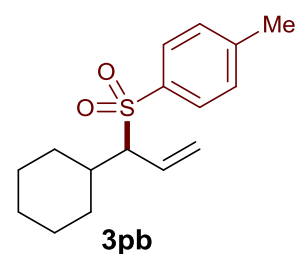

${ }^{1} \mathrm{H}$ NMR spectrum $\left(400 \mathrm{MHz}, \mathrm{CDCl}_{3}\right)$ of $3 \mathrm{pb}$

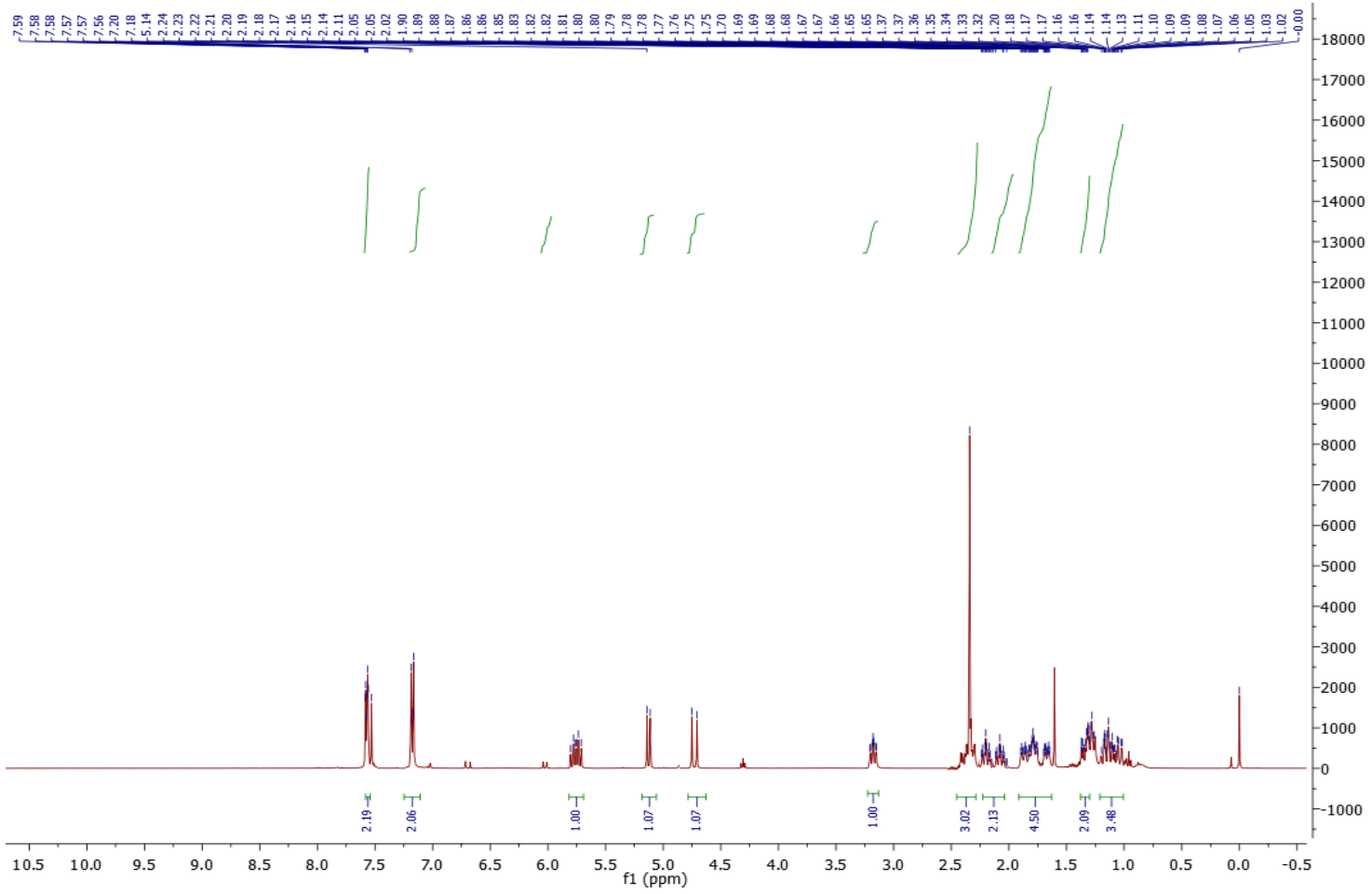

${ }^{13} \mathrm{C}$ NMR spectrum $\left(100 \mathrm{MHz}, \mathrm{CDCl}_{3}\right)$ of $3 \mathrm{pb}$

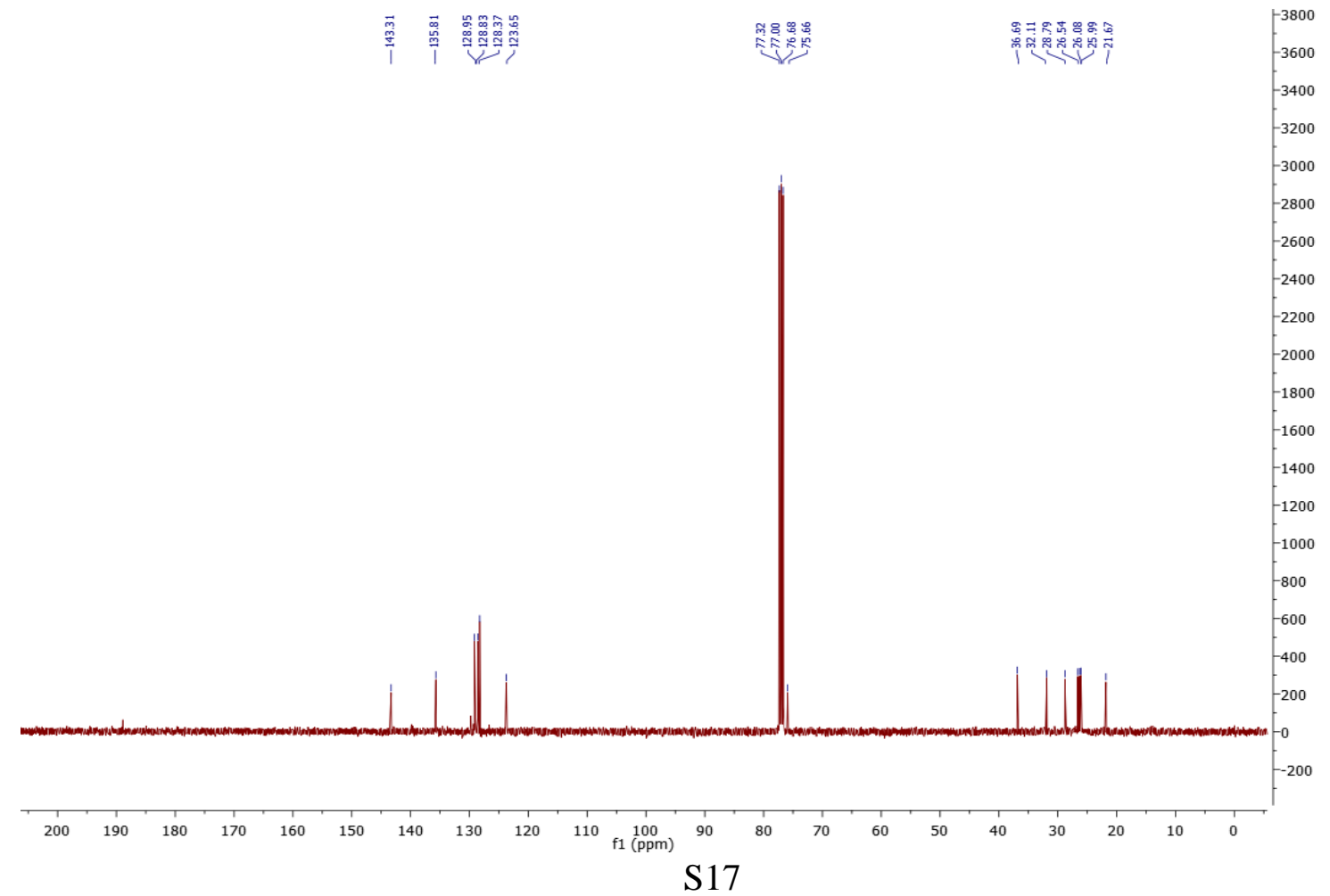




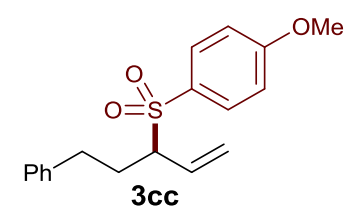

${ }^{1} \mathrm{H}$ NMR spectrum $\left(400 \mathrm{MHz}, \mathrm{CDCl}_{3}\right.$ ) of $3 \mathrm{cc}$

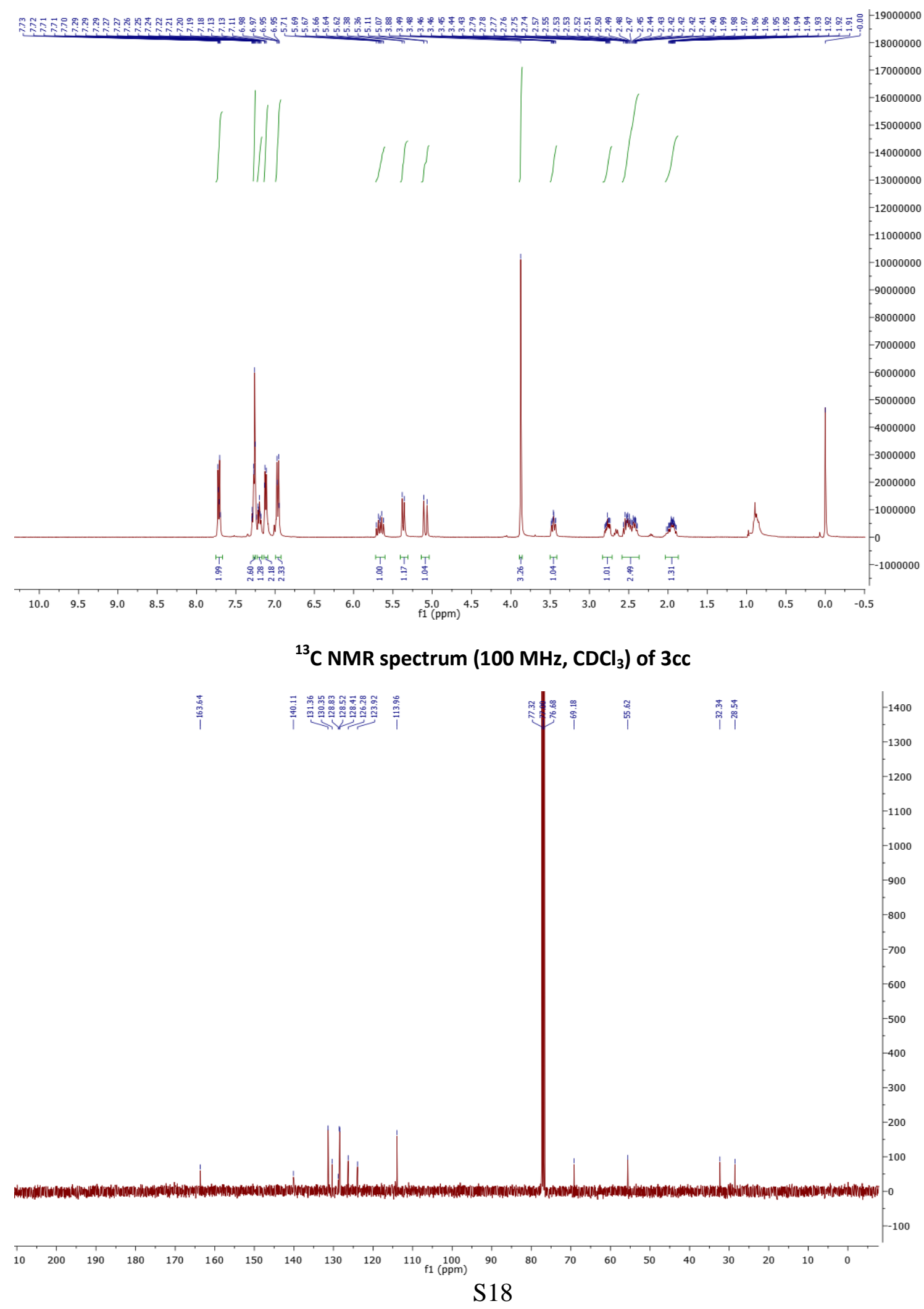


<smiles>C=CC(CCc1ccccc1)S(=O)(=O)c1ccc(Cl)cc1</smiles>

${ }^{1} \mathrm{H}$ NMR spectrum (400 $\mathrm{MHz}, \mathrm{CDCl}_{3}$ ) of $3 \mathrm{~cd}$

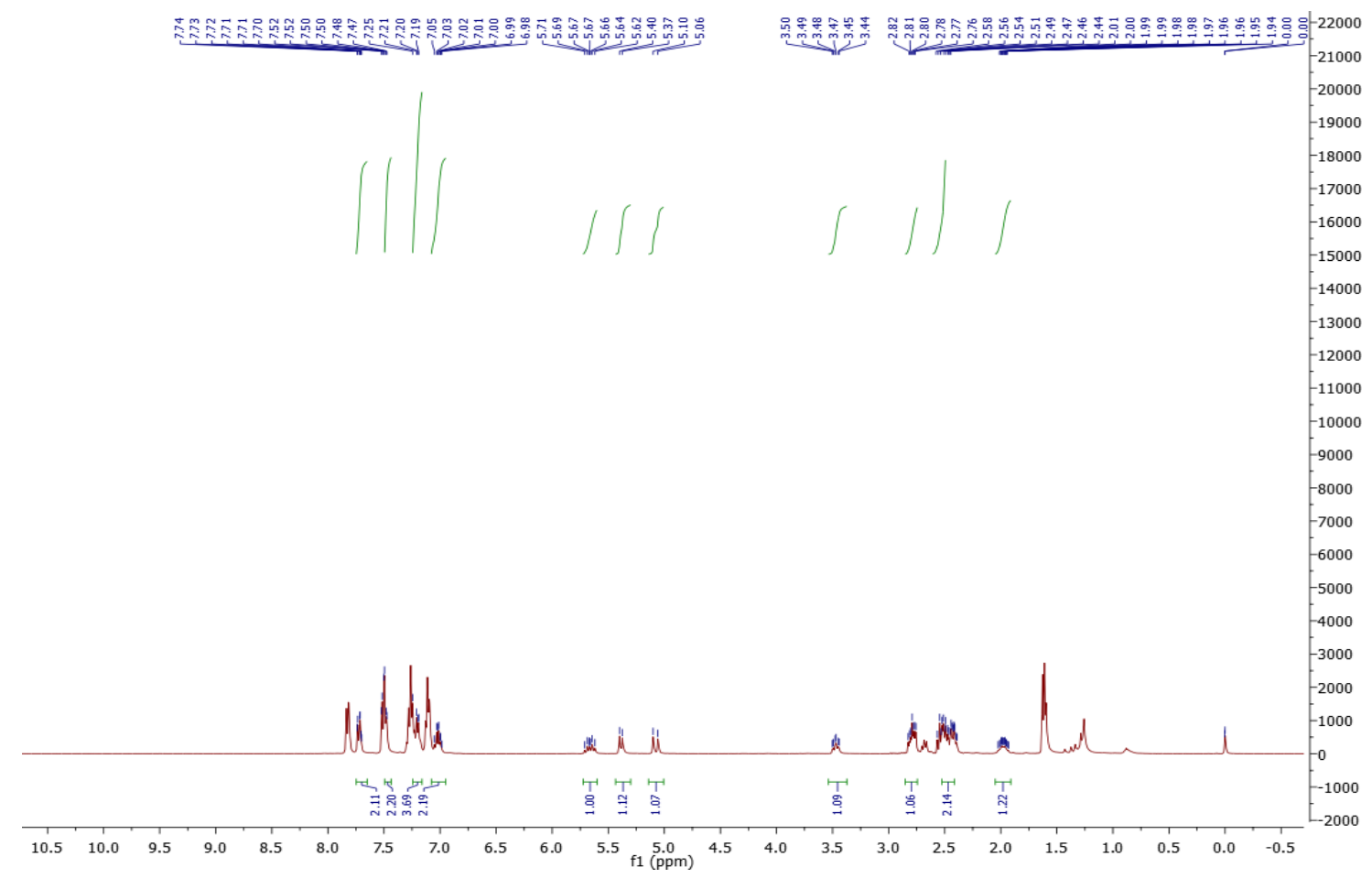

${ }^{13} \mathrm{C} \mathrm{NMR} \mathrm{spectrum}\left(100 \mathrm{MHz}, \mathrm{CDCl}_{3}\right)$ of $3 \mathrm{~cd}$

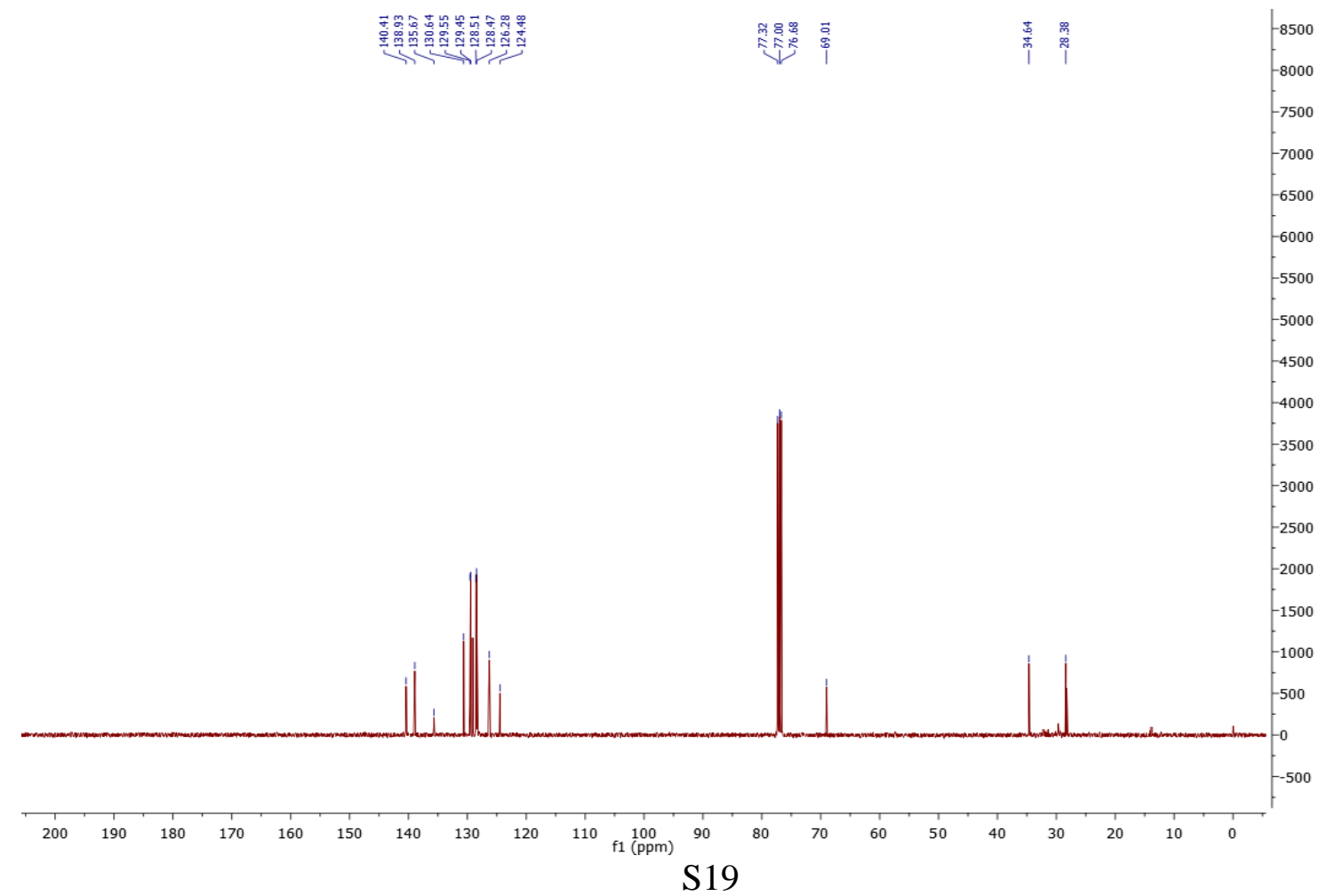




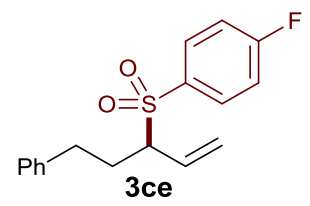

${ }^{1} \mathrm{H}$ NMR spectrum $\left(400 \mathrm{MHz}, \mathrm{CDCl}_{3}\right)$ of $3 c e$

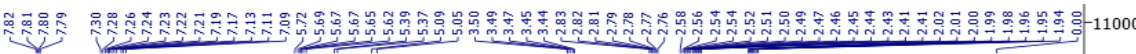
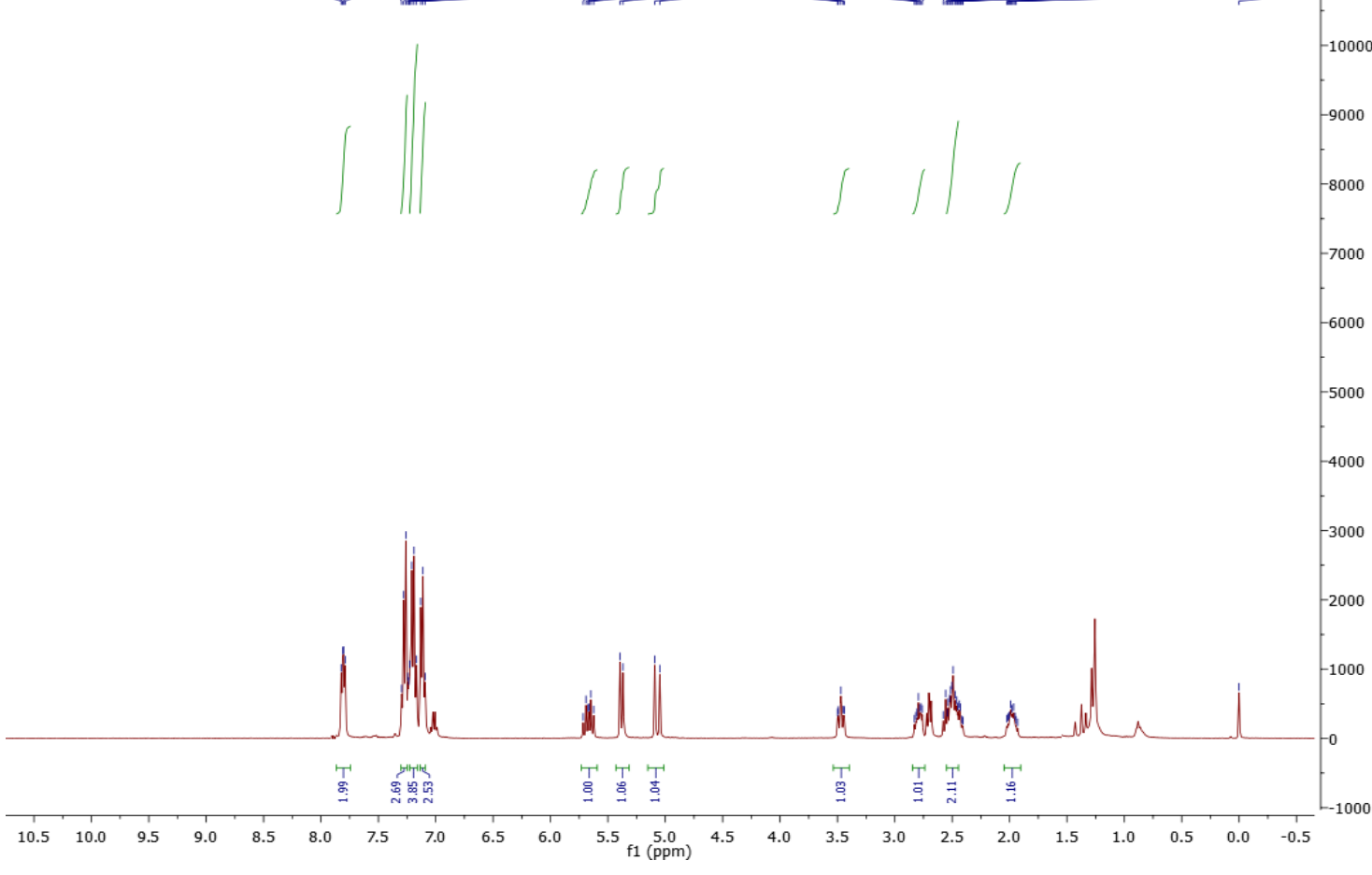

${ }^{13} \mathrm{C}$ NMR spectrum $\left(100 \mathrm{MHz}, \mathrm{CDCl}_{3}\right)$ of $3 \mathrm{ca}$

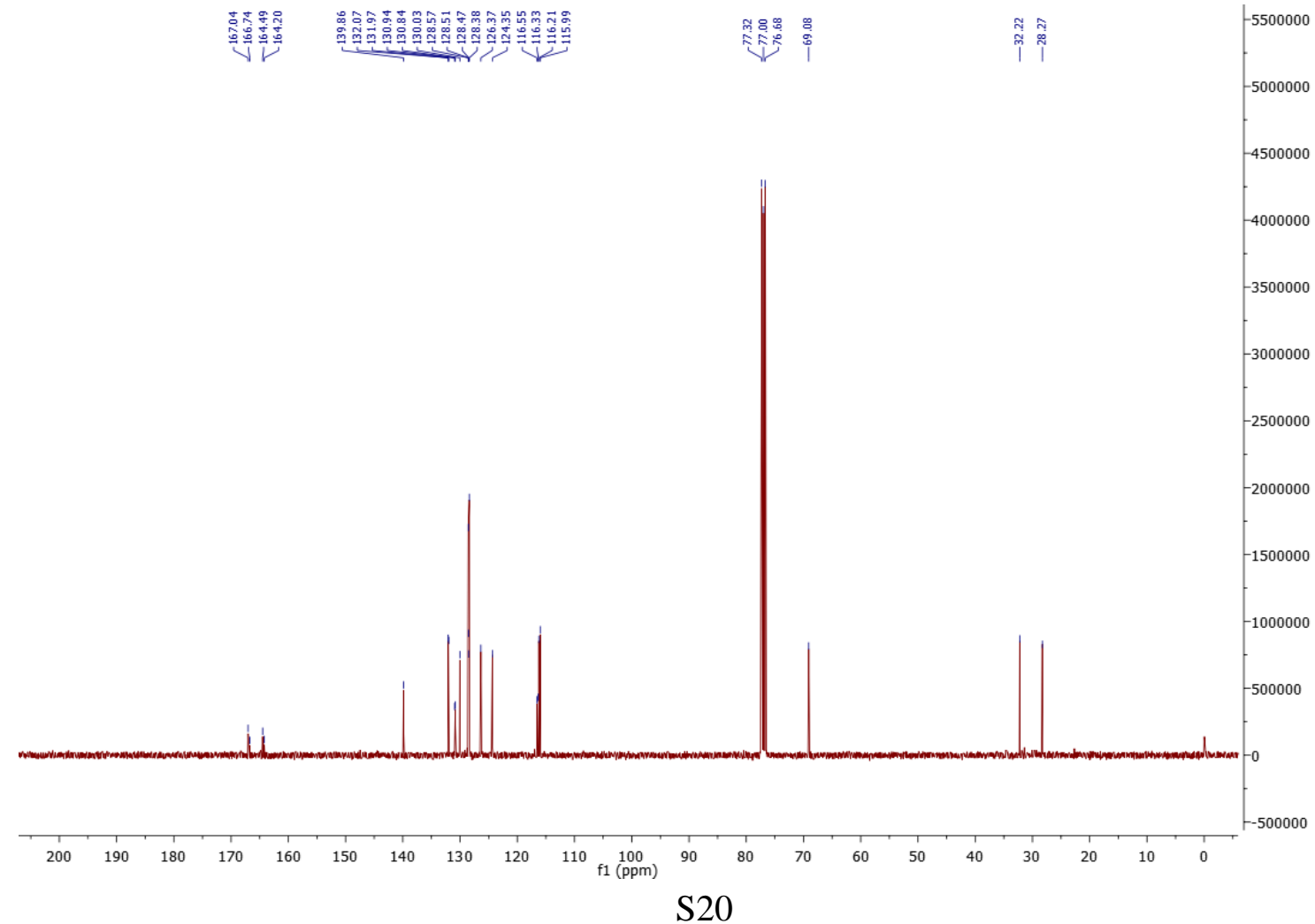




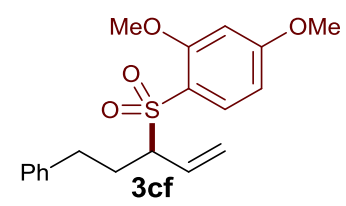

${ }^{1} \mathrm{H}$ NMR spectrum $\left(400 \mathrm{MHz}, \mathrm{CDCl}_{3}\right)$ of $3 \mathrm{cf}$

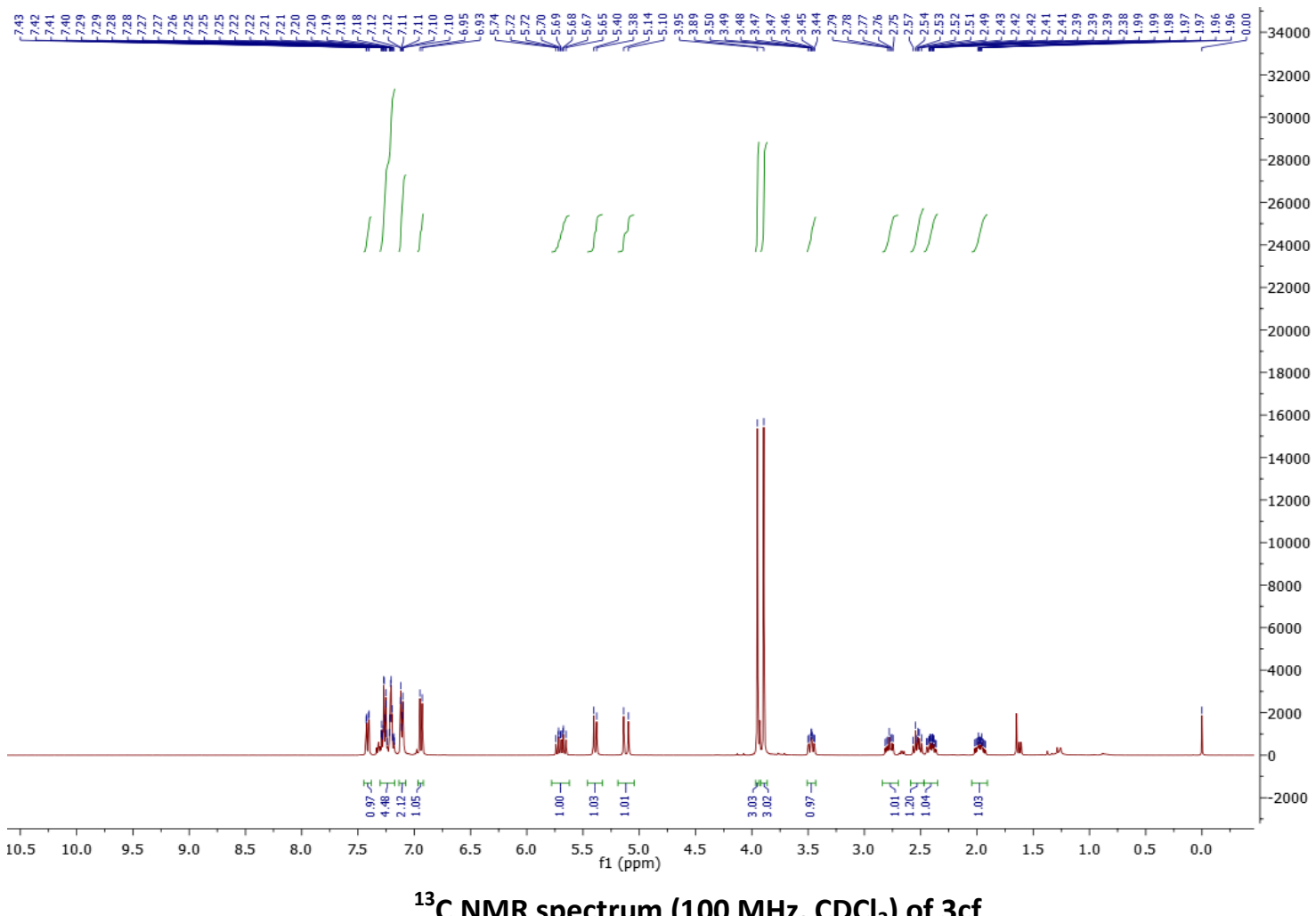

${ }^{13} \mathrm{C}$ NMR spectrum $\left(100 \mathrm{MHz}, \mathrm{CDCl}_{3}\right)$ of $3 \mathrm{cf}$

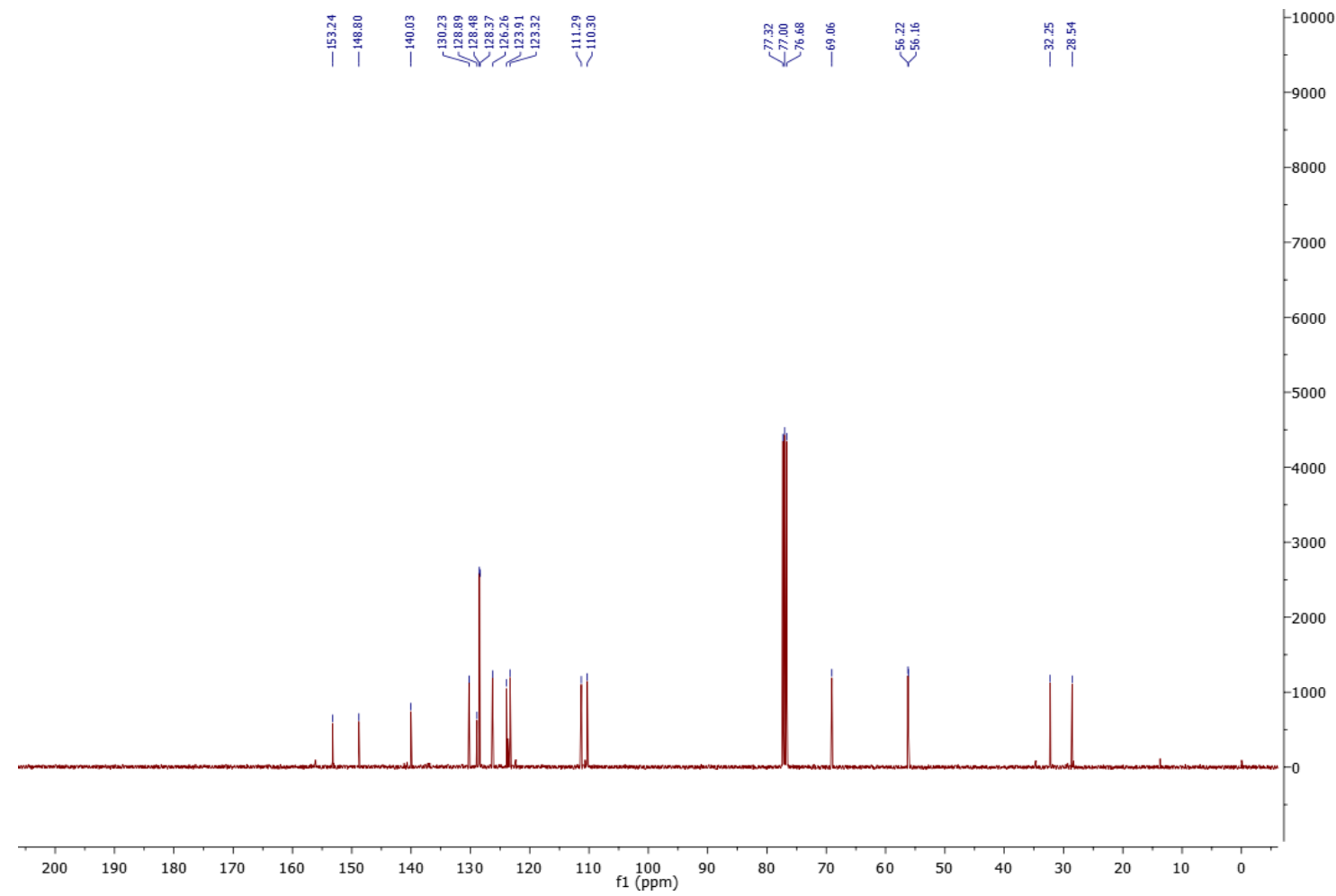




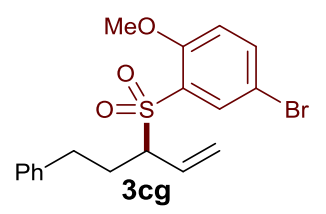

${ }^{1} \mathrm{H}$ NMR spectrum $\left(400 \mathrm{MHz}, \mathrm{CDCl}_{3}\right)$ of $3 \mathrm{cg}$

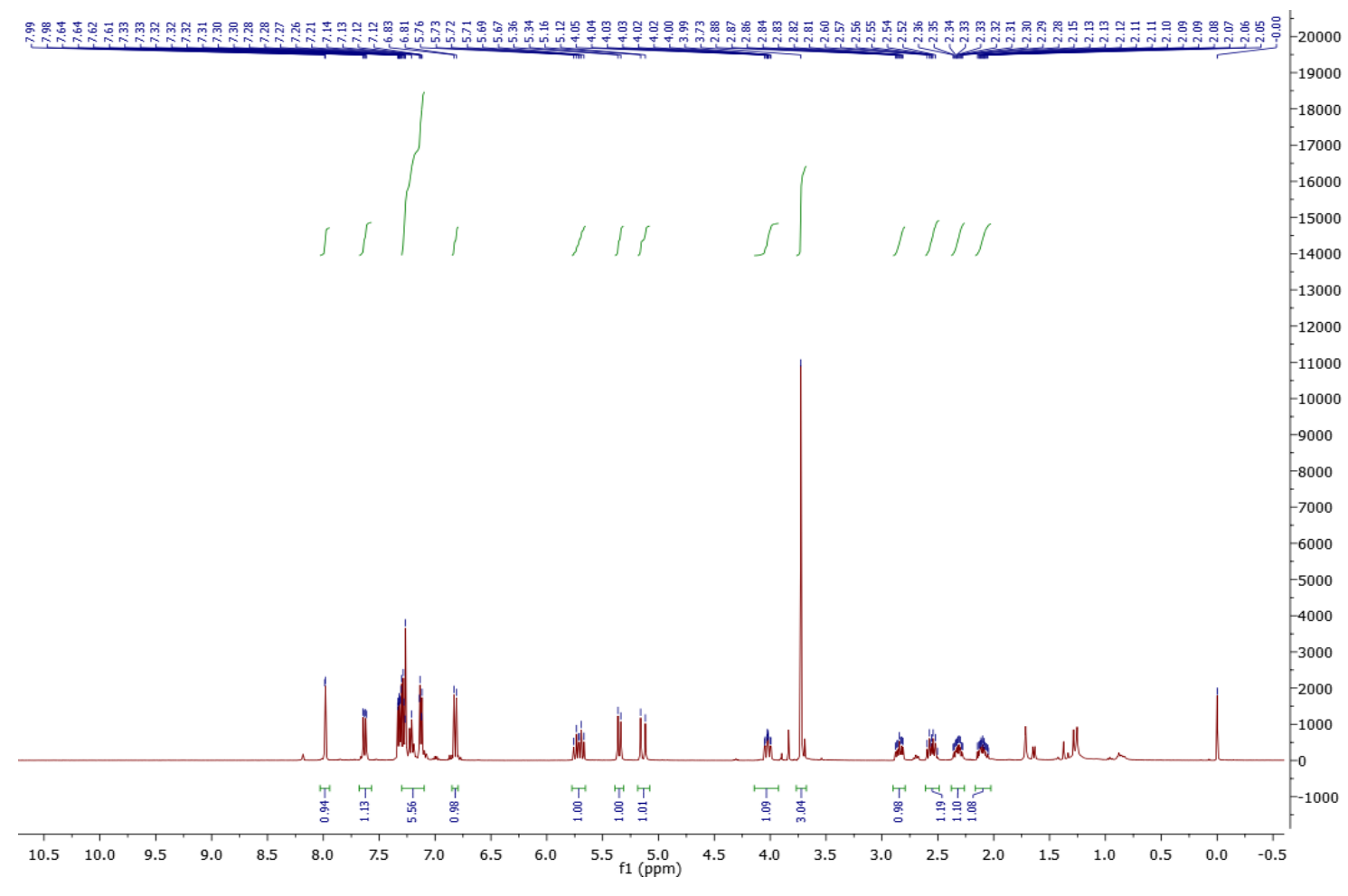

${ }^{13} \mathrm{C}$ NMR spectrum $\left(100 \mathrm{MHz}, \mathrm{CDCl}_{3}\right)$ of $3 \mathrm{cg}$

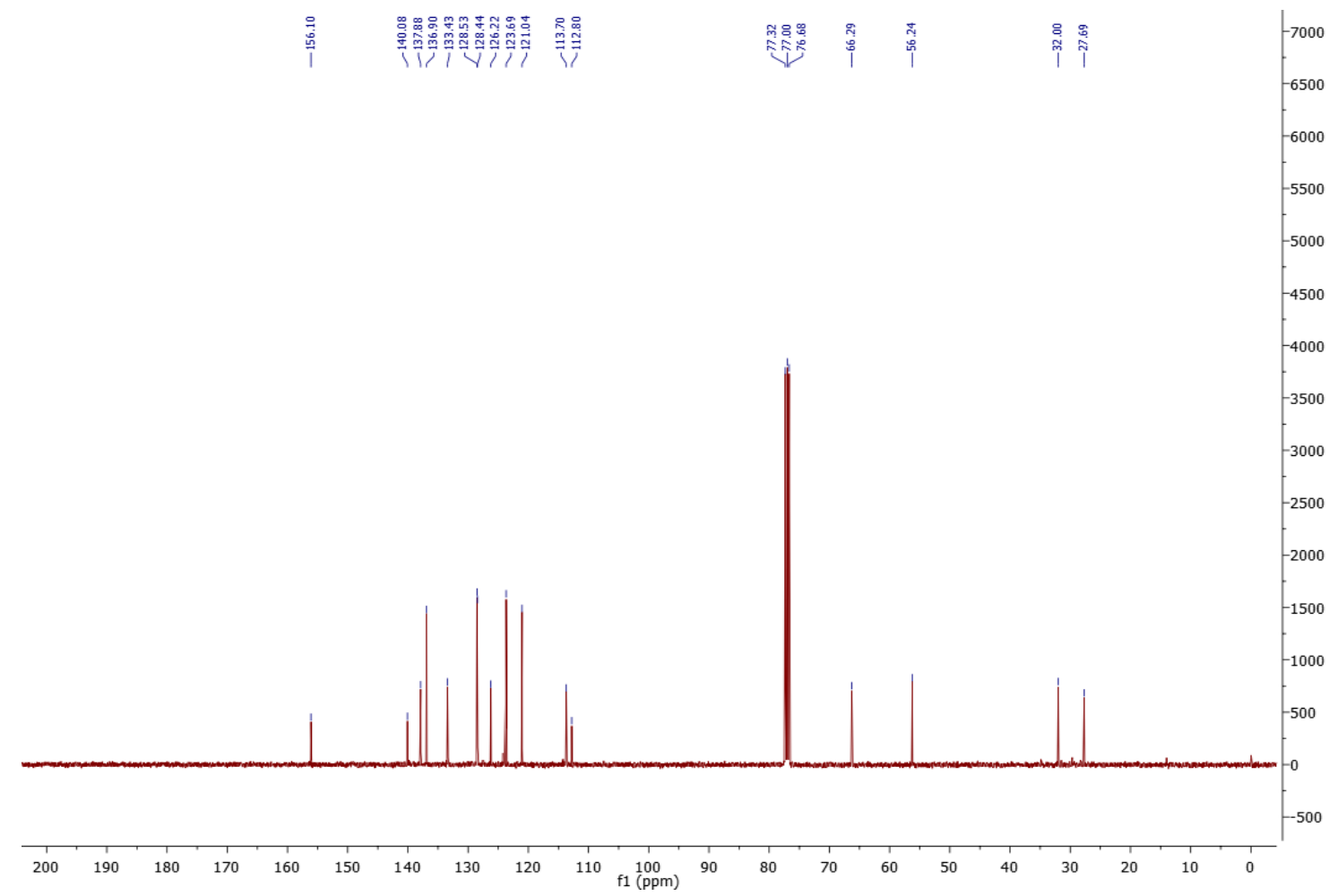




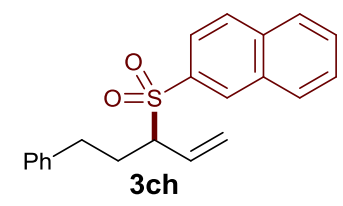

${ }^{1} \mathrm{H}$ NMR spectrum $\left(400 \mathrm{MHz}, \mathrm{CDCl}_{3}\right)$ of $3 \mathrm{ch}$

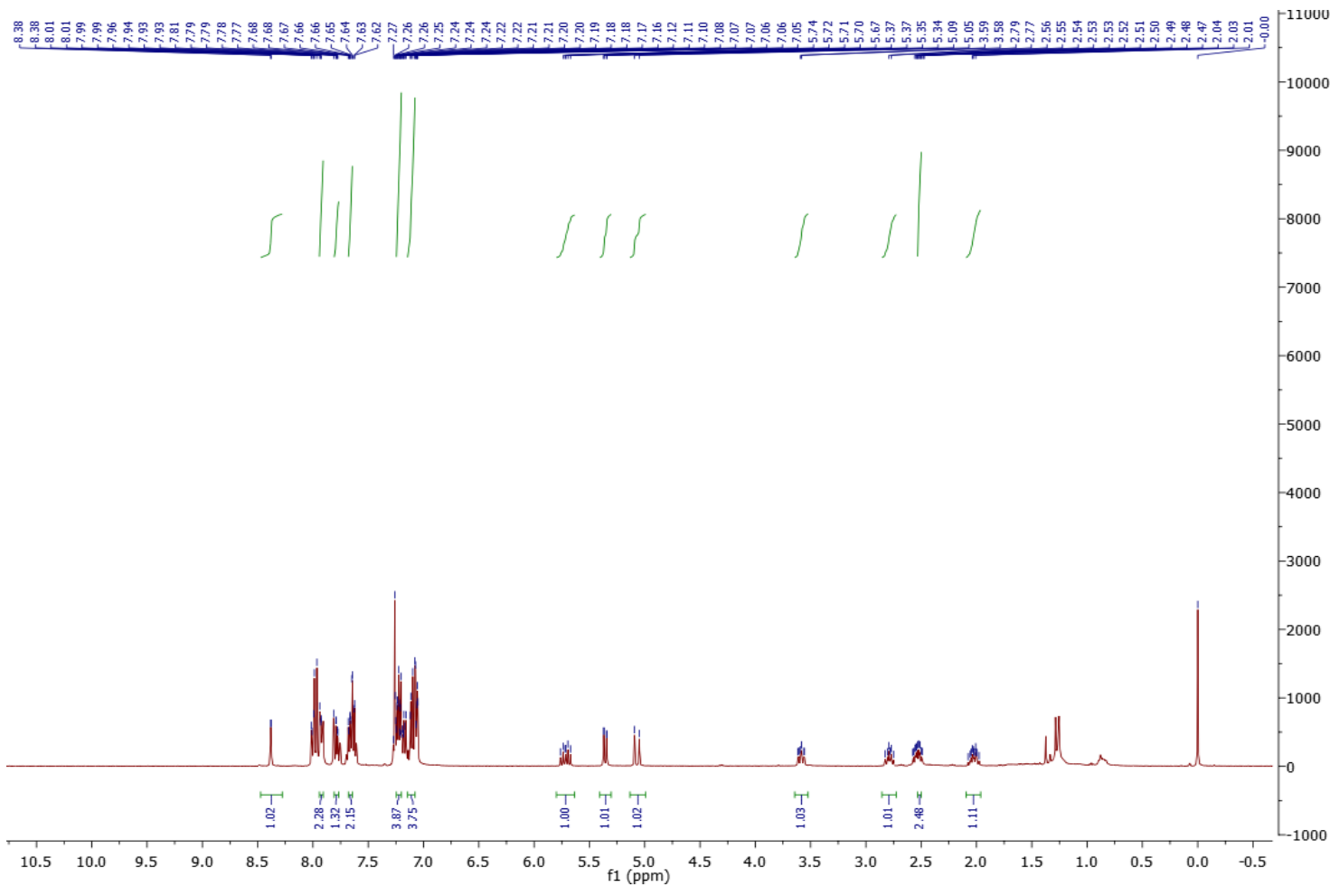

${ }^{13} \mathrm{C}$ NMR spectrum $\left(100 \mathrm{MHz}, \mathrm{CDCl}_{3}\right)$ of $3 \mathrm{ch}$

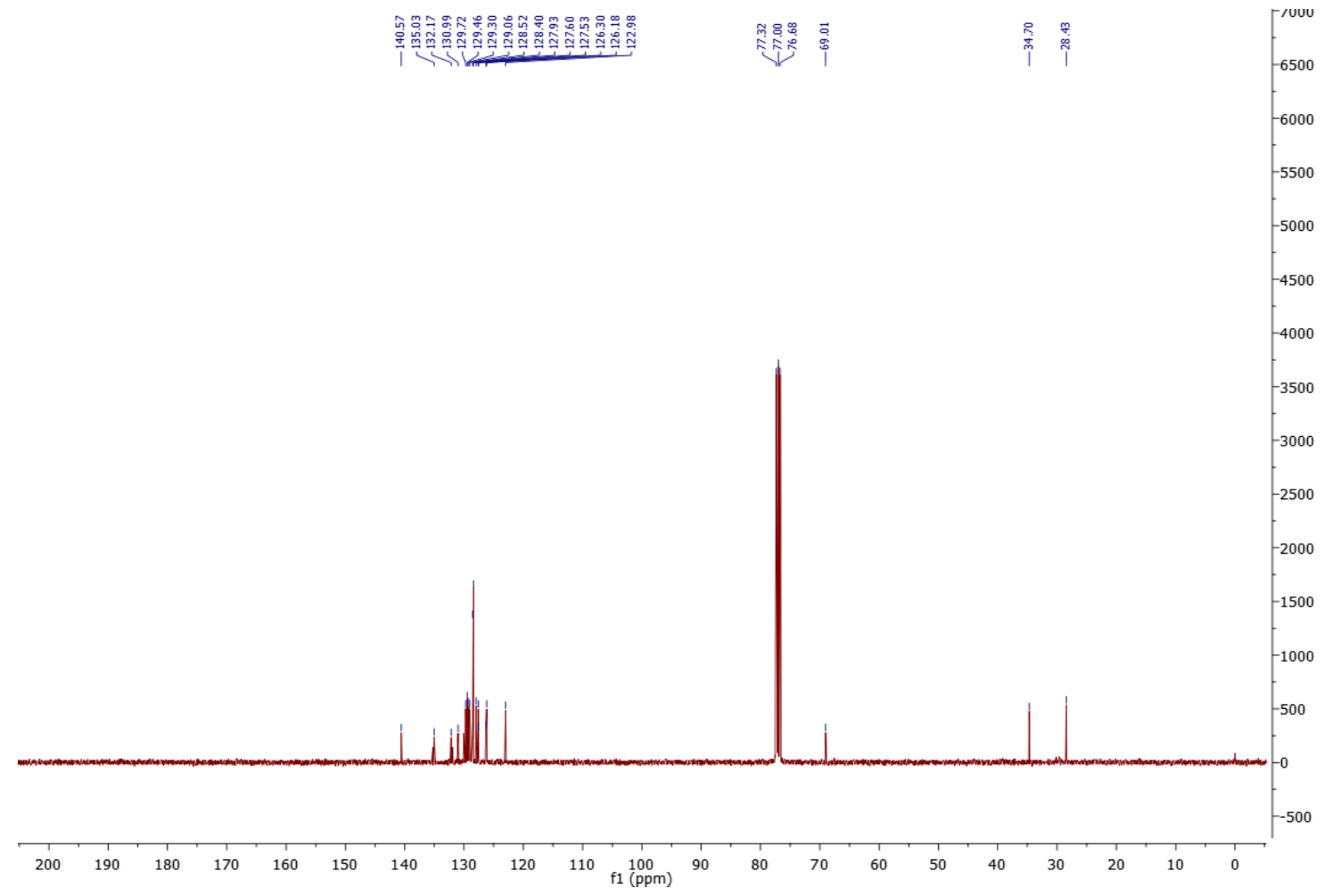




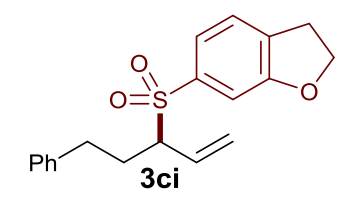

${ }^{1} \mathrm{H}$ NMR spectrum $\left(400 \mathrm{MHz}, \mathrm{CDCl}_{3}\right)$ of $3 \mathrm{ci}$

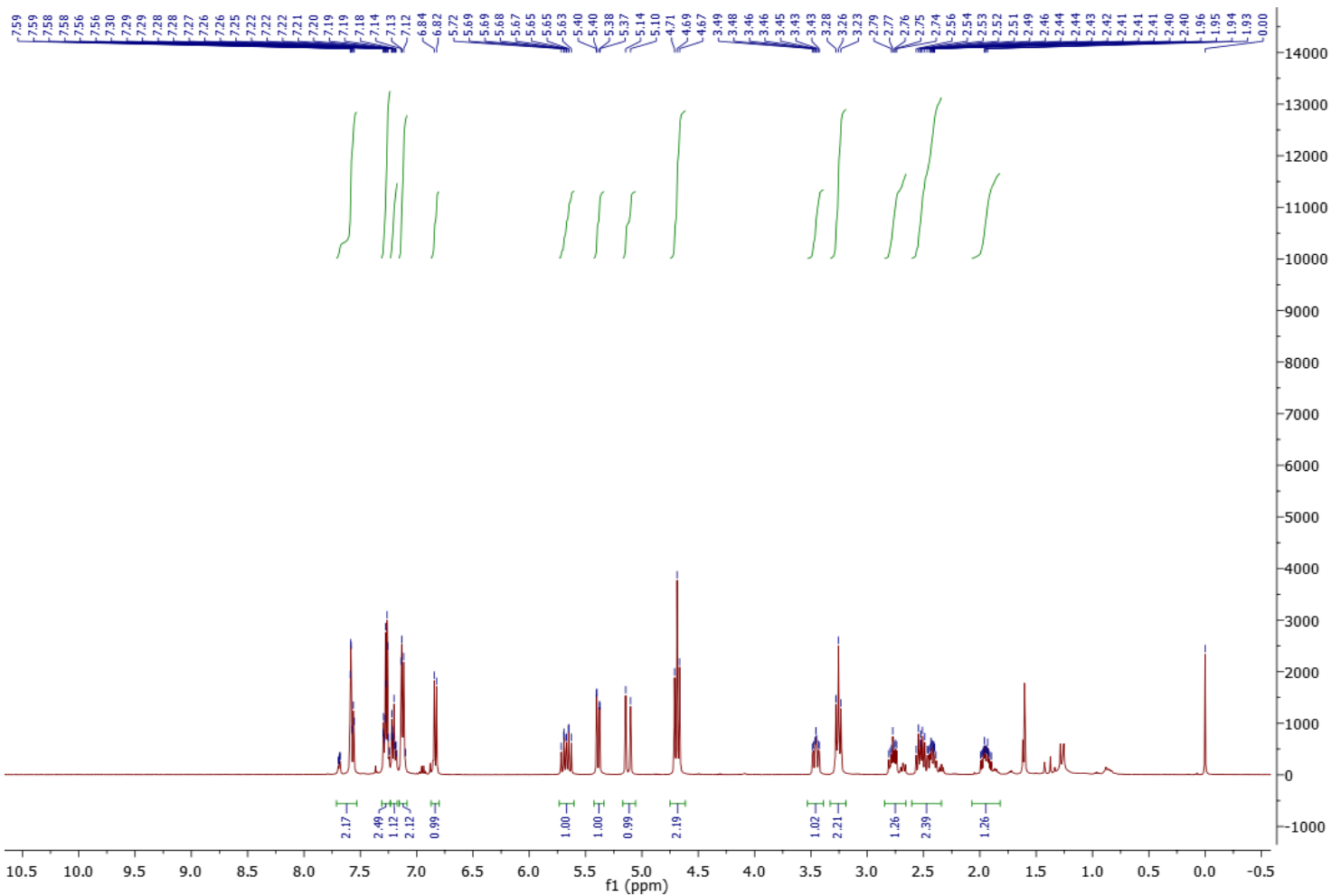

${ }^{13} \mathrm{C} \mathrm{NMR}$ spectrum $\left(100 \mathrm{MHz}, \mathrm{CDCl}_{3}\right)$ of $3 \mathrm{ci}$

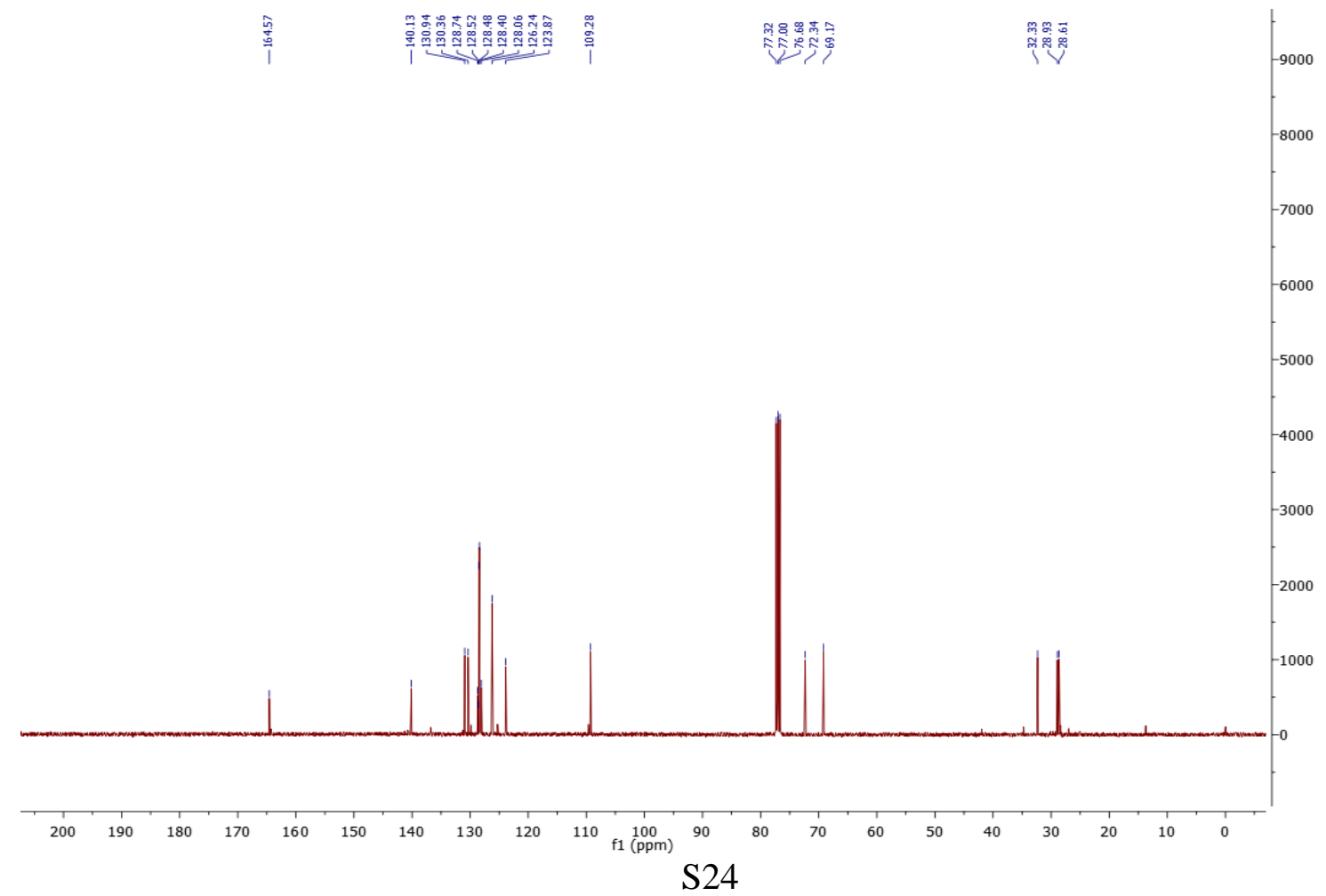




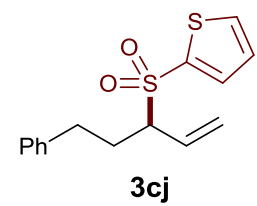

${ }^{1} \mathrm{H}$ NMR spectrum $\left(400 \mathrm{MHz}, \mathrm{CDCl}_{3}\right)$ of $3 \mathrm{cj}$
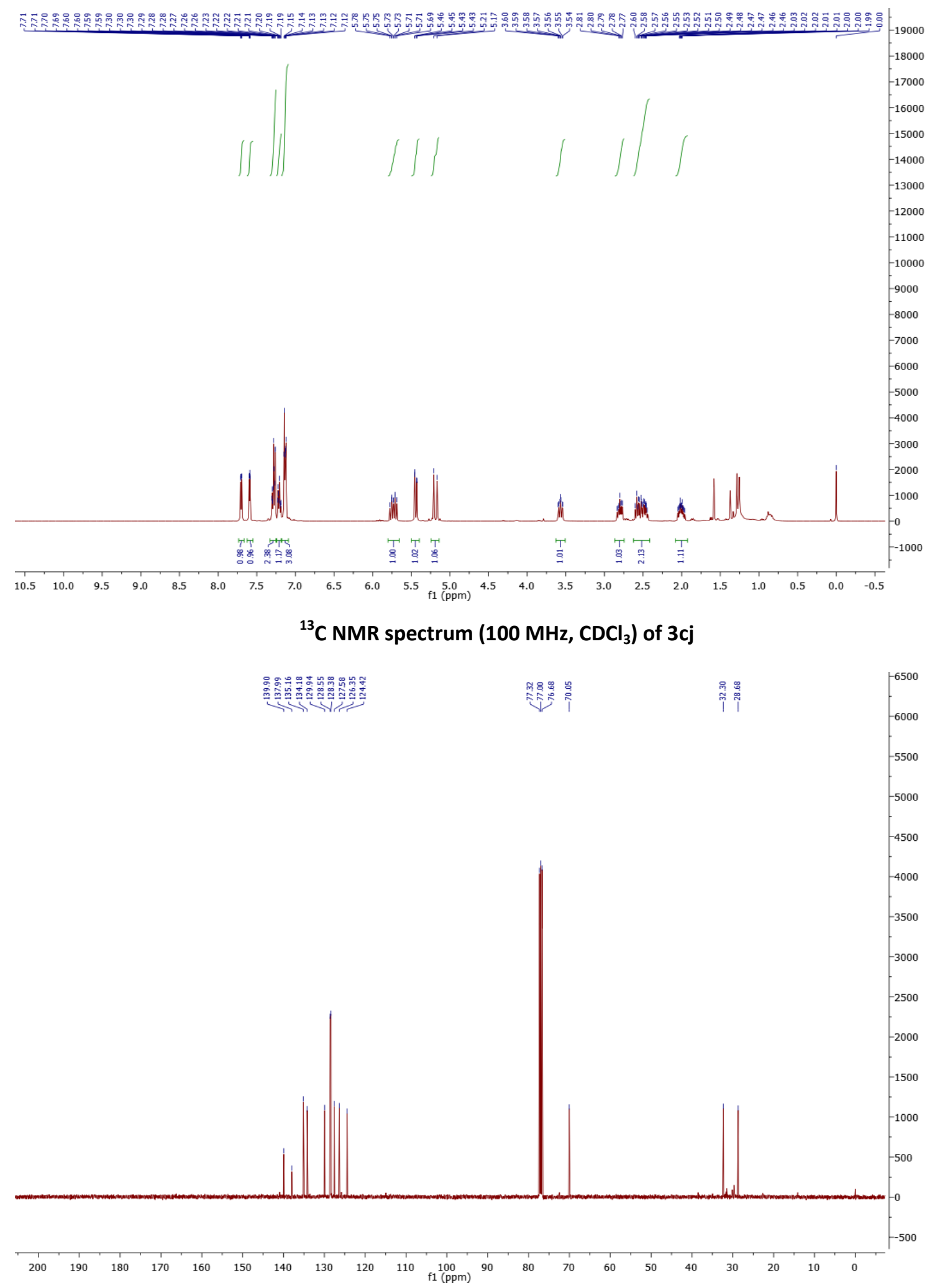


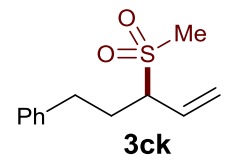

${ }^{1} \mathrm{H}$ NMR spectrum $\left(400 \mathrm{MHz}, \mathrm{CDCl}_{3}\right.$ ) of 3ck

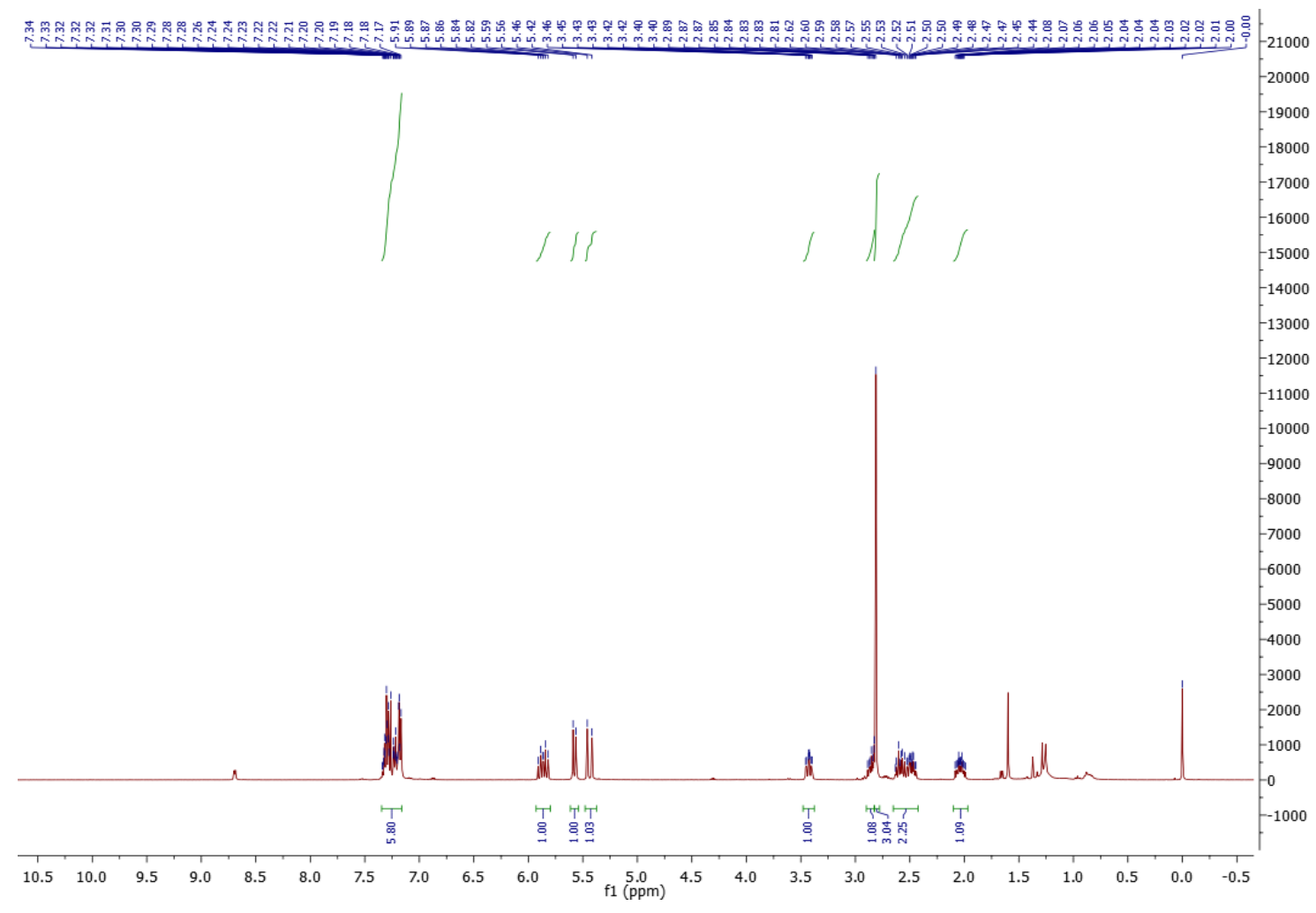

${ }^{13} \mathrm{C} \mathrm{NMR} \mathrm{spectrum}\left(100 \mathrm{MHz}, \mathrm{CDCl}_{3}\right)$ of $3 \mathrm{ck}$

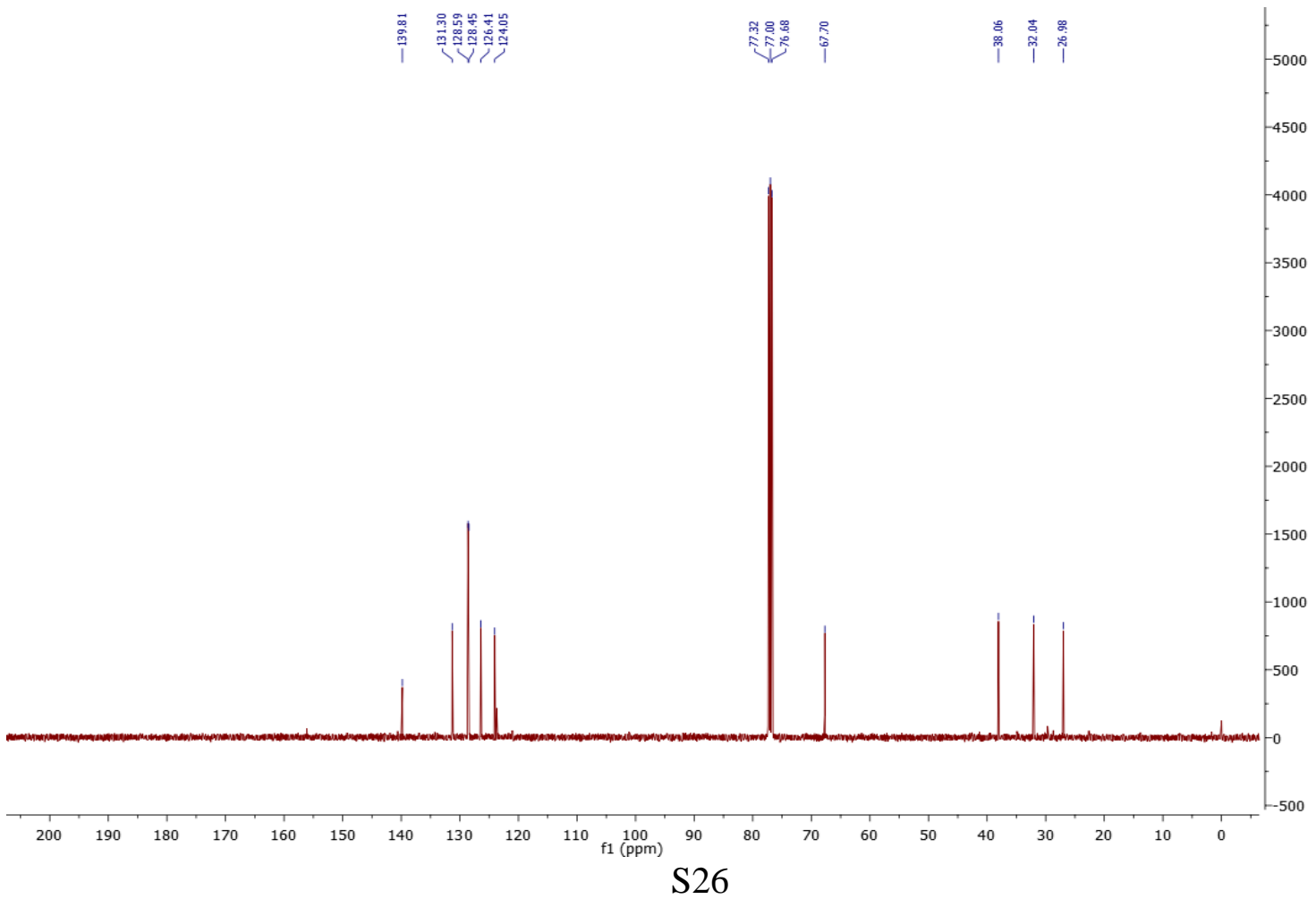




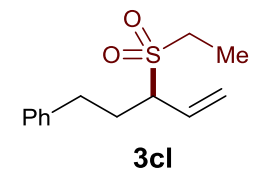

${ }^{1} \mathrm{H}$ NMR spectrum $\left(400 \mathrm{MHz}, \mathrm{CDCl}_{3}\right)$ of $3 \mathrm{cl}$

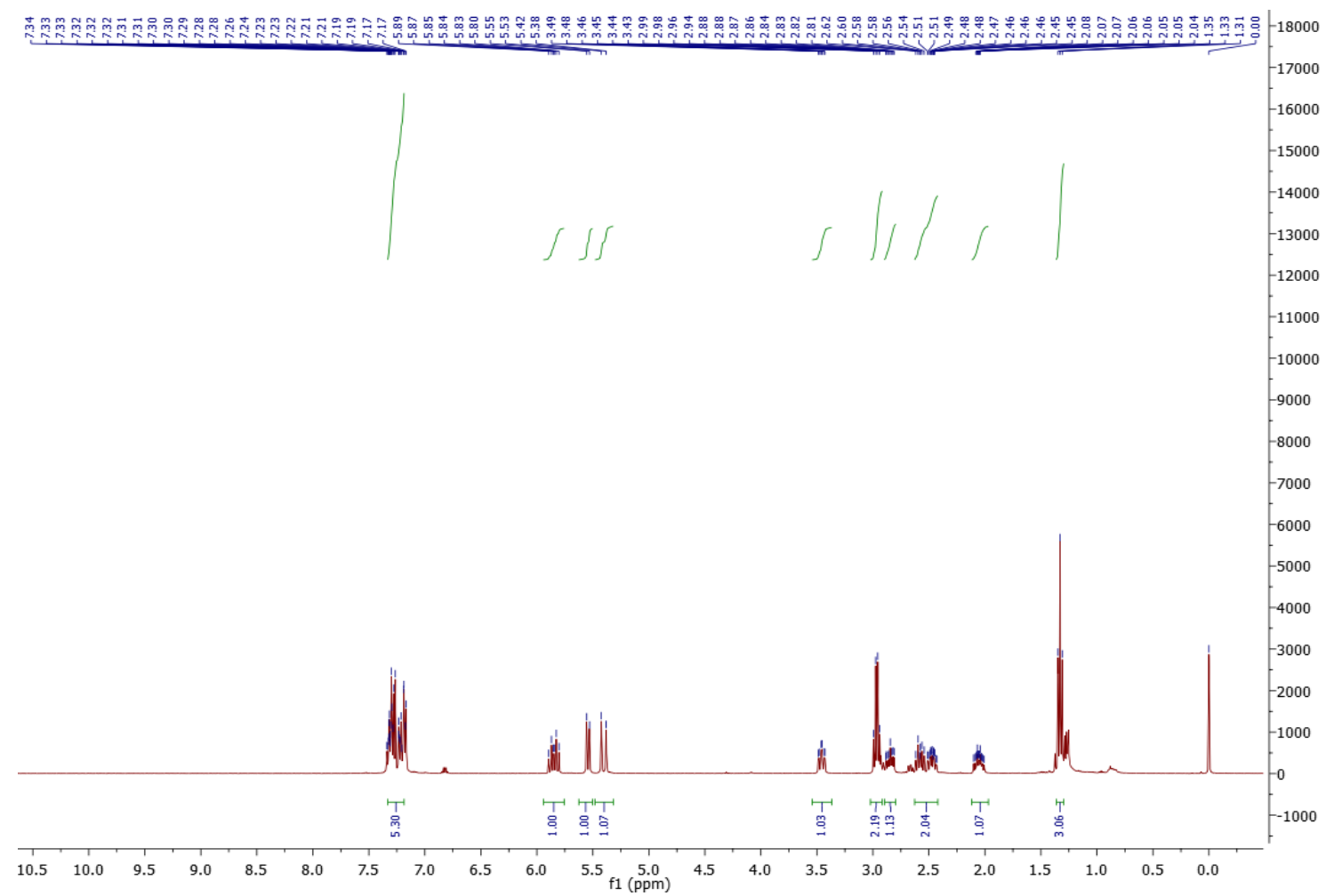

${ }^{13} \mathrm{C} \mathrm{NMR}$ spectrum $\left(100 \mathrm{MHz}, \mathrm{CDCl}_{3}\right)$ of $3 \mathrm{cl}$

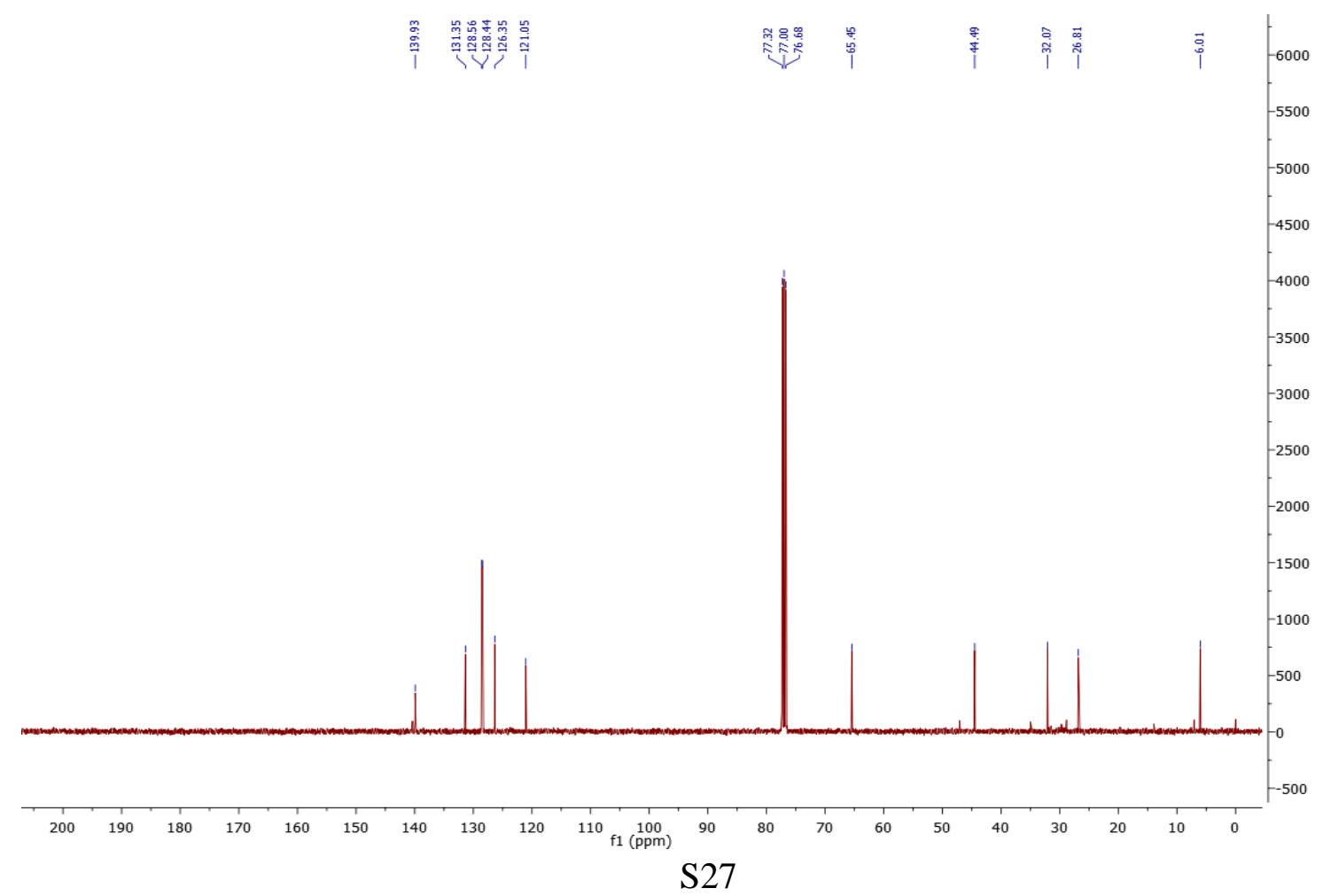




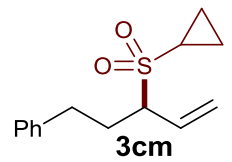

${ }^{1} \mathrm{H}$ NMR spectrum $\left(400 \mathrm{MHz}, \mathrm{CDCl}_{3}\right)$ of $3 \mathrm{~cm}$

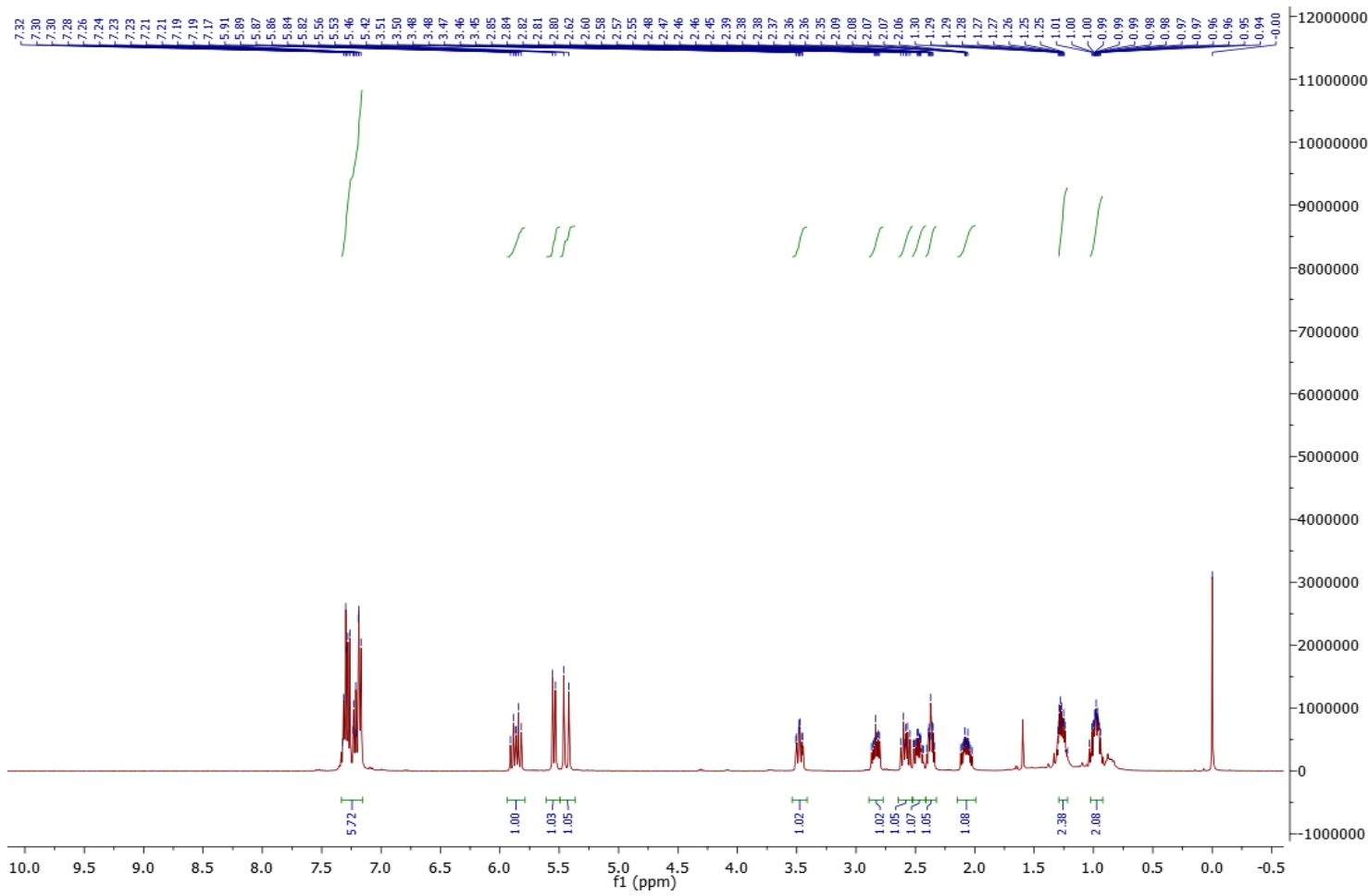

${ }^{13} \mathrm{C}$ NMR spectrum $\left(100 \mathrm{MHz}, \mathrm{CDCl}_{3}\right)$ of $3 \mathrm{~cm}$

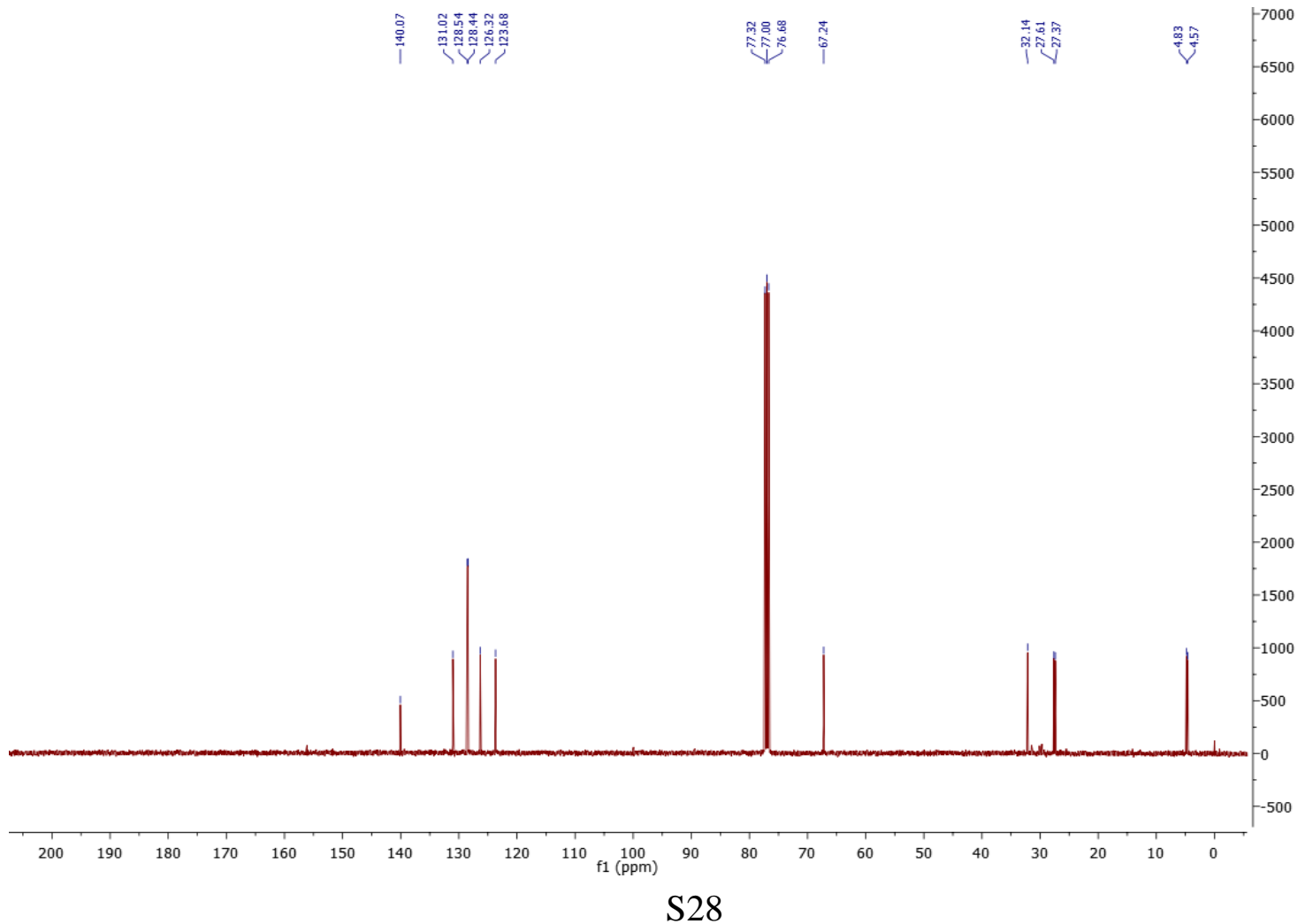




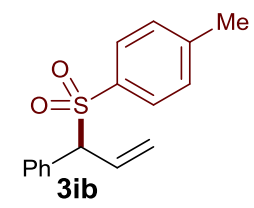

${ }^{1} \mathrm{H}$ NMR spectrum $\left(400 \mathrm{MHz}, \mathrm{CDCl}_{3}\right)$ of 3ib

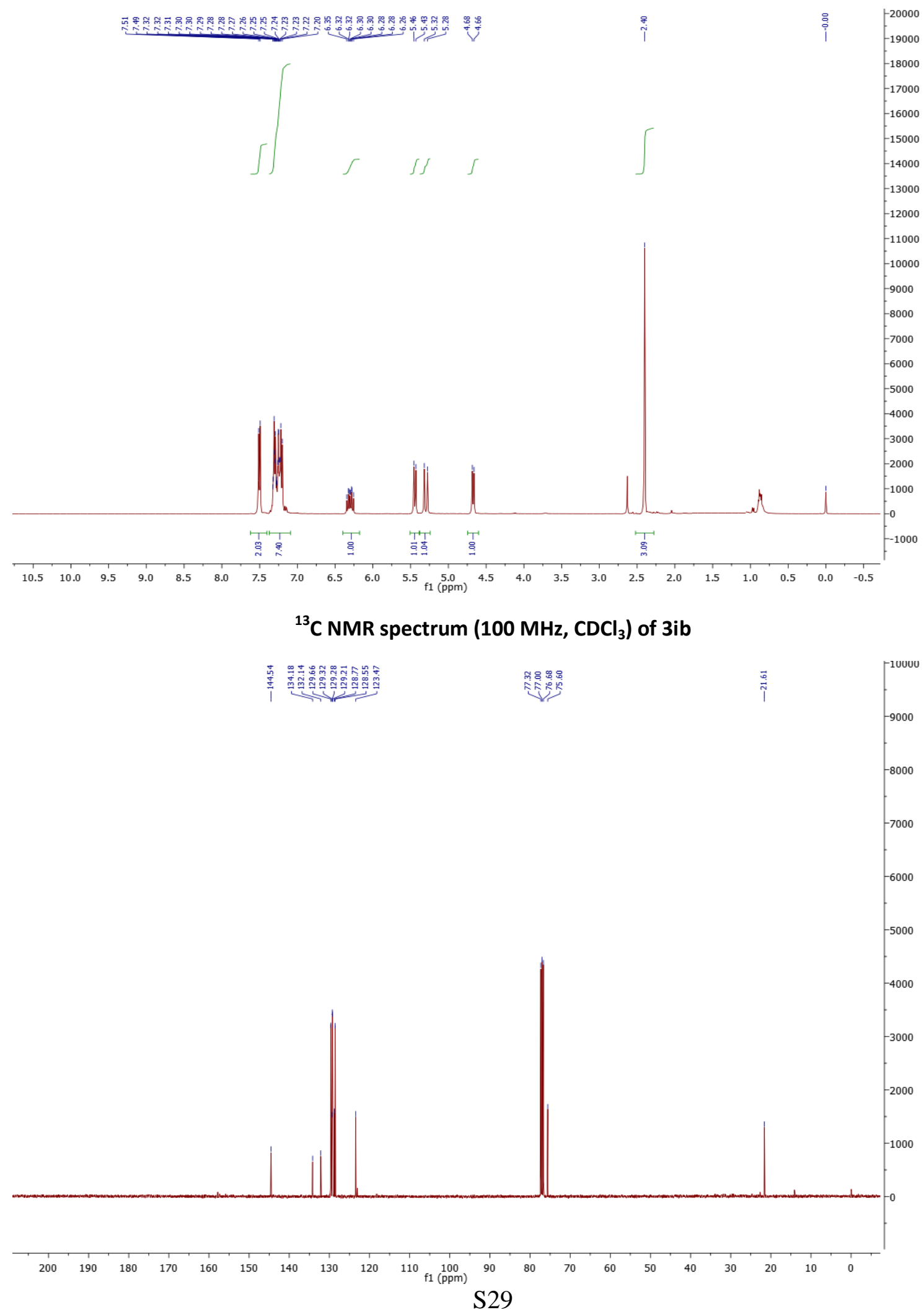




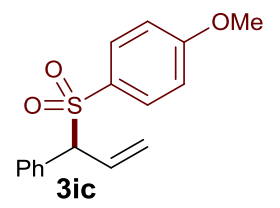

${ }^{1} \mathrm{H}$ NMR spectrum $\left(400 \mathrm{MHz}, \mathrm{CDCl}_{3}\right.$ ) of 3ic

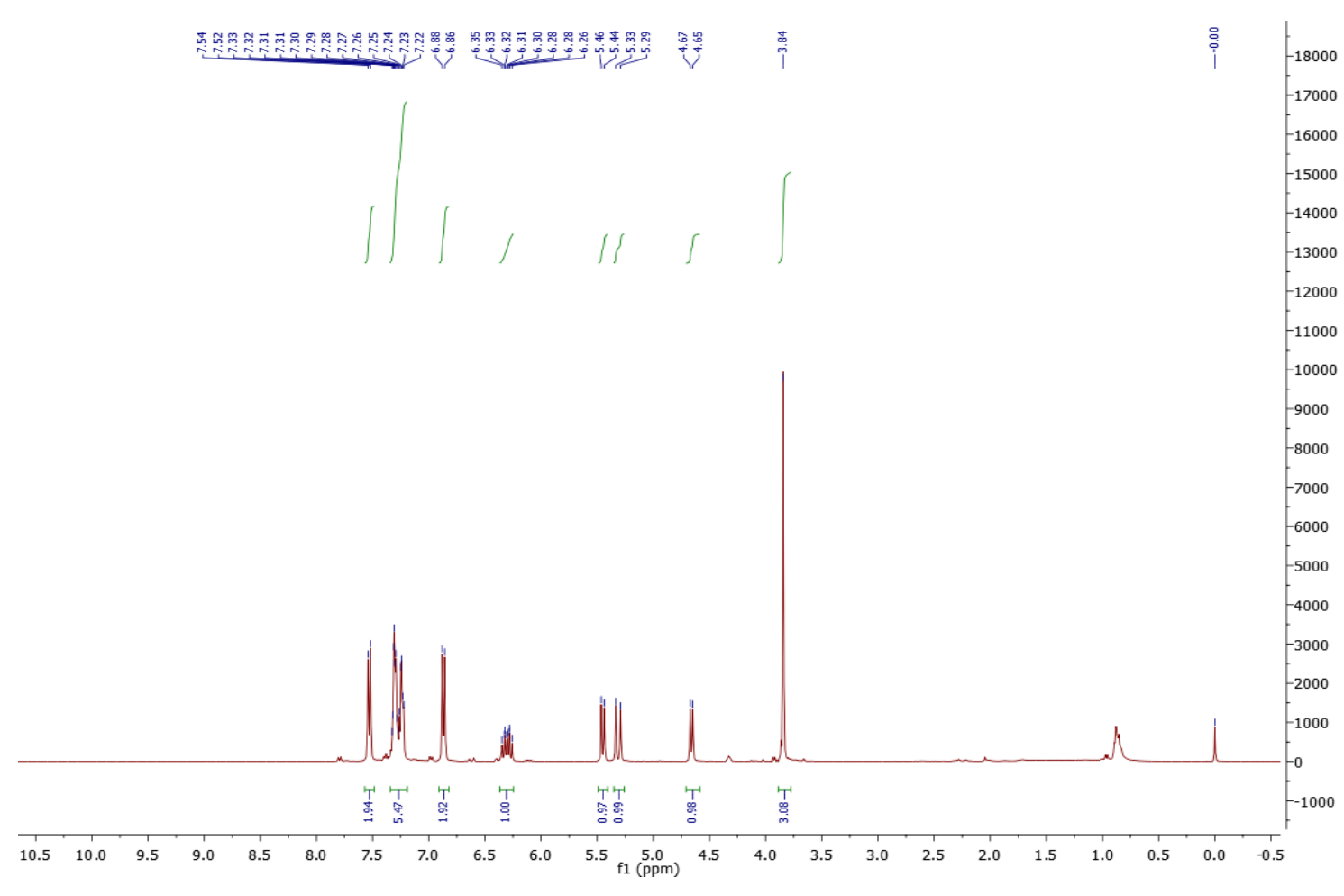

${ }^{13} \mathrm{C}$ NMR spectrum $\left(100 \mathrm{MHz}, \mathrm{CDCl}_{3}\right)$ of 3ic

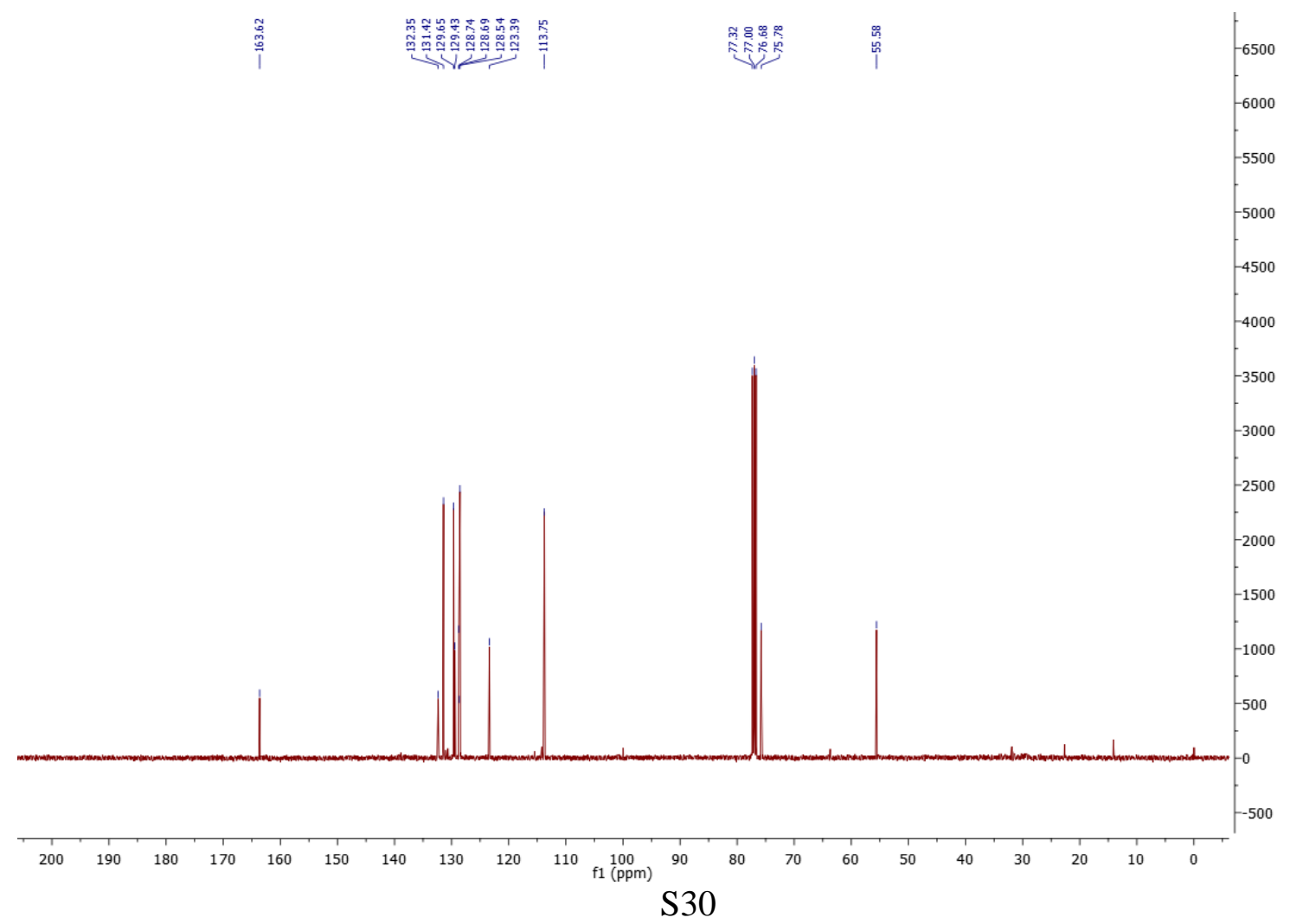




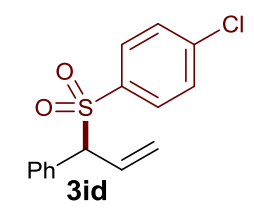

${ }^{1} \mathrm{H}$ NMR spectrum $\left(400 \mathrm{MHz}, \mathrm{CDCl}_{3}\right)$ of 3id

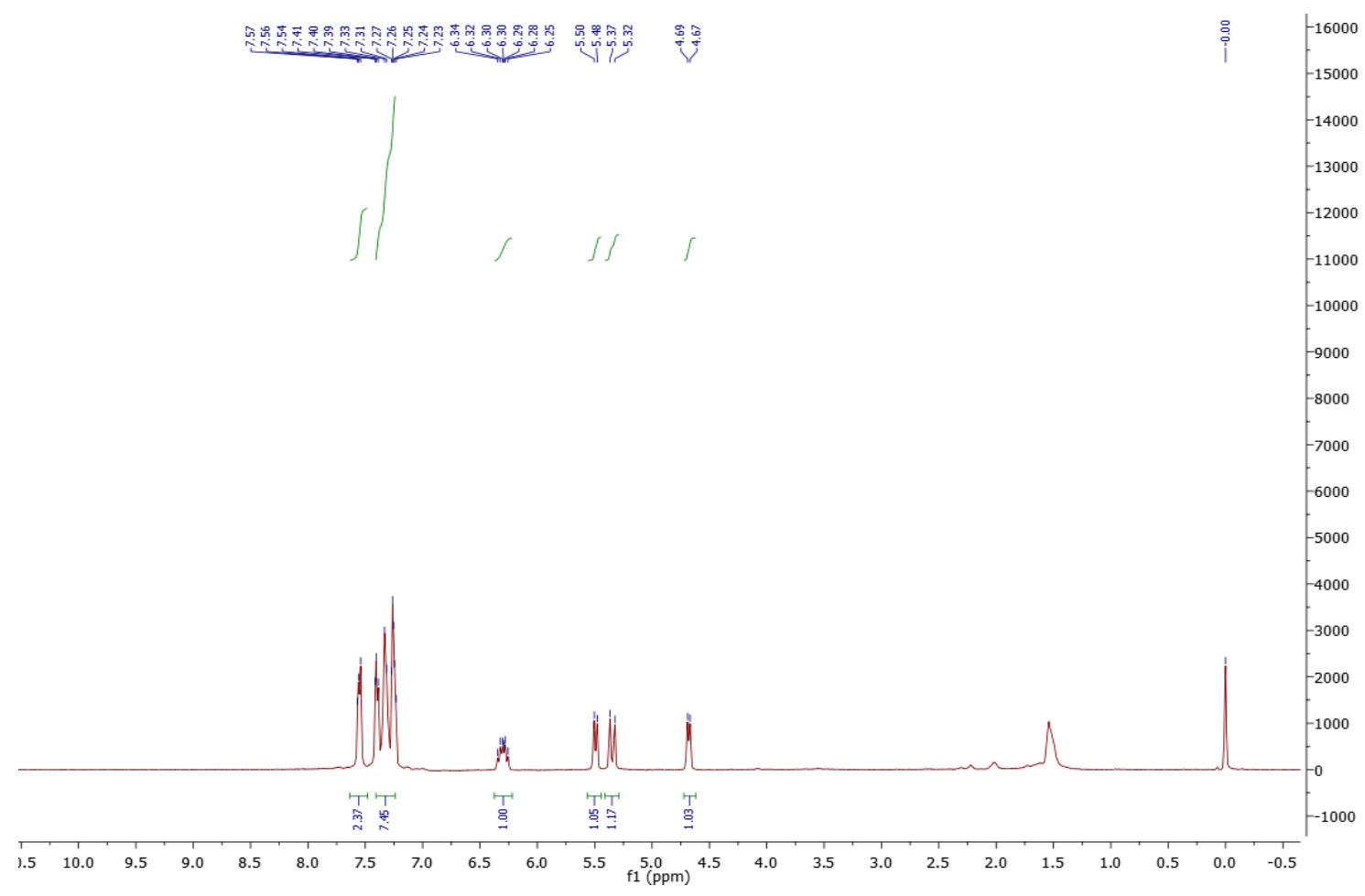

${ }^{13} \mathrm{C} \mathrm{NMR}$ spectrum $\left(100 \mathrm{MHz}, \mathrm{CDCl}_{3}\right)$ of 3id

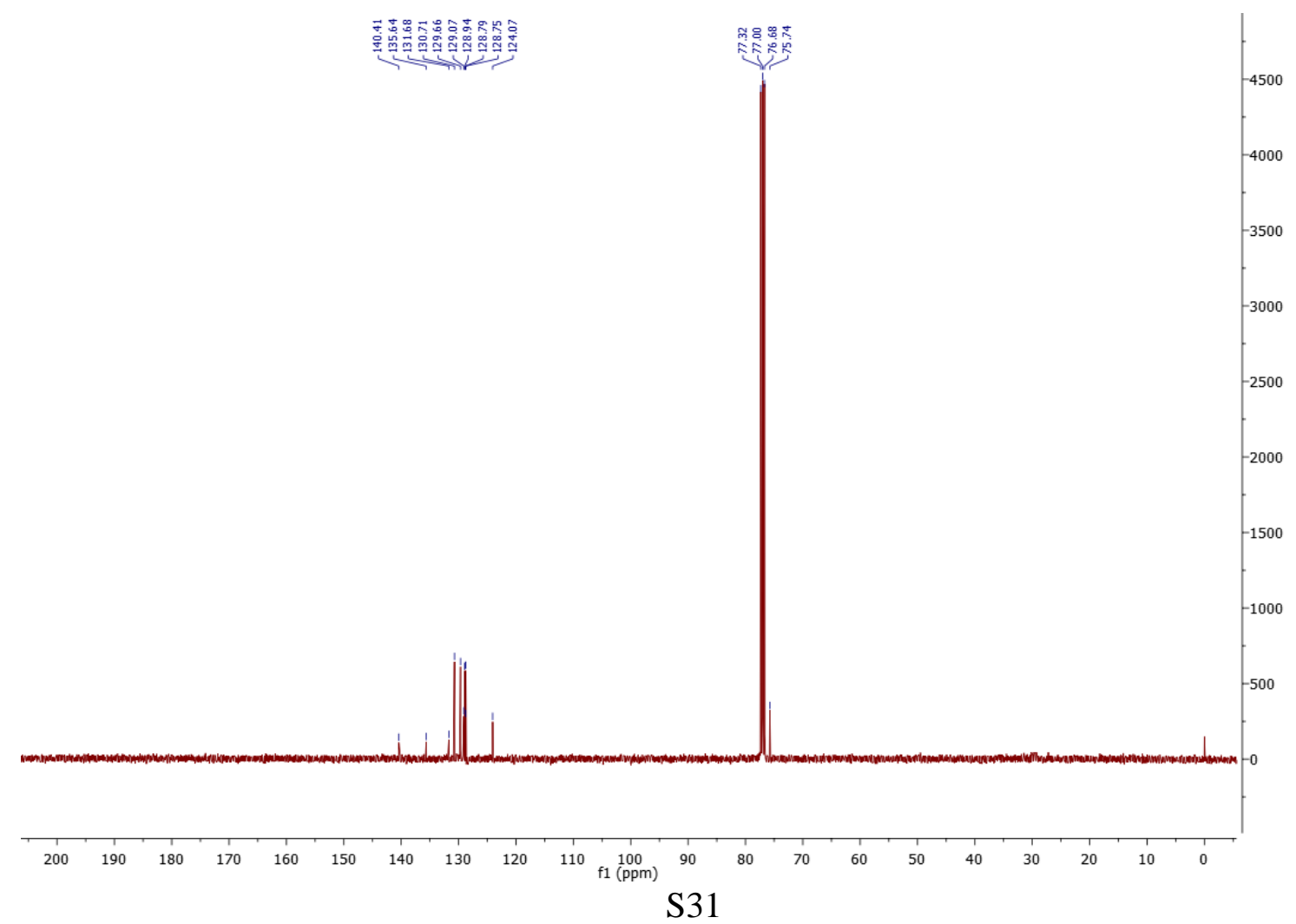




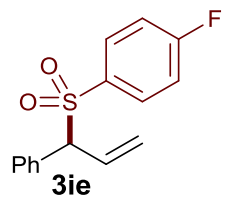

${ }^{1} \mathrm{H}$ NMR spectrum $\left(400 \mathrm{MHz}, \mathrm{CDCl}_{3}\right)$ of 3ie
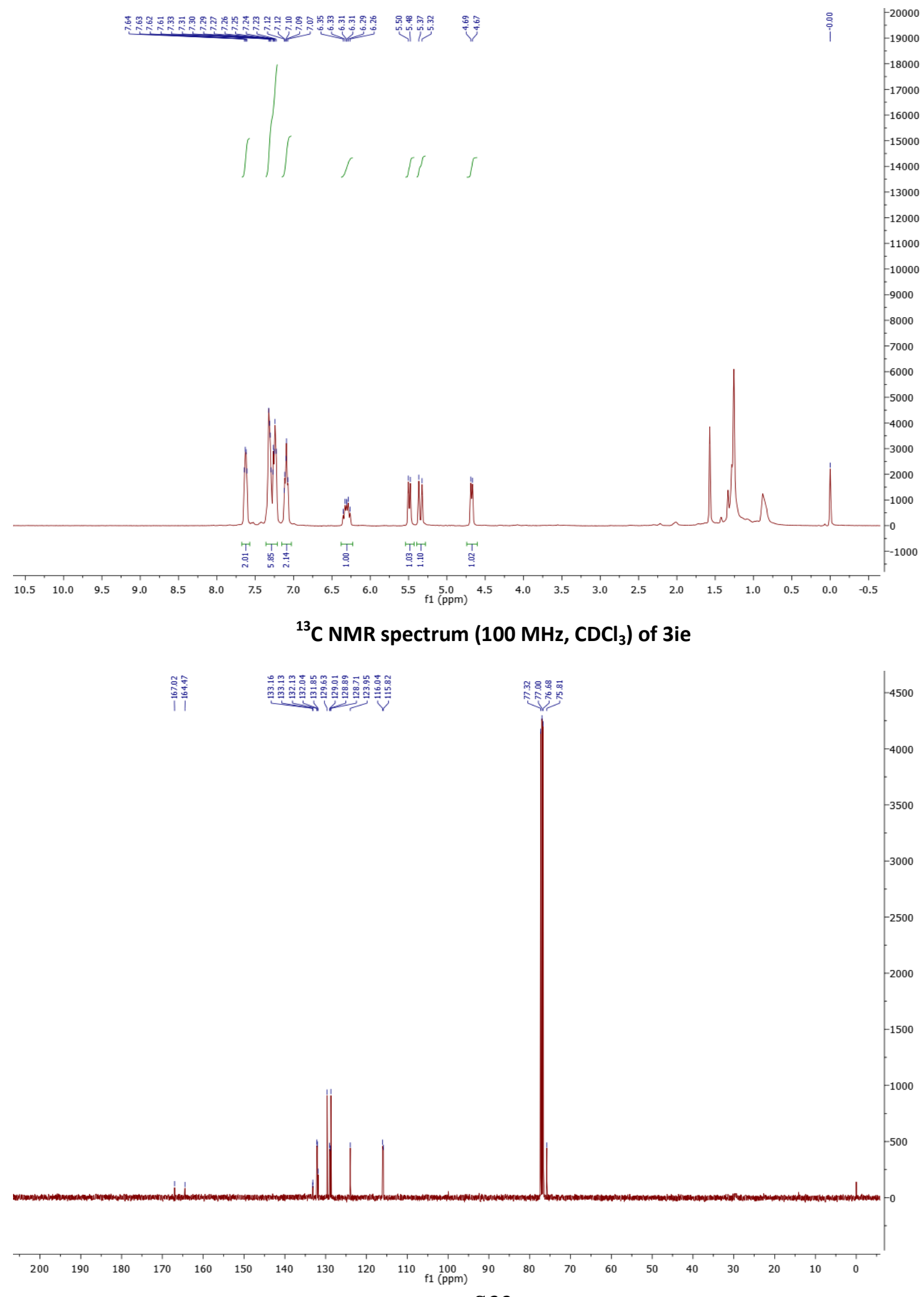


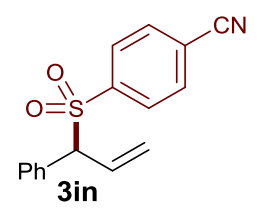

${ }^{1} \mathrm{H}$ NMR spectrum $\left(400 \mathrm{MHz}, \mathrm{CDCl}_{3}\right)$ of 3 in

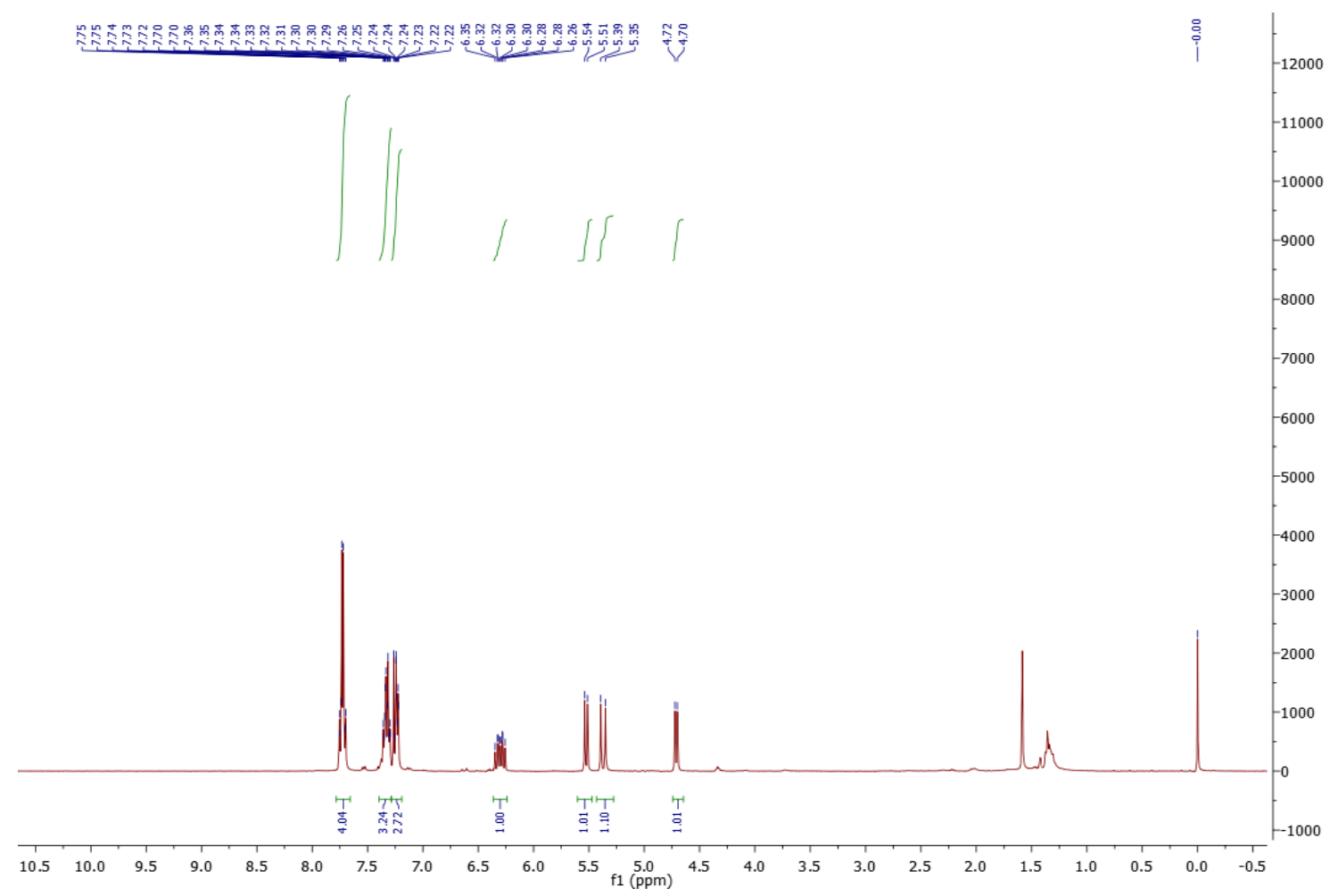

${ }^{13} \mathrm{C} \mathrm{NMR}$ spectrum $\left(100 \mathrm{MHz}, \mathrm{CDCl}_{3}\right)$ of 3in

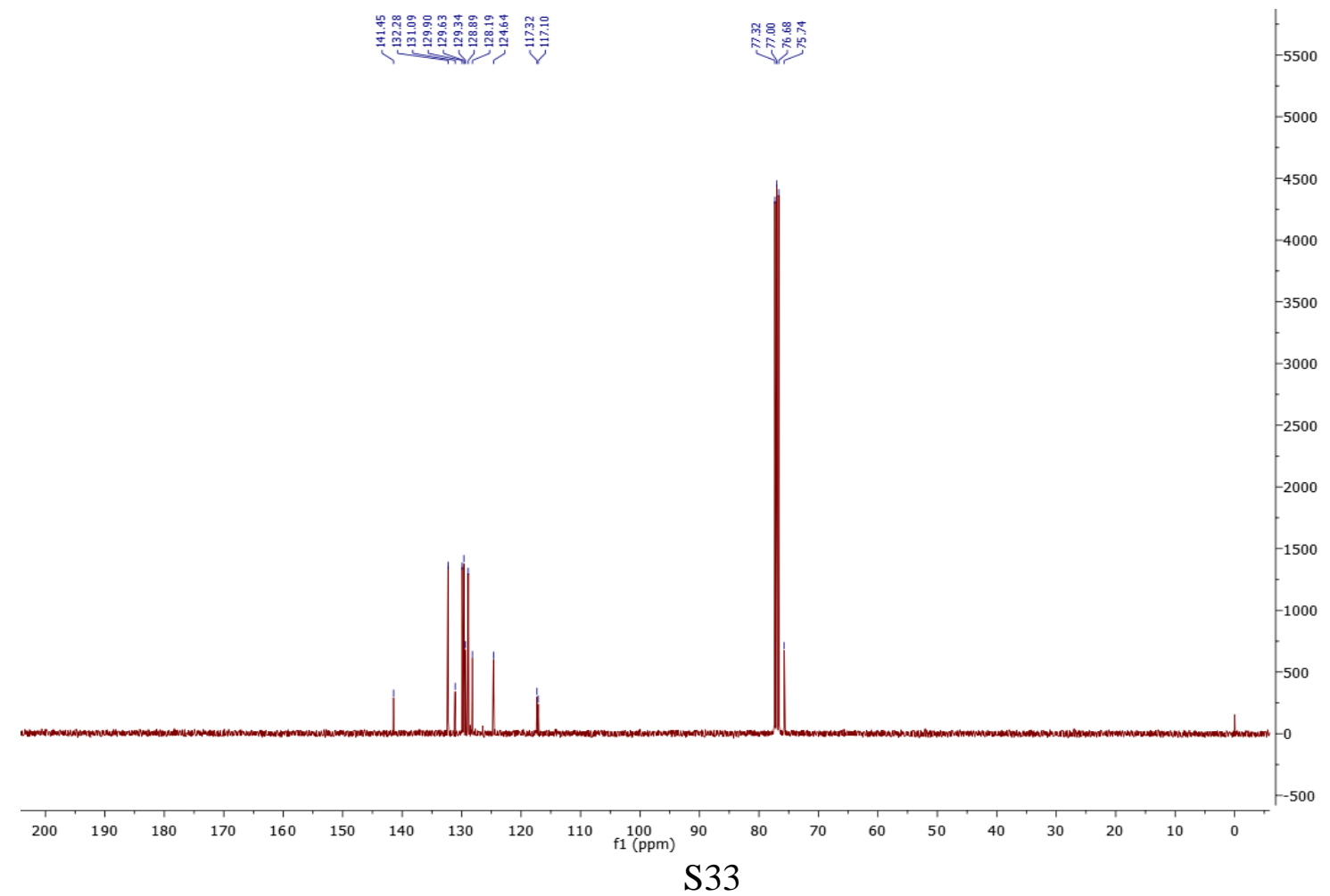




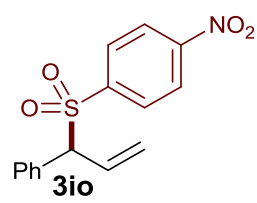

${ }^{1} \mathrm{H}$ NMR spectrum $\left(400 \mathrm{MHz}, \mathrm{CDCl}_{3}\right)$ of 3io

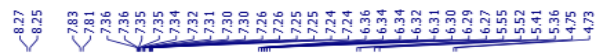

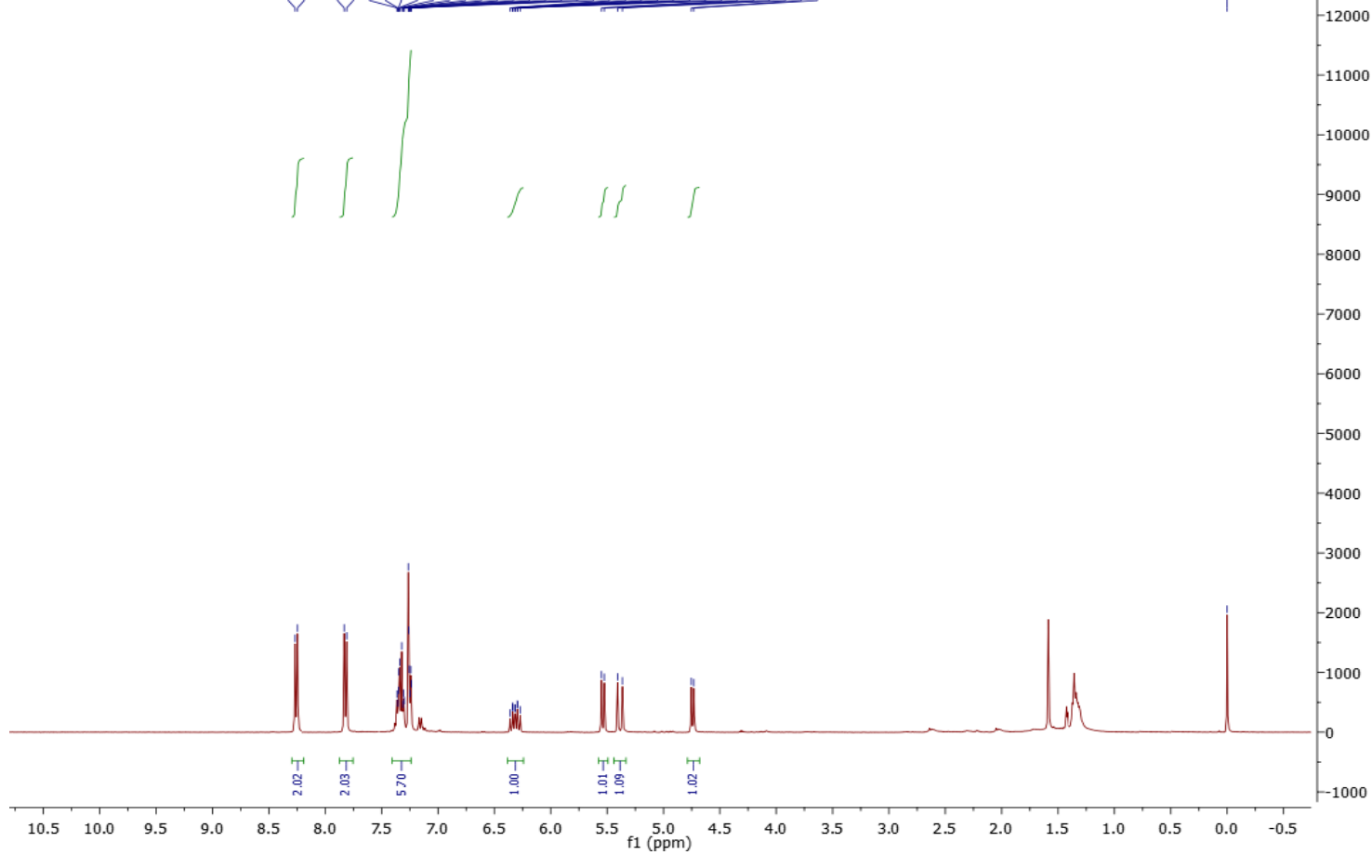

${ }^{13} \mathrm{C} \mathrm{NMR}$ spectrum $\left(100 \mathrm{MHz}, \mathrm{CDCl}_{3}\right)$ of 3io

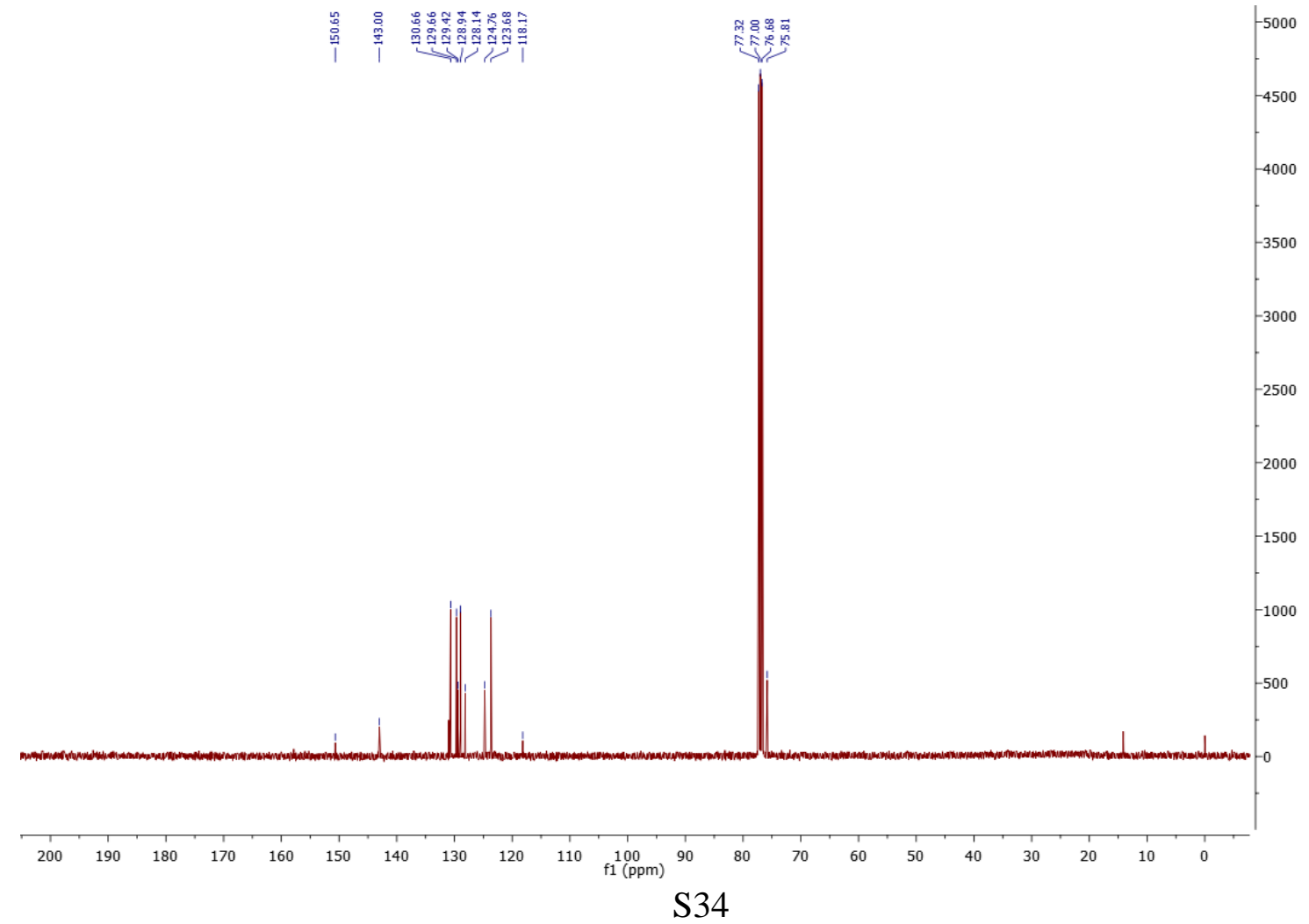




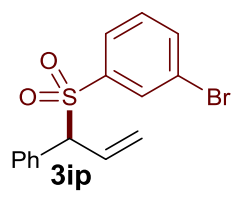

${ }^{1} \mathrm{H}$ NMR spectrum $\left(400 \mathrm{MHz}, \mathrm{CDCl}_{3}\right)$ of 3ip
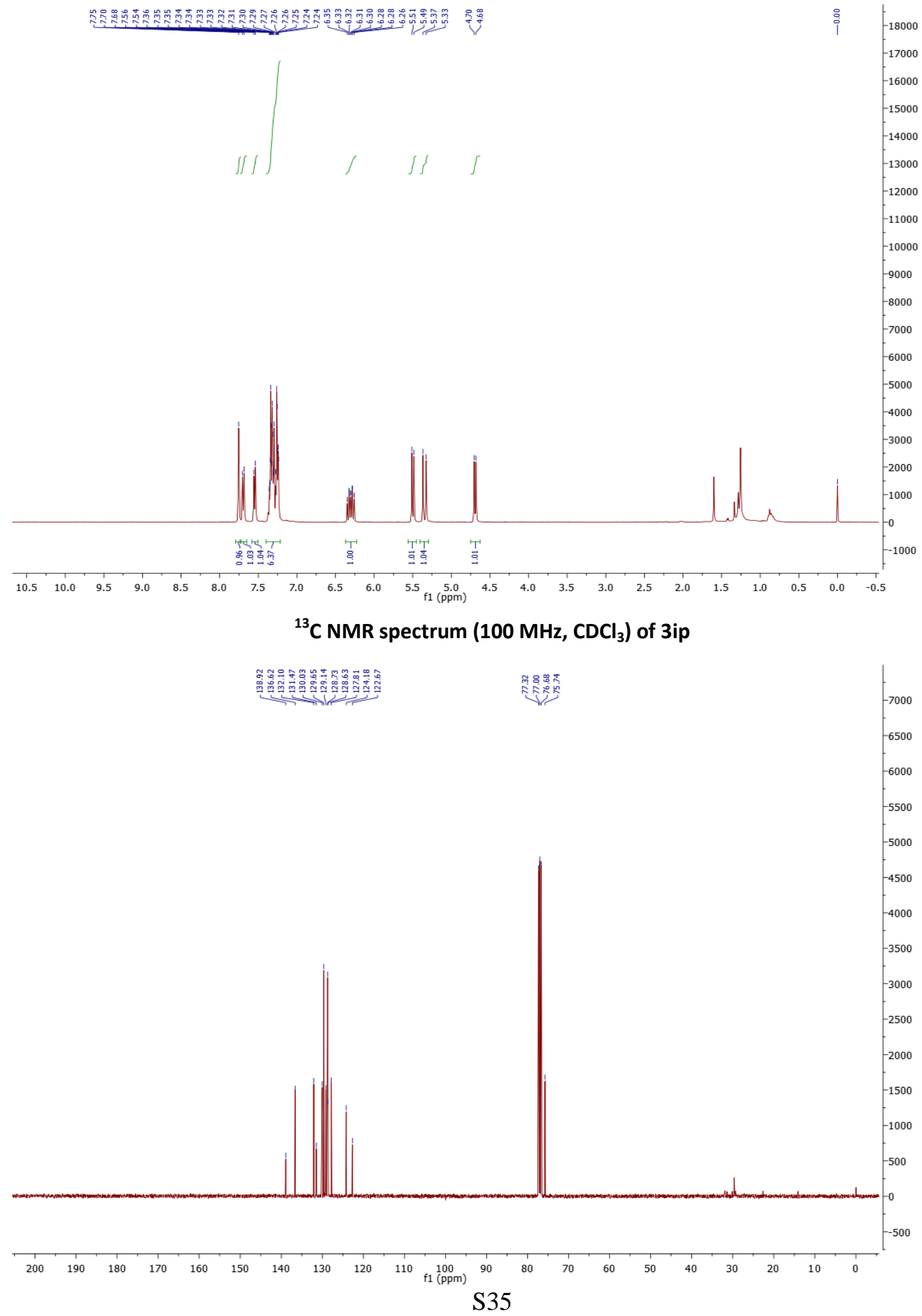


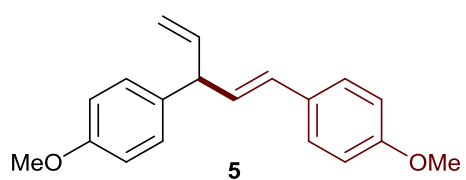

${ }^{1} \mathrm{H}$ NMR spectrum $\left(400 \mathrm{MHz}, \mathrm{CDCl}_{3}\right.$ ) of 5

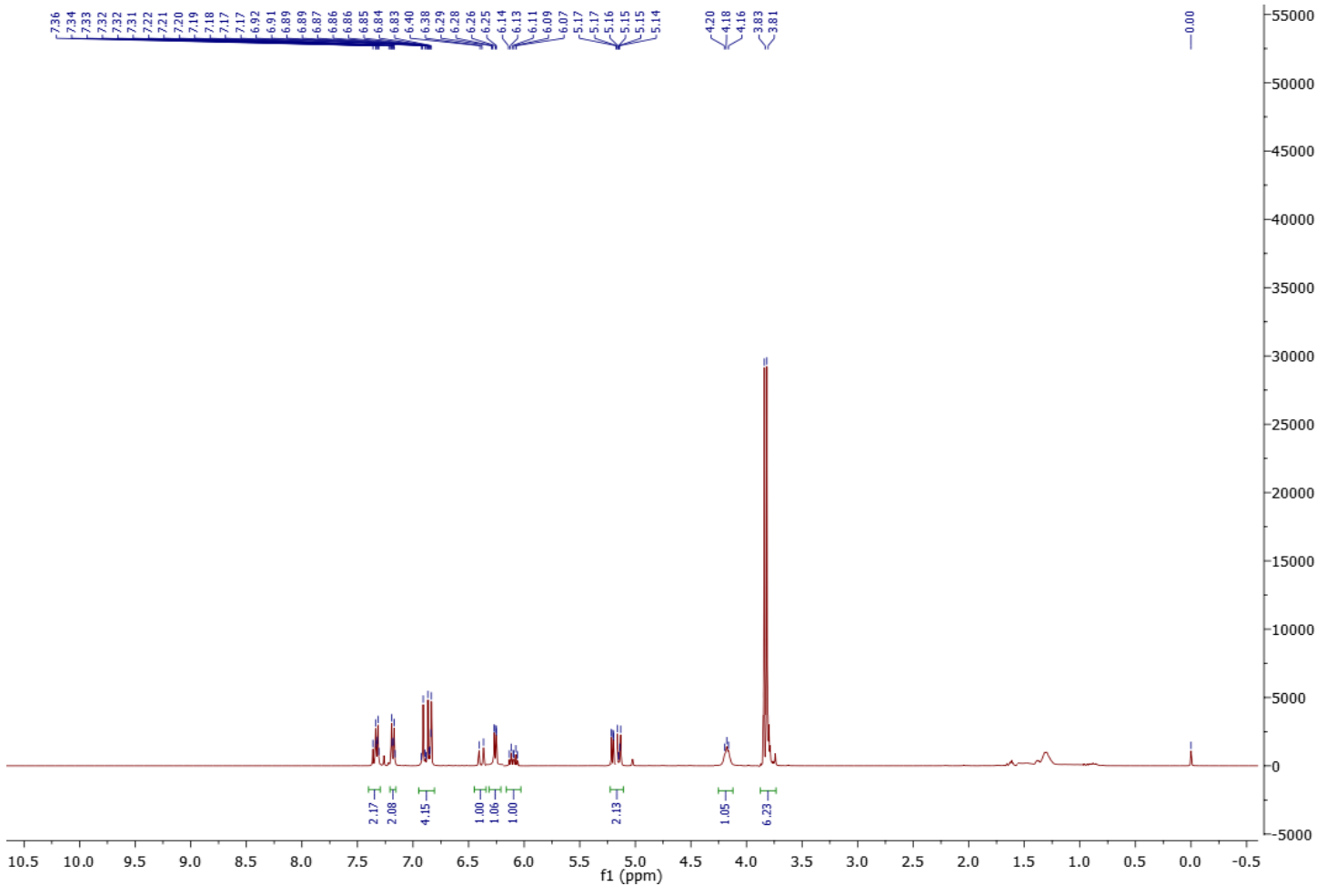

${ }^{13} \mathrm{C}$ NMR spectrum $\left(100 \mathrm{MHz}, \mathrm{CDCl}_{3}\right)$ of 5

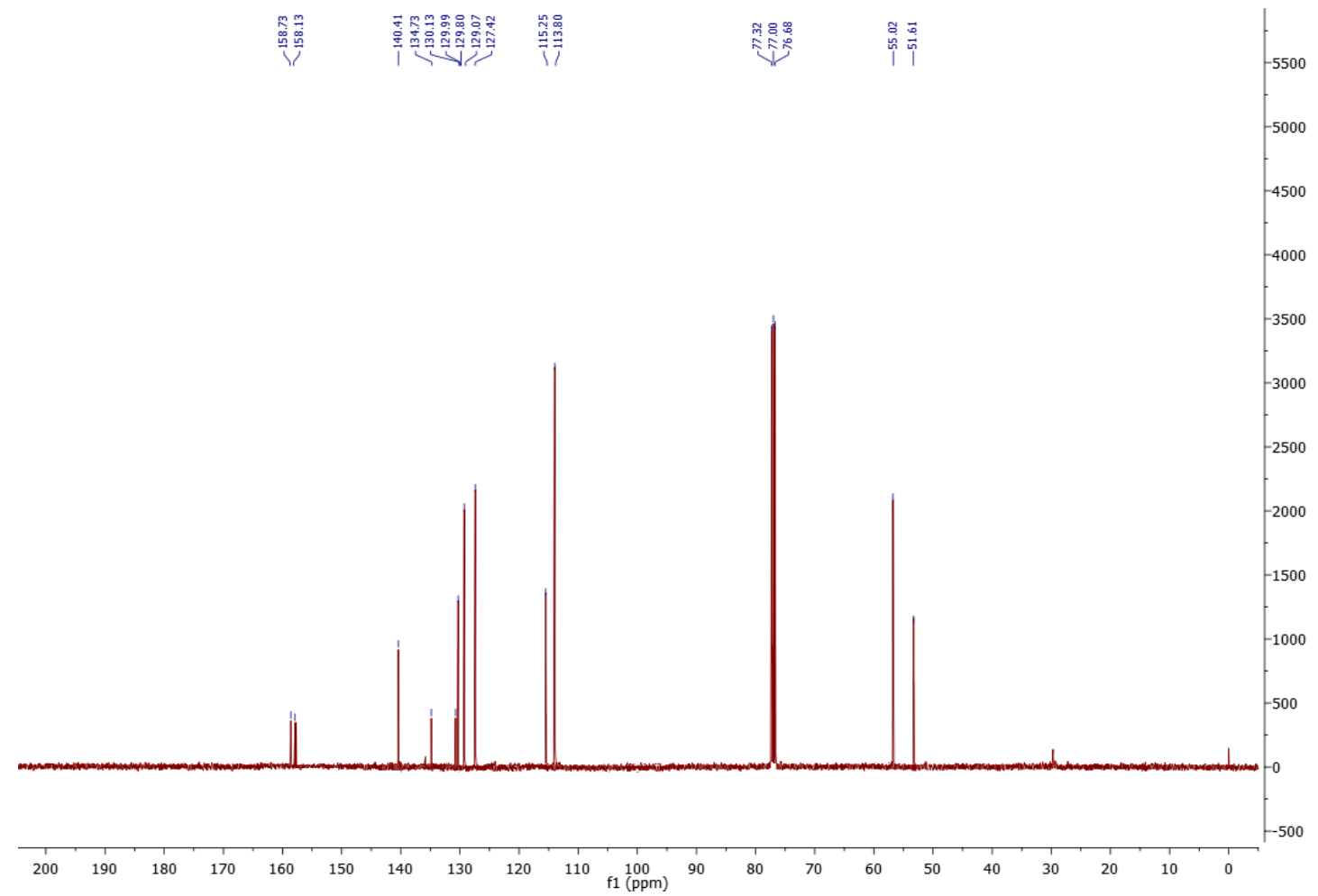




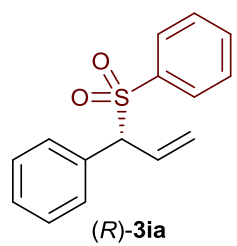

HPLC Chart for ( \pm )-3ia

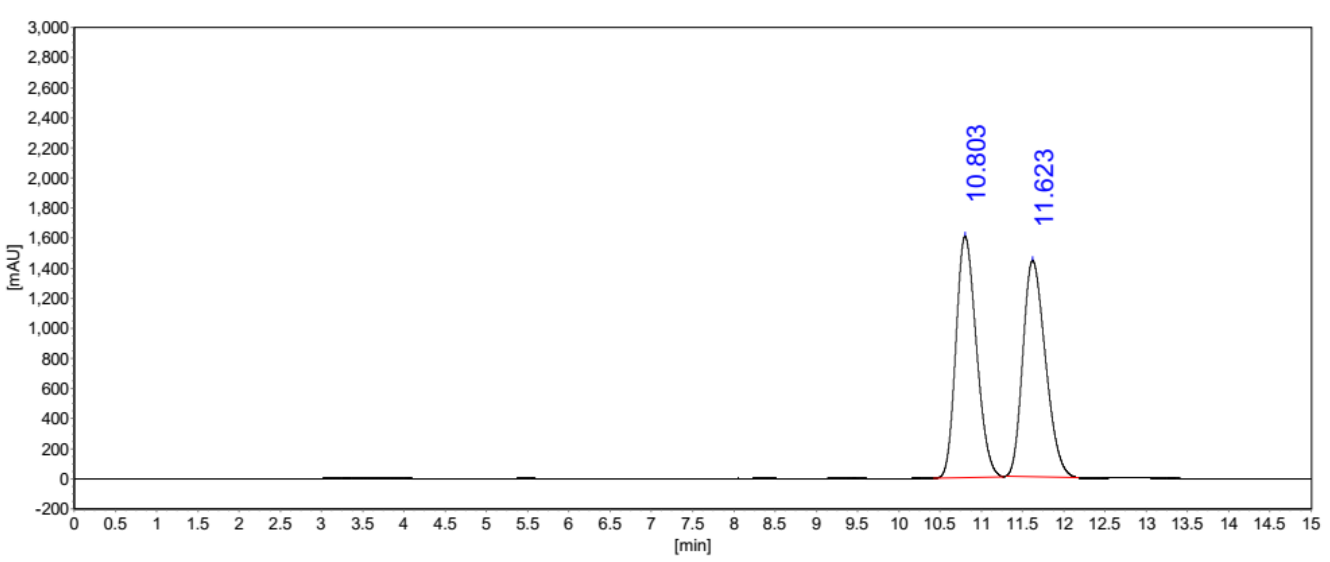

Analysis Results

\begin{tabular}{llrrrrrr}
\hline No. & Compound & R.Time & Height & Area & Area\% & Conc. & Type \\
\hline 1 & & 10.803 & 1605648.1 & 27623633.6 & 50.1729 & 50.1729 & + BB \\
2 & & 11.623 & 1438798.2 & 27433274.8 & 49.8271 & 49.8271 & + BB \\
\hline & & $\mathbf{3 0 4 4 4 4 6 . 3}$ & $\mathbf{5 5 0 5 6 9 0 8 . 4}$ & $\mathbf{1 0 0 . 0 0 0 0}$ & $\mathbf{1 0 0 . 0 0 0 0}$ &
\end{tabular}

HPLC Chart for (R)-3ia

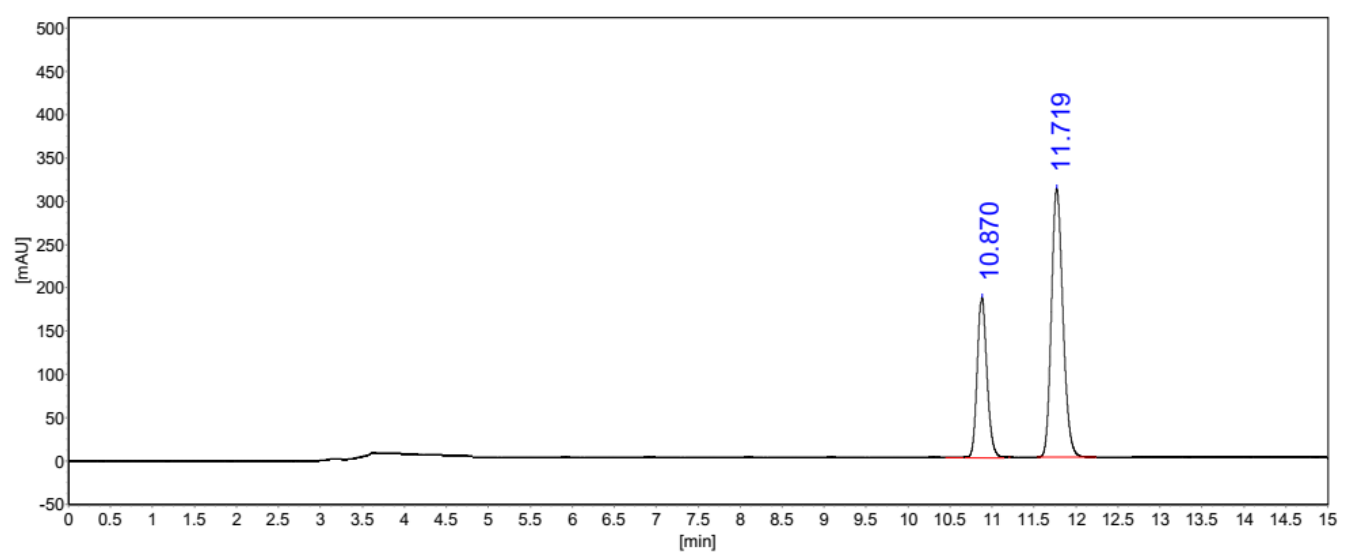

Analysis Results

\begin{tabular}{llrrrrrr}
\hline No. & Compound & R.Time & Height & Area & Area\% & Conc. & Type \\
\hline 1 & & 10.870 & 62307.7 & 1327487.9 & 32.2674 & 32.2674 & + BB \\
2 & & 11.719 & 89392.9 & 3179087.5 & 67.7326 & 67.7326 & + BB \\
\hline & & $\mathbf{1 7 1 7 0 0 . 6}$ & $\mathbf{5 5 0 6 5 7 5 . 4}$ & $\mathbf{1 0 0 . 0 0 0 0}$ & $\mathbf{1 0 0 . 0 0 0 0}$ &
\end{tabular}

